\title{
Utilizing of Digital Printing Techniques to Create Customize Designs for Textile Floor Covering
}

\author{
Dr. Wafaa El-Sayed Aly Rokia \\ Assistant Professor of Weaving and Garment-Faculty of science and arts - AL Baha \\ University- KSA \\ Email: wafaarokaya@yahoo.com
}

\begin{abstract}
Industry researchers estimate that the global Textile covering flooring market size was estimated at USD 84.49 billion in 2018 and expected to register a CAGR of $3.2 \%$ from 2020 to 2025 . Rising demand for carpet tiles on account of availability in a range of colors, patters, and textures is expected to drive the growth. Textile covering flooring manufacturers are involved into production of different products including carpets and area rugs which such as roll goods, carpet tiles, bath mates, and broadlooms among others. Carpet tiles and broadloom are the majorly used Textile covering floorings on account of superior attributes, such as flexibility and dimensional stability. While tufting covering floor about $90 \%$ share of this volume, and $7 \%$ needle punch covering floor $50 \%$ of tufting and needle punch covering floor printed.

While digital printing currently amounts to about $2 \%$ share of this volume, digital printing continues to expand with the movement from mass-production to mass customization of printed goods. Offset/gravure to inkjet/laser printing technology, digital carpet printing offers new creative possibilities for printing over traditional screen-printing. As a result, digital printing enables a shift from printing in large scale manufacturing facilities to smaller cottage businesses focusing on specialty printing Applications. In today's digital technology age, there is greater demand for better technology and faster turnaround cycles in terms of mass production, mass customization and cost effectiveness for the textile, apparel and printing sectors, and will be in carpet also. (THE FUTURE OF PRINTING @ ITMA 2019).
\end{abstract}

Some reasons for why digital printed is suitable for carpet customize.

1. Short run printing advantage: Digital Textile floor covering printing efficiently produces designs at run lengths as low as one yard of carpet without the need for screen changes.

2. Lower water and power consumption: Digital Textile floor covering printing eliminates the substantial amount of water and electrical energy one requires for rotary screen or chromo jet preparation, printing and cleanup. Even greater water and power savings can be achieved with disperse/sublimation and pigment Digital Textile floor covering inks, which only require a heat-fixation step for post treatment. 


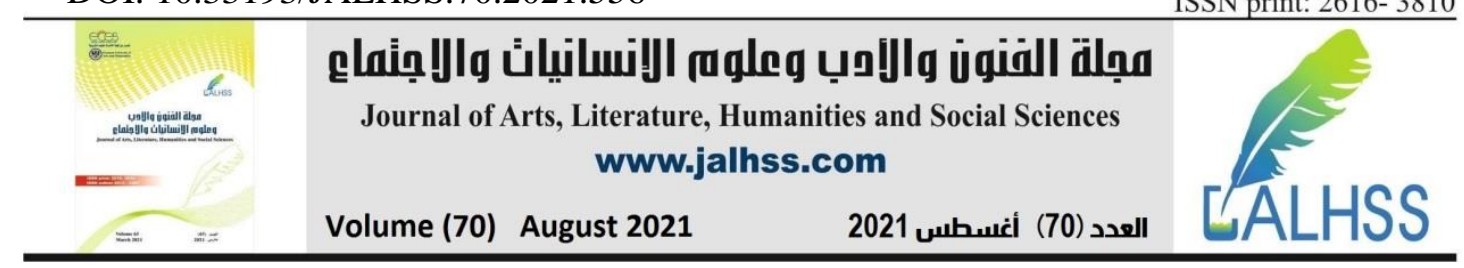

3. Less chemical waste: Digital Textile floor covering printing results in significantly less ink usage and waste Relative to screen and chromo jet -printing. Taking into account the additional chemistry and chemical waste from Screen production, printing digitally offers a greener advantage for printing.

4. Large repeat sizes: Digital textile printers can print large designs (e.g. cartoon characters on Runners and Area Rug) on roll wall to wall carpet without the usual rotary screen-printing limitation in pattern repeat size.

5. Reduced production space requirements: By not having to prepare and store customer screens for future use, the production footprint for digital printing is a fraction of the size one requires for a rotary screen print facility.

6. Less printed inventory needed: Digital Textile floor covering printing permits the option to print a design at will. This means that manufacturers with an integrated digital printing system in their production chain can keep a stock of unprinted textiles on hand to print as required. This reduces the need for pre-printed inventory of Textile floor covering that may or may not be used.

7. Sampling and production done on same printer: By being able to print samples (strike-offs) on the same printer one uses for production, digital Textile floor covering print shops can present their customers with proof samples of designs that will exactly match the final printed material.

8. Print flexibility: Printing houses utilizing all-digital, chromo jet and screen technologies can choose to print a small quantity of designs with different color combinations (colorways) first with their digital Textile floor covering printing solutions for test the market. They can later opt to print higher volumes of the most desired color designs using chromo jet or rotary screen technology.

9. Variety of creative design choices for printing: Digital Textile floor covering printing provides the option to print photographic/continuous tone images, spot color pattern designs or a combination of both. This expands the creative printing alternatives for carpet and interior designers.

10. Low capital investment: The relatively low capital investment to setup a digital Textile floor covering print shop, especially compared to rotary screenprinting production, makes it possible to start small and expand as business grows special in scatter rug, bath mat and tiles.

The research deals with the following axes:

1. Definition of digital printing and its uses.

2. Comparison between traditional and digital printing methods

3. Conducting many technical experiments of digital printing on different types of textile floor covering.

4. The use of digital printing of textile floor covering in the field of small industries

Keywords: Textile Floor covering, Tufting carpet, Textile digital printing, carpet printing, carpet digital printing, Tufting, velvet. 


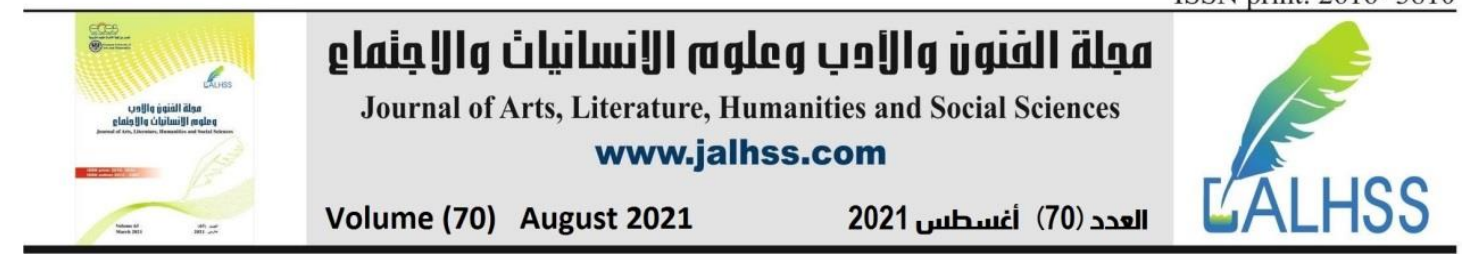

\section{INTRODUCTION}

The development of carpet fabric printing began in the early tuft carpet industry. Since the beginning of the 1950s, this industry has made great progress with the United States as the head. After more than half a century of development, there are basically three types of printing carpets used by printing carpet manufacturers: 1 flat screen printing machine; 2 rotary screen printing machine; 3 microcomputer controlled inkjet printing machine. The digital inkjet printing used by our company began in the 1970s with the aim of developing a contactless printing system and applying digital technology to produce multicolor patterns. The technology developed rapidly in the 1990s, completing the transition from technical models to production applications. At the 1999 International Textile Machinery Exhibition in Paris, the digital jet printing system received wide attention and application in the industry. What is the working principle of the inkjet printer? The inkjet printing machine is actually an enlarged version (the latest version) of a color printer. It is controlled by a computer, and the designed pattern is printed on the carpet by a program control solenoid valve to form a pattern. It can print carpets with a maximum width of $4 \mathrm{~m}$ and a maximum of 16 colors. The inkjet printer has an initial resolution of $16 \mathrm{dpi}$ and $25 \mathrm{dpi}$. The so-called 16dpi and 25dpi are the number of dots per inch. The analogy of the image is the pixel of the camera. The base carpet is similar to the photo paper.

What is the difference between 16dpi and 25dpi? The smallest point printed at 25dpi can be slightly larger at $1 \mathrm{~mm}$, and the smallest point at 16dpi is slightly larger at $1.6 \mathrm{~mm}$. The $25 \mathrm{dpi}$ pattern is finer than the $16 \mathrm{dpi}$. But it also has a certain relationship with the flatness of the carpet and the velvet. Therefore, high-resolution carpets rarely have high-velvet-high carpets. If the pile is high and the weight is low, the flame retardant effect is poor, and it is difficult to meet the fire protection requirements. The pattern printed on the 16dpi is brighter and fuller than 25dpi. The new technology. Accuracy, carpet manufacture launched the fine-printed carpet, using color digital printing technology, the pattern is realistic and delicate, the local details are up to 600DPI printing, 24 times the traditional precision, making the pattern appear on the carpet surface, the stereo image is more prominent, and the carpet color reaches the photo quality.

color, fine print carpet manufacturing process can print any photos, breaking the traditional process limits up to 24 colors, natural color transition, allow a personalized custom carpet more pure, more thorough;

it is environmental protection, the fine print carpet washing-free printing technology , no printing and dyeing sewage discharge, environmentally friendly, making people and nature more harmonious; 
The research problem: is the current method used in the production of carpet factories limited response for customer demand for various reasons, including:

1- Colors number of design, Traditional machine is limited colors, as example max. Colors is 12 on chromo jet machine , 6 colors on rotary screen printing, but customer need more than 12 colors for his designs.

2- Resolution of designs, Traditional printing machine with max. 25 DPI and customers need more resolutions as example 75 DPI.

3- $\quad$ Photo design, Traditional printing machine can't print photo designs.

4- $\quad 3 \mathrm{D}$ designs, Traditional printing machine limited in print $3 \mathrm{D}$ designs, and that is will depending on designer skill.

5- $\quad$ Size of design, Rotary printing is limited in length of design, the max. Length of design equal the circumference of the circle of the screen, carpet printer have max. $91 \mathrm{~cm}$ nearly

6- $\quad$ The time of implementation of the order, Traditional printing machine like Rotary screen need very long time to preparing design, reach to 2 weeks at least if you have department of engraving screen, if not have it take more than 2 months abroad, for chromo jet take at least 1 week to prepare design, but for digital max. One day according designer skill.

7- $\quad$ Cost of design, it is very expensive for rotary screen printing, set of rotary screen consists of 6 colors around 20000 USD if you make out of factory.

8- Quantity of order design , in rotary screen printing, Minimum order quantity are 5000 meter square, and for chromo jet around 500 meter square and that is big quantity for customer especially who need customize order .

9- Impact on the environment, rotary scream printing and chromo jet have some bad effect for environment due to remaining dyes, washing water and evaporations.

\section{The problem of the study is formulated in the following questions:}

1. What's the possibility of produce carpet with different category multi colors and different effect of viewing with Approaches to Minimizing the quantity of Carpet Manufacture?

2. What's the possibility of creating a different type of textile floor covering with digital printing type?

3. What's the possibility of Contribution digital carpet printing to the development of small industries?

\section{The importance of search to:}

1- Identify the ways which have decrease the cost of carpet production, with a high specification.

2- Development of Scientific and Technical Approaches to Minimizing time Implementation of order.

3- Development of Scientific and Technical Approaches to Minimizing the quantity of order, and at the lowest possible cost. 


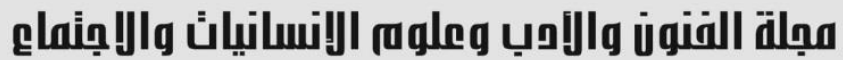 \\ Journal of Arts, Literature, Humanities and Social Sciences www.jalhss.com \\ Volume (70) August 2021 \\ العدد (70) أغسطس 2021}

4- Identify the way for small business industry to produce carpet with low investment, cost, area, operators and materials in short time with high quality suitable for market demand.

Research objectives: the aims to

1- Study the various methods used in the production of Textile Floor covering printing and comparison between them.

2- $\quad$ Formulation vocabulary and technology of the Textile floor covering printing industry (which are exclusive to this day, and secrets of the those who hold them) In the form of a scientific reference for those interested in this field In an attempt to link the research centers and centers of industry to prepare a generation able to deal with the technology of this industry Graduates from colleges and specialized institutes and those who want to invest in this field.

3- Development of a method to minimizing the time waste of printing Carpet Manufacture.

4- Development of a new method to produce Textile floor covering printing.

5- $\quad$ Open scope for small industries to invest in this field.

6- $\quad$ Create new employment opportunities to solve the problem of unemployment.

\section{Theoretical study}

Different shapes and uses of textile floor coverings:

Textile floor covering are produced according to the type of use required, and are classified into the following types:

1- Wall - to - Wall Textile Floor Coverings

2- $\quad$ Tile Textile Floor Coverings

3- $\quad$ Carpet or Rug Textile floor coverings

4- $\quad$ Stair Mat Textile Floor Coverings

5- $\quad$ Bath Mat Textile Floor Coverings

6- Kitchen Mat Textile Floor Coverings

7- $\quad$ Runners Mat Textile Floor Coverings

8- Children Mat

Divided to next:

- $\quad$ Education children mat

- $\quad$ Play Children mat

- $\quad$ Shape and characters Children mat

9- Door Mat

10. - Sports Rug

There are different type as example:

- Club Logo Mat

- $\quad$ Carpet forms of sports stadiums and tools

11.- Advertising Carpet

12. - Car Mat

13. - Mosque carpets and prayer rugs

CARPET FABRIC CONSTRUCTION

The primary carpet fabric construction methods include 


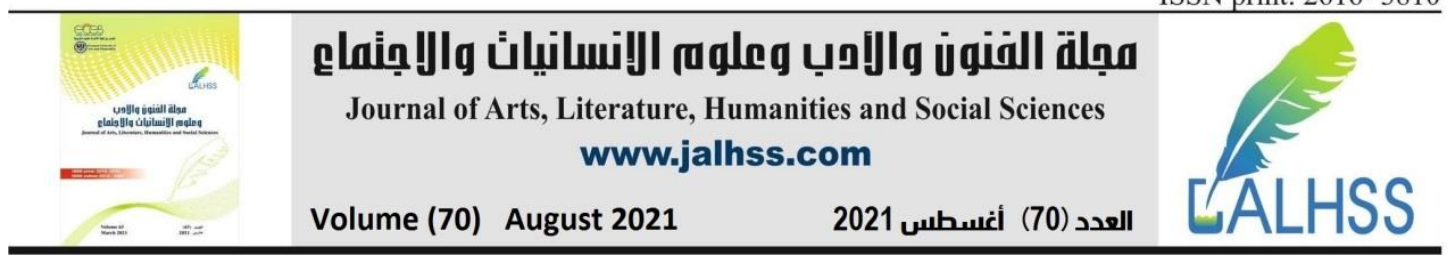

1.

Tufting Technique.

2.

Weaving Technique.

3.

Needle Felt technique.

4.

Flocking technique.

5.

Knitting technique.

6.

Bonded technique.

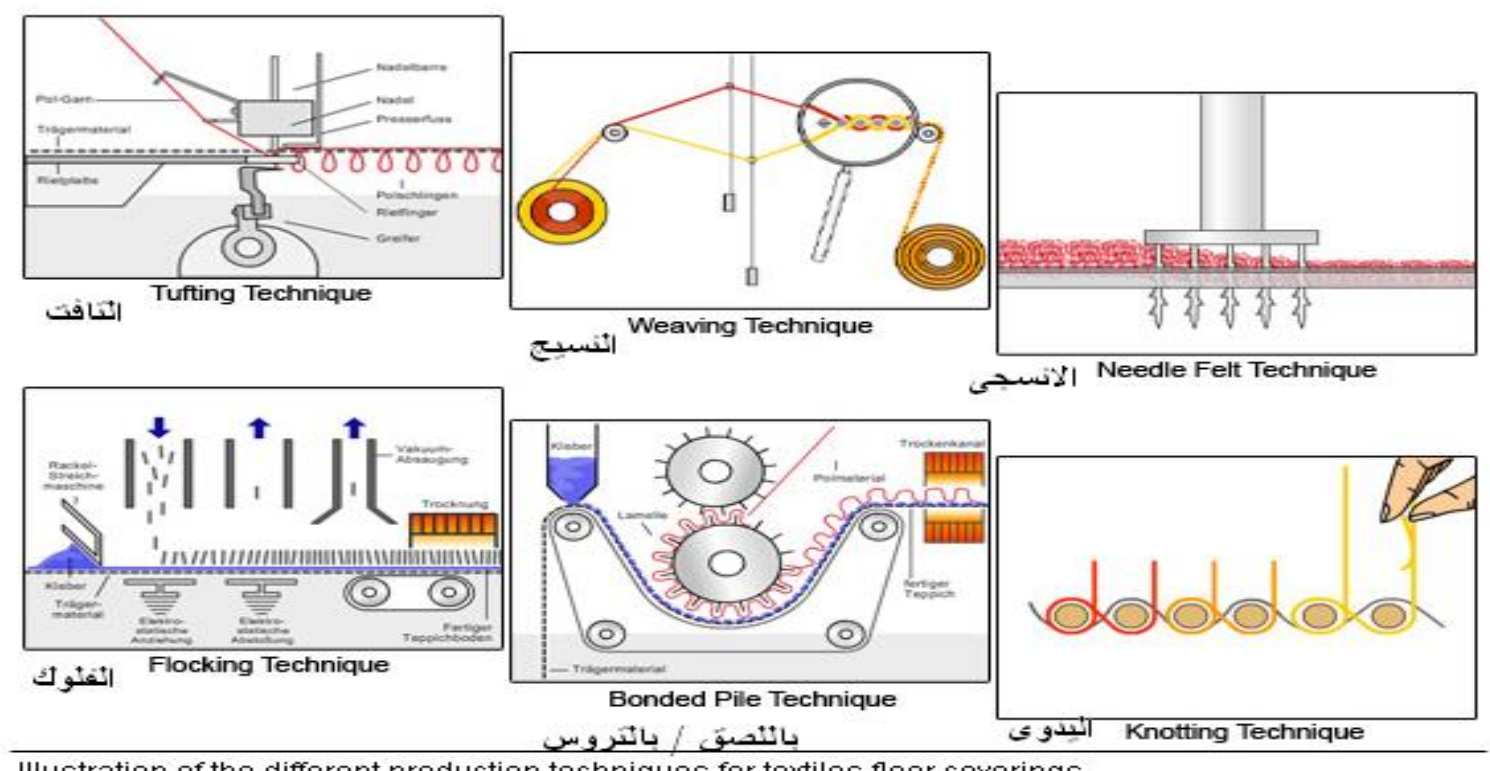

Illustration of the different production techniques for textiles floor coverings

Fig (1) Production Methods for Textile floor coverings

\section{TUFTING}

Over $90 \%$ of carpet produced is tufted, the most prevalent carpet construction method. Tufting machines are similar to giant sewing machines, using hundreds of threaded needles in a row across the width of the machine. Today's machines are increasingly complex and sophisticated, providing a wide variety of styles and constructions.

\section{WEAVING}

While there are several methods of weaving and several types of looms, there are basic similarities to all. In general, woven carpet is formed by the interweaving of warp and weft yarns. The warp yarns are wound from parallel or heavy beams that unwind slowly as weaving progresses. Two main types of warp yarns form the carpet back: chain and stuffer. Chain yarns provide structure and stability while stuffer warp yarns increase bulk and stiffness of the fabric. The face yarns of woven carpet are pre-dyed warp yarns or Raw white for printing yarn ,that are normally fed into the loom from a yarn creel.

\section{KNITTING}

A carpet knitting machine, known as a double needle bar knitter, has a row arrangement of hundreds of latch needles that move in an up-and-down motion in 


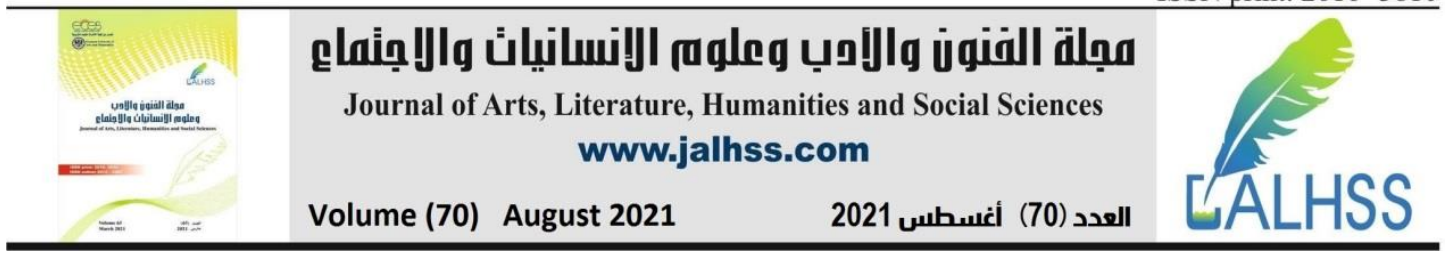

conjunction with yarn guide bars. Yarn guide tubes are attached to a guide bar that passes the yarns between and about the needles, thus laying down the pile face yarns and weft backing yarns. Separate sets of guide bars control each of the yarnsknitting, backing and face yarns. Additional bars may be used for color and design variety.

\section{NEEDLEPUNCHING}

- In the needle punching process, several webs of staple fibers are superimposed to create a thick, loose batting. The batting is then tacked, or lightly needled, to reduce its thickness before it is fed into the machine. As the batting is fed into the machine, it passes between two plates. The stationary lower plate contains many holes, while the upper plate, or headboard, and contains several rows of barbed needles. The batting passes between the plates and the headboard moves up and down, passing the barbed needles through the fibers. As the needles pass through the fibers, they carry fiber ends from the top of the batting to the bottom, and when they are withdrawn, vice versa. The needles are passed repeatedly through the batting as it moves through the machine to form the carpet.

\section{BONDING}

Fusion bonded carpet is produced by implanting the pile yarn directly into a liquid polymer, usually PVC, which fastens it directly to the backing. This results in very little buried yarn compared to other processes. The yarns can be closely packed, producing very high densities suitable for high-use areas. This process is used most frequently to produce carpet to be cut into carpet tiles or modules. Fusion bonded carpet may be loop construction, but most often is a cut pile product, made by a twoback process, slicing apart two simultaneously made carpets that are mirror images.

\section{Carpet Printing}

Carpet printing uses machinery that essentially is enlarged, modified textile printing equipment. Traditional printing (Flatbed and rotary screen printers) and computerized printing (chromo jet and Digital printers) are common. Printed carpet is available in a wide variety of patterns or textures that can simulate woven patterns at a much lower cost. 


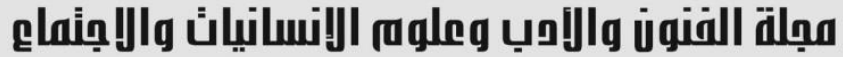 \\ Journal of Arts, Literature, Humanities and Social Sciences www.jalhss.com}

Volume (70) August 2021

العدد (70) أغسطس 2021

\section{Method of carpet printing}

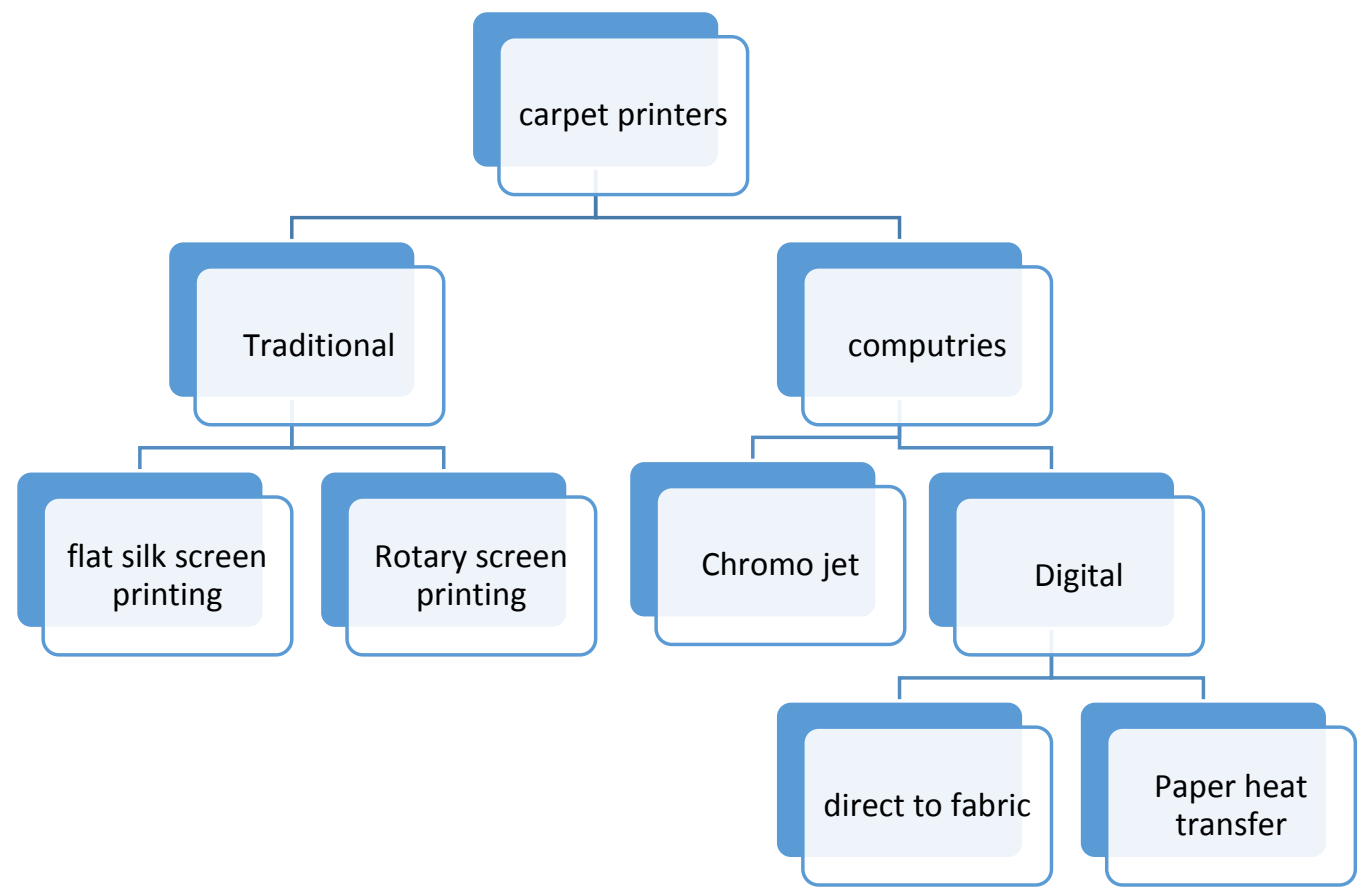

Fig (2) Method of carpet printing

\section{Flat-Screen Printer}

The first flat screen printer for carpet - the legendary TDA62 - was developed by Peter Zimmer and put into operation in 1962 at Barwick, Lafayette, Georgia, and USA. This machine was for a long time the workhorse of the industry. Still today some of these machines are in operation. 


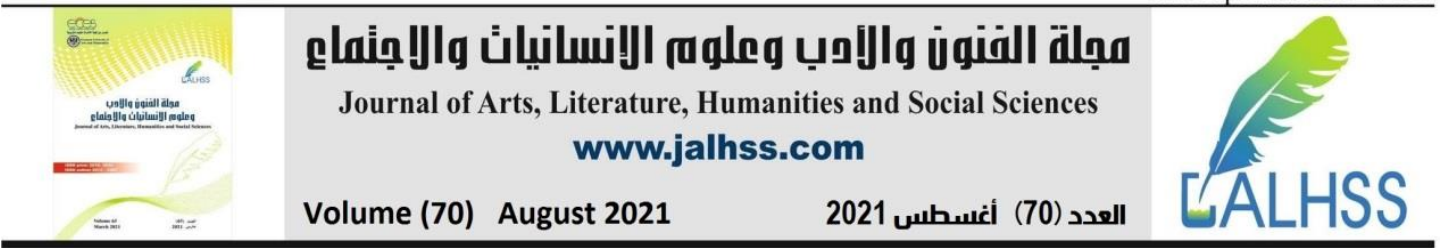

\section{Industrial flad-bed screen printing}
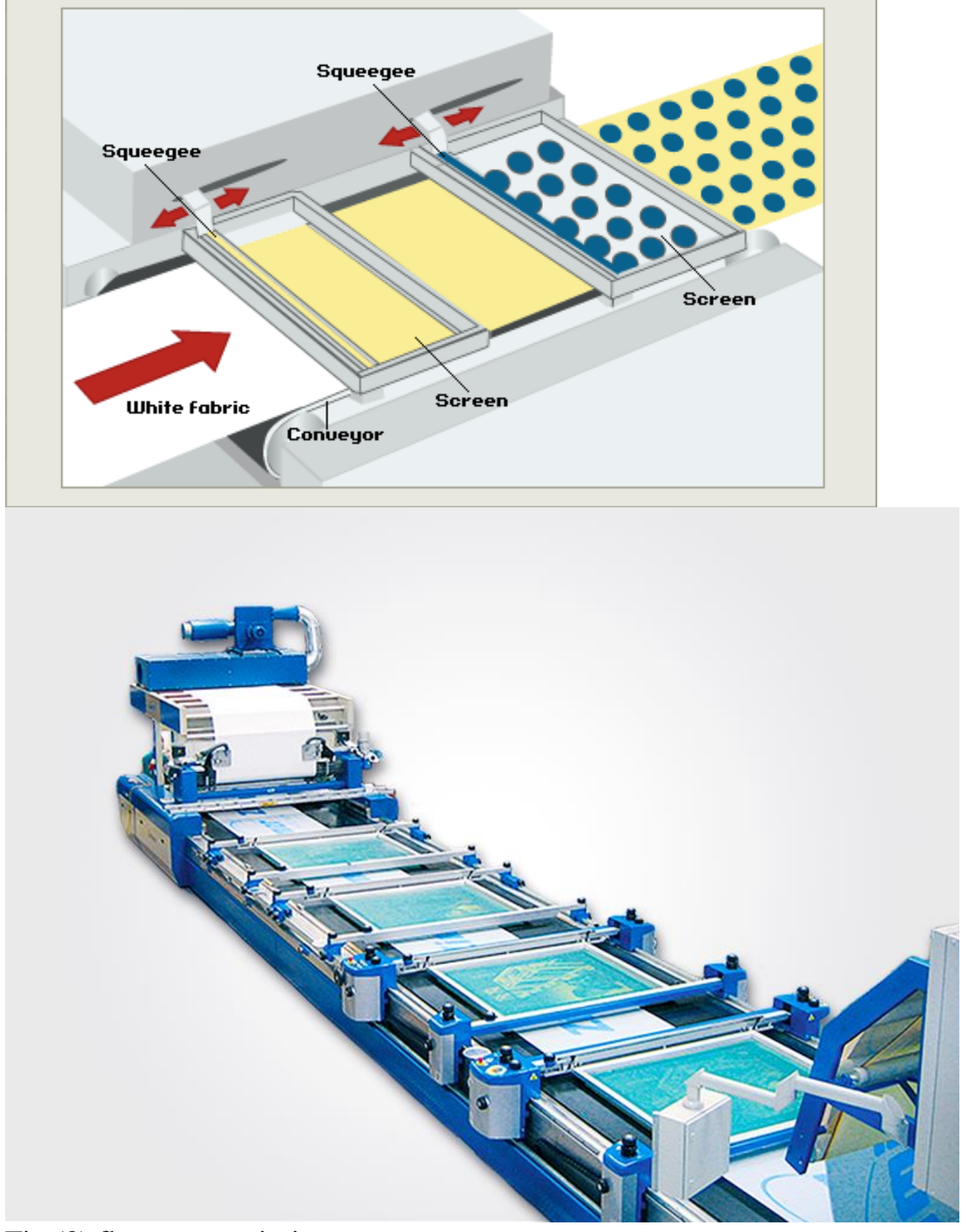

Fig (3) flat screen printing

In Flat Screen Printing Technology the screen is flat and moves up and down. The Squeeze is used. Small width fabric (45-50") is printed on Flat Screen Printing. There are only 6 to 8 colors printing patterns. 


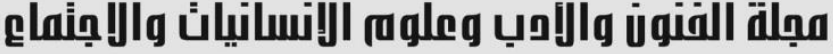 www.jalhss.com}

Journal of Arts, Literature, Humanities and Social Sciences

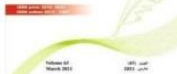

Volume (70) August 2021

العدد (70) أغسطس 2021

\section{Screen frame making process}

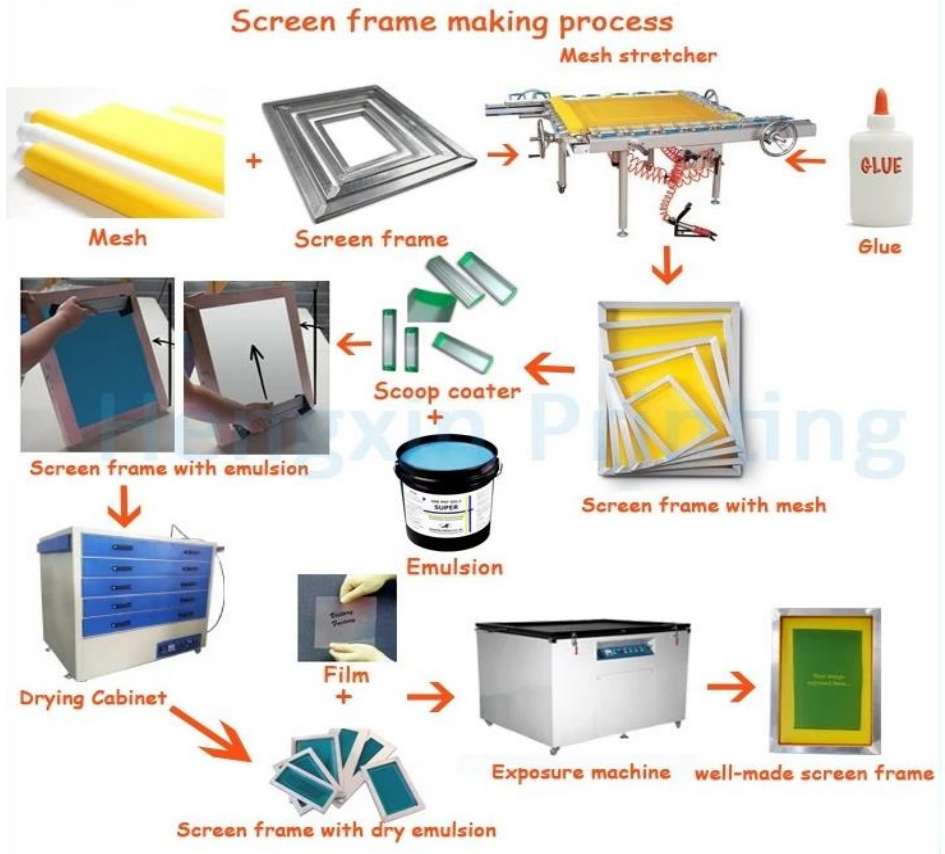

Fig (4) Screen frame making process

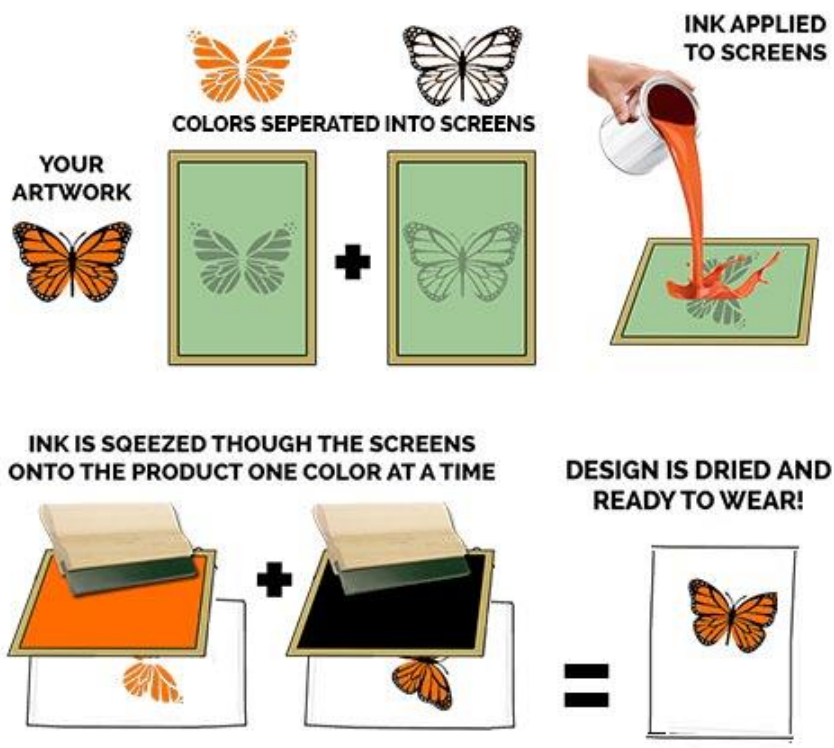

Fig (5) Silk screen printing Process 


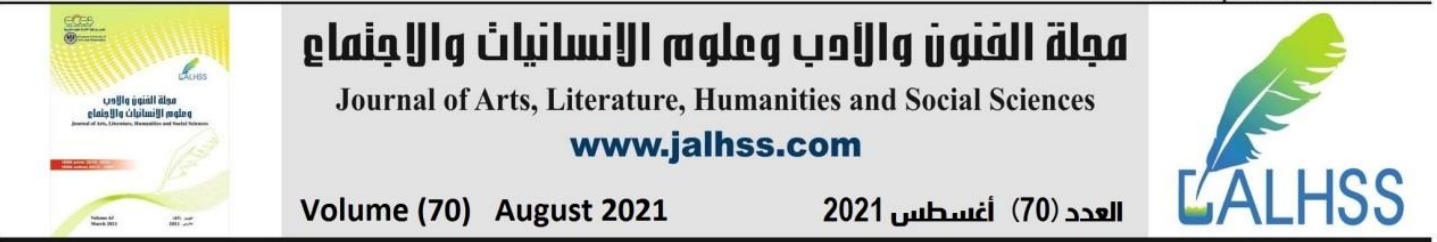

\section{Rotary Printer}

- $\quad$ This type of printer brought production costs down on the long runs. Speeds up to $30 \mathrm{~m}$ per minute is possible and nowadays most of printed carpet is produced on screen printing machines. The first rotary printer for the carpet industry was shipped to the USA in 1969 from Zimmer.

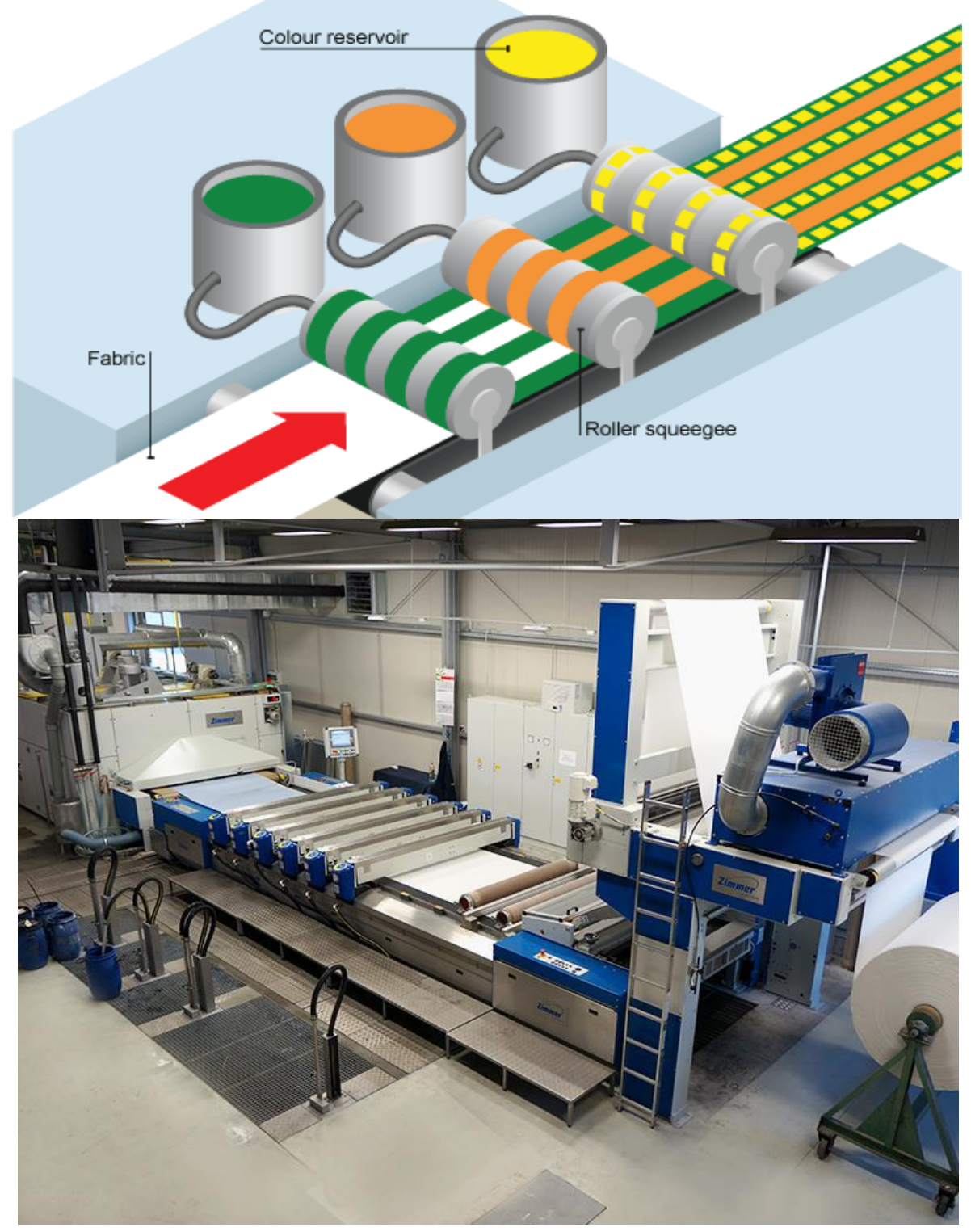

Fig (6) Rotary Screen Printing 


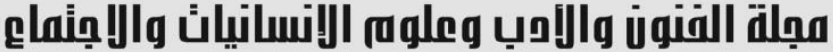 \\ Journal of Arts, Literature, Humanities and Social Sciences www.jalhss.com}

\section{ROTARY SCREEN EXPOSING PLANT...}

Screen length $4560 \mathrm{~mm}$

Repeat: only $926 \mathrm{~mm}$.

[1] EXPOSING MACHINE [Film type]

With sturdy m.s fabrication PLC with HMI operated Pneumatic

Air filling system with u.v Tube light trolley with cone and perfect

Marking device. Machine has no any rubber tube and any other mandril Refer photo

\section{CURING OVEN}

M.sfabricated insulatedcuring oven with high speed BlowerfanAnd ElectricHeater and digital controlled Temperature controller with perfect Locking system $926 \mathrm{~mm} \times 8$ nos screen Capacity.

\section{LACQURE COATING MACHINE}

$926 \mathrm{~mm} \times 4560 \mathrm{~mm}$ screen lacquer coating machine with PLC HMIControlled and variable speed drive Allocating Cone 2 Pic, of $926 \mathrm{~mm}$ repeats.

\section{CLIMATIZER BOX}

M.s Fabricated and Plywood with insulated structed climatizer box With heater and Air circulation blower fan Assembly with electrical Panel Board \{With Out Air Conditioner\}

COATING EQUIEPMENT FOR MANUAL HAND COATING With aluminum Coating Cone Set With Aluminum Rubber coating Ring Handle and Stand.

[6] SCREEN HOLDING CLAMP fiber Use for heated screen caring

[7] SCREEN CARRING CLAMP S.s material clamps for screen caring

[8] SCREEN UNPACKING TROUGHT

S.S Material screen packing and unpacking table $4560 \times 2$ repeats $926 \mathrm{~mm}$

[9]

\begin{tabular}{ll} 
RINGS SET & \\
\hline S.S SHAPPING RING & 8 NOS \\
TENSION RINGS & 8 NOS
\end{tabular}




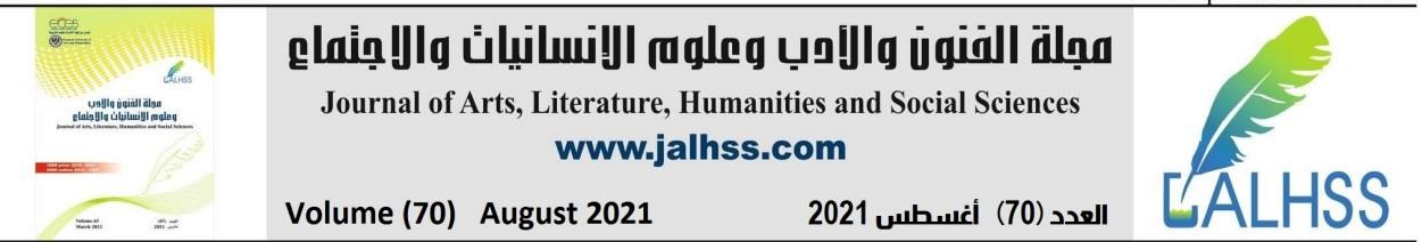

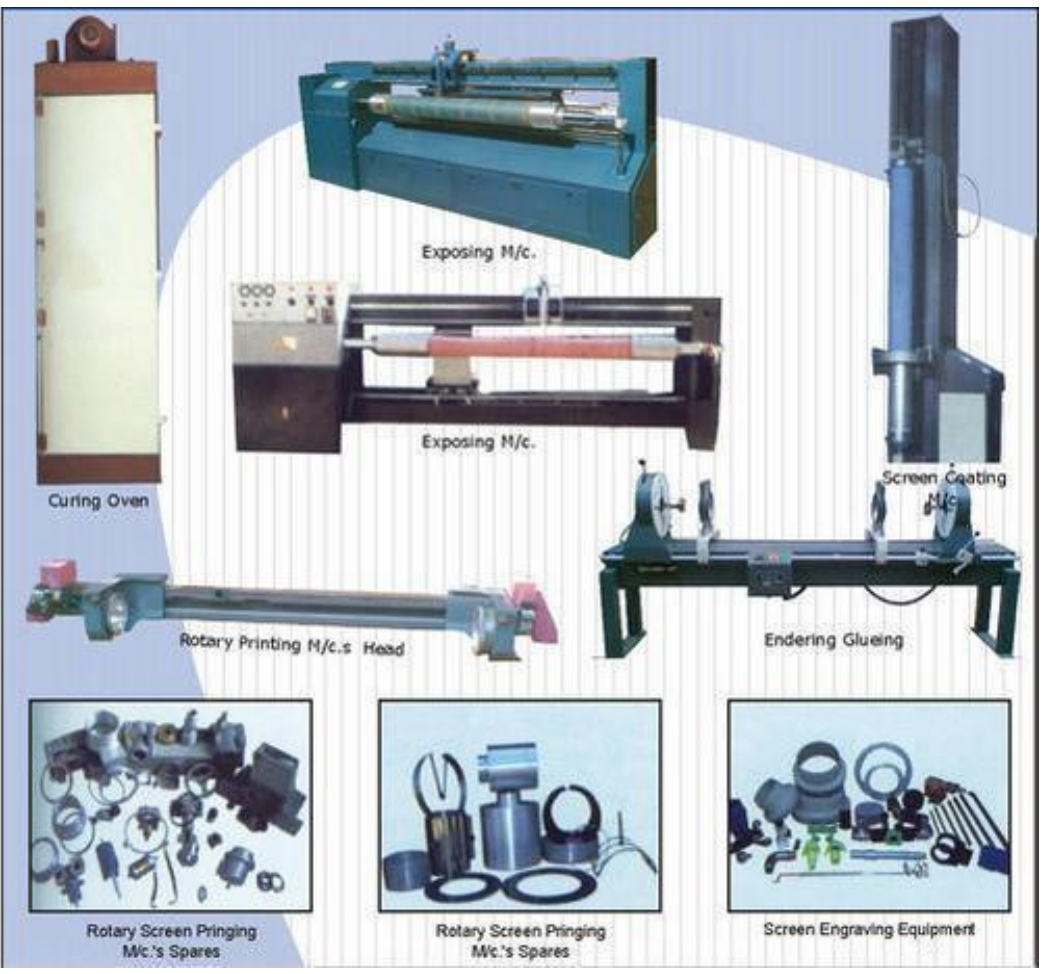

Fig (7) Equipment needed for making rotary screen design

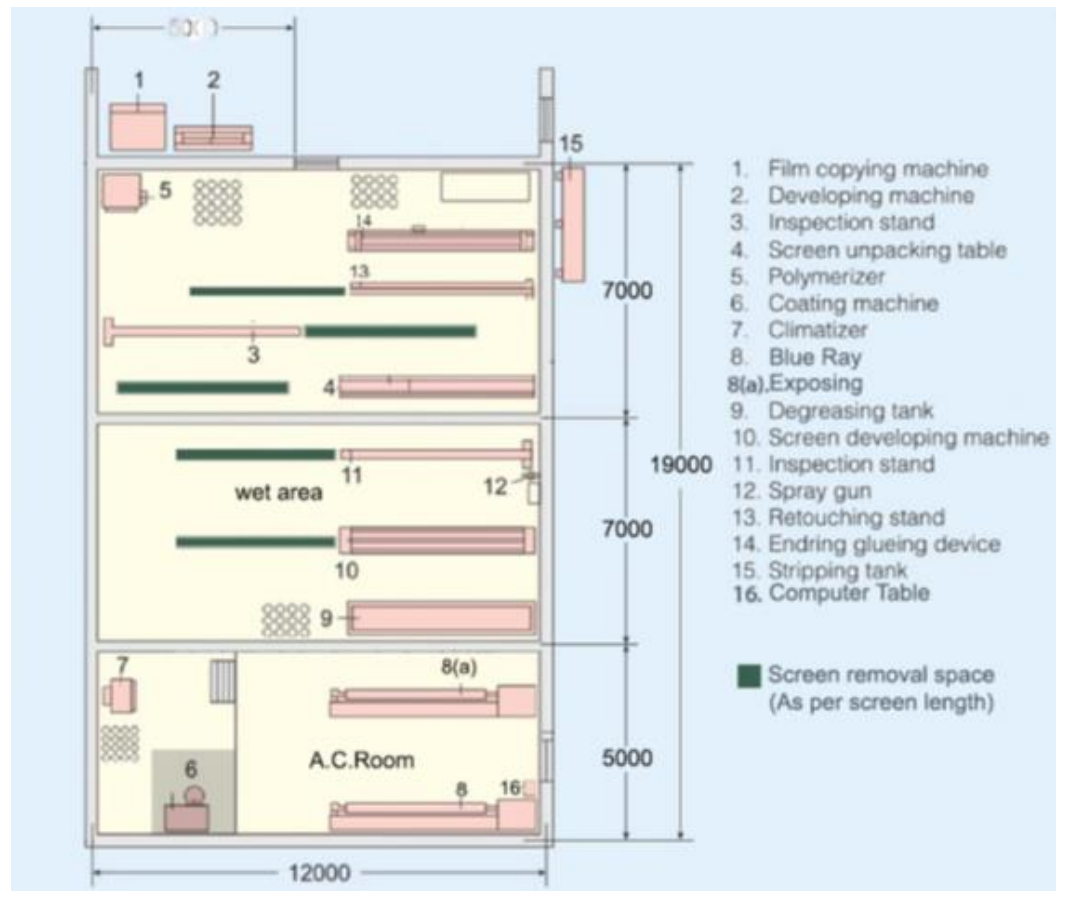

Fig (8) Engraving shop area needed for making rotary screen design 


\begin{tabular}{|c|c|c|c|}
\hline Les & 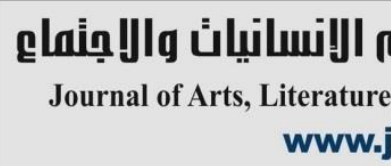 & 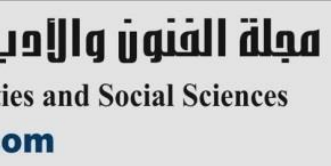 & \\
\hline$=$ & Volume (70) August 2021 & العدد (70) أغسطس 2021 & \\
\hline
\end{tabular}

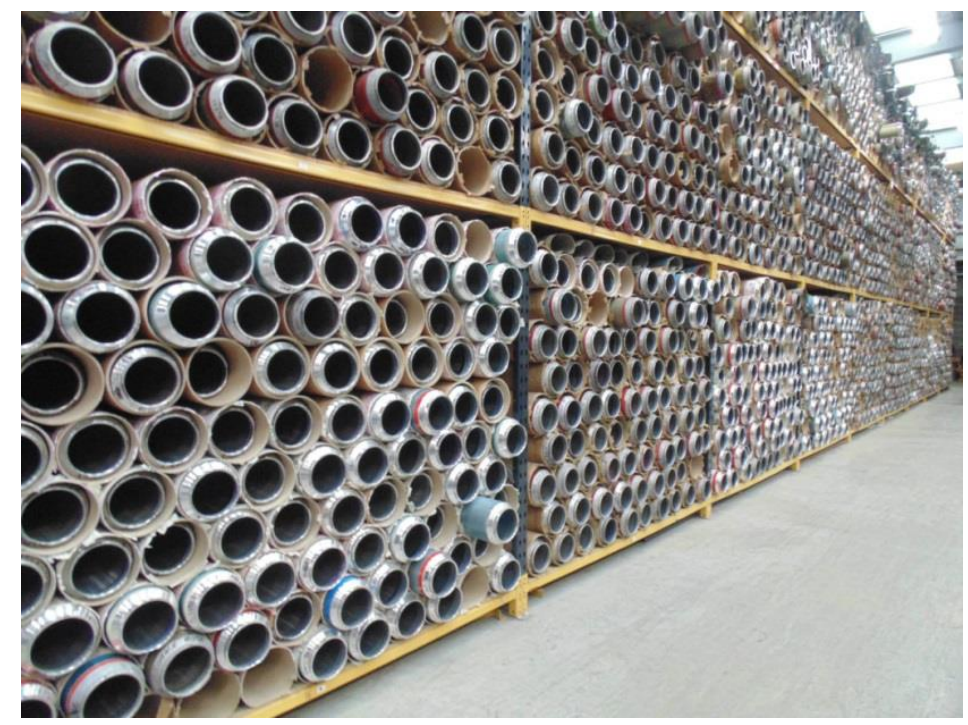

Fig (9) rotary screen designs store

The Rotary screen is round in size and it rotates. , just Roller is used. Large width fabric is printed on Rotary screen printing. Able to use 16 to 24 colors in a pattern. The initial cost of investment in Rotary screen printing is too high; so, it's expensive.

\section{Chromo-Jet}

In the 70's another important technological development by Zimmer arrived, the Chromo-Tronic Carpet Printing Machine. For the first time, computer controlled jets - not traditional Screens - were used to print a pattern. This was the first digital jet printer from Zimmer. Three Units were in operation. The problem at this time was the computer control but also the chemistry and other components were not ready yet. The unit was ahead of its time.

Chromo-Jet was developed and brought to its success under Johannes Zimmer. The basic concept was taken from the Chromo-Tronic, but a number of improvements and new technologies were implemented. Since the beginning of the 80's Chromo-jet is constantly developed further and improved and more than 600 units have been sold since then. Chromo-Jet is now the number one production method for individual carpet worldwide. Digital printing has a great future in the carpet and textile market. Zimmer developed High speed magnetic valves in-house are controlled with up to1000 cycles per second and inject pressurized color deeply into the carpet pile. Today Chromo JET is the leading printing system for wall-to-wall carpets, individually sized carpets, mats and carpet tiles. A wide range of machine models is available, featuring printing widths from 2 to 5 meters and production speeds from 1 to 10 meters per minute at a resolution of $25 \mathrm{dpi}$.

The companies provides the carpet industry with a complete production lines with fabric feeding system, Chromo JET printer, 


\section{هوالة الفنو \\ Journal of Arts, Literature, Humanities and Social Sciences www.jalhss.com}

Volume (70) August 2021

العدد (70) أغسطس 2021

Steamer, washer, dryer, fabric discharge, color kitchen, SupraMIX and SupraFOAM in-line mixer.

\section{What is Chromo-JET?}

Jets are electromagnetically opened and closed, Dye-jet is formed by a nozzle. Different nozzles for different applications. Color is pressurized (1-3 bar) and supplied from a pump- and filter-system directly to the jets. Jets are arranged in groups on a moving print-head which traverses the carpet - like a shuttle. Number of jets per group determine the production speed Up to 16 color-groups are arranged per print-head

\section{ChromoJET400 Basics}

\section{Function}

ChromoJET is a printing system using high speed valves which are computer controlled. The pre-mixed pressurized spot colors are injected with high precision deep into the face of the pile without any machine parts touching the fabric. Deepest color penetration and excellent print definition are the result.

\section{Print Speed}

Production speed is almost proportional to the number of jets used per color. More jets offer higher production speed.

\section{Modes of Operation}

\section{Single Speed Mode (SSM)}

Each group of jets is used for one individual color.

\section{Double Speed Mode (DSM)}

Two groups of jets are combined and filled with the same color. The linear production speed is almost doubled in comparison to single speed mode.
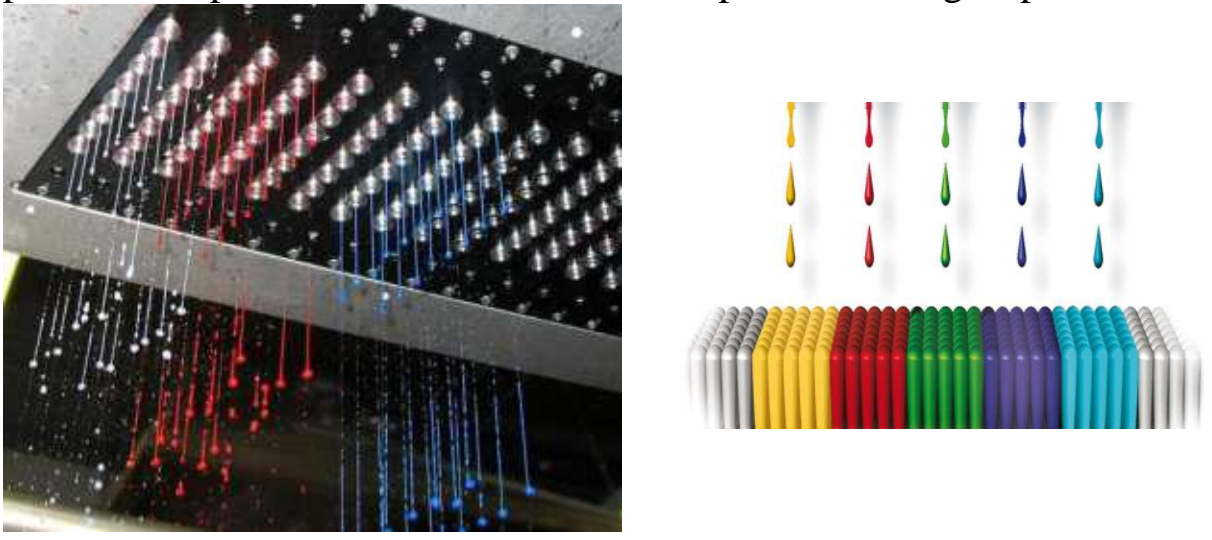

Fig (10) chromo jet nozzles 


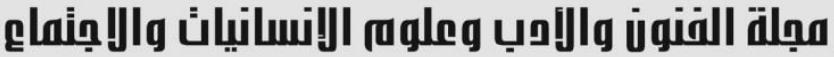
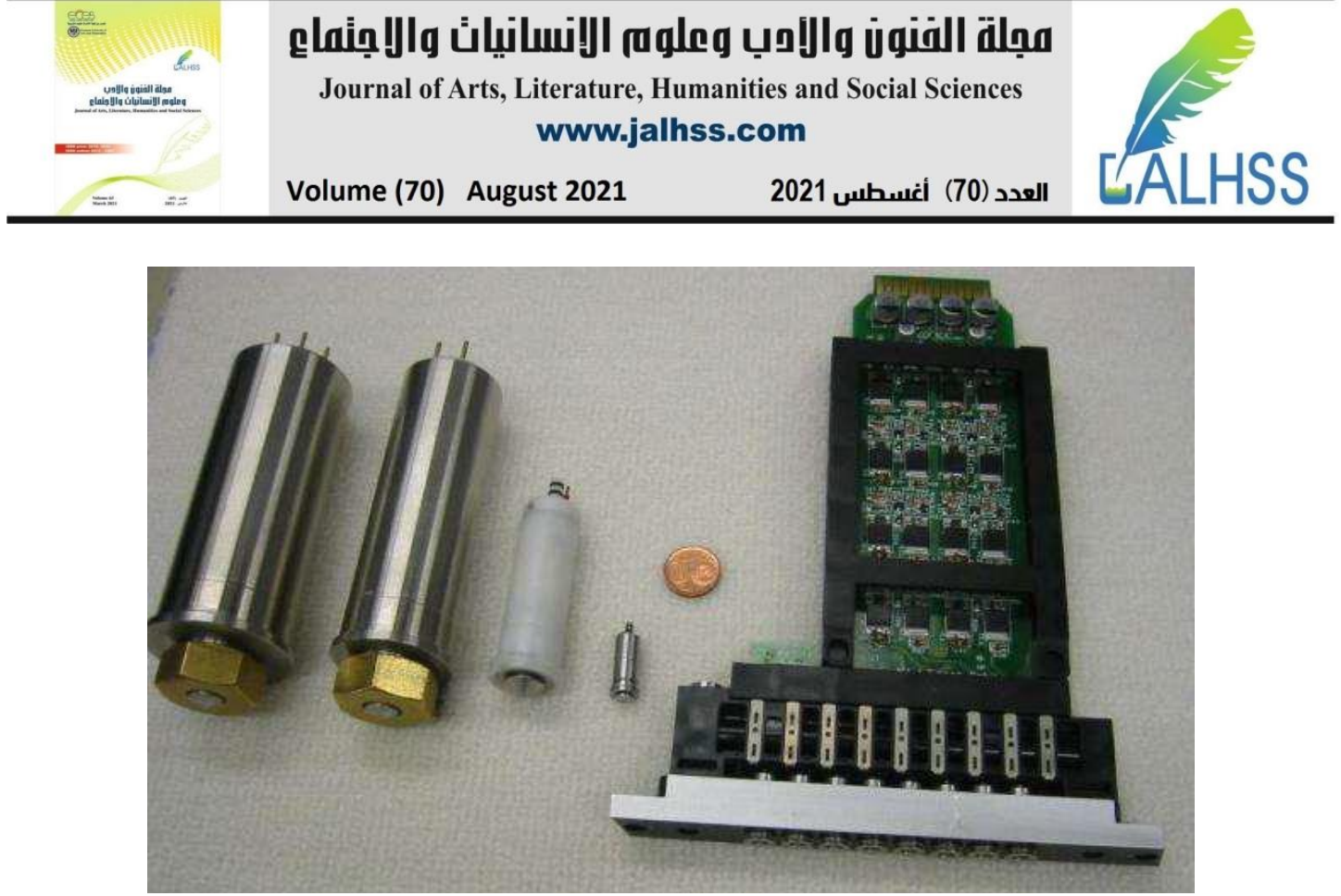

Fig (11) Jet Generations

\section{VALVE-JET.TECHNOLOGY}

\section{CONTROLLING.PICK-UP}

There are a number of parameters which influence dropsize, ejection speed, coverage and total pick-up.

The easiest way to control pick-up is to rasterize the coverage.

This raster can be in a range between 10\% and 100\% - depending on fabric and pick-

up.

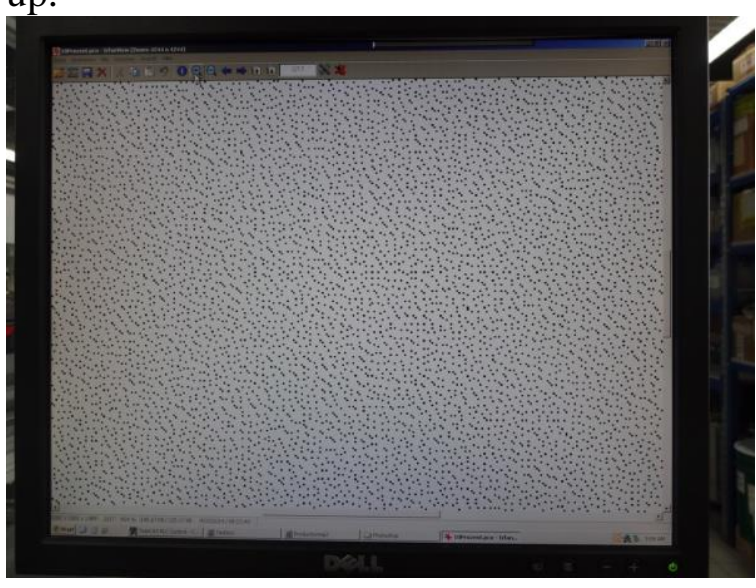

This is a $10 \%$ coverage of a pre-coat coat

Fig (12 ) Pick up \% covering

The next is

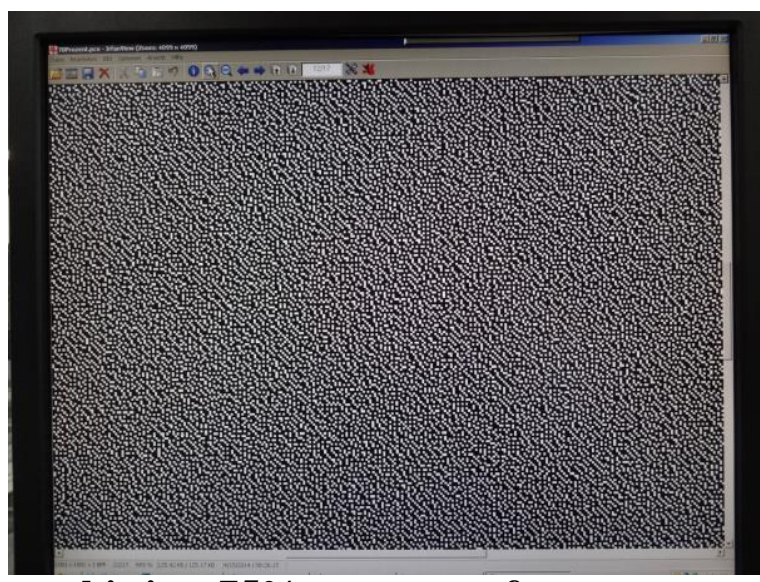

this is a $75 \%$ coverage of a pre- 


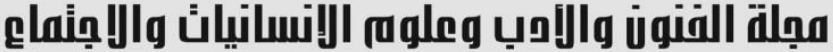 \\ Journal of Arts, Literature, Humanities and Social Sciences www.jalhss.com}

Volume (70) August 2021

العدد (70) أغسطس 2021

\section{Calculation of possible pick-up ranges using CHROMOJET800 jets}

\begin{tabular}{|l|c|c|c|}
\hline Parameter & min & max & pick-up range \\
\hline Pressure & $1.0 \mathrm{bar}$ & $3.5 \mathrm{bar}$ & 5 \\
\hline Head speed $(1 \mathrm{~m} / \mathrm{sec}=100 \%)$ & $40 \%$ & $100 \%$ & 2.5 \\
\hline Coverage by raster & $25 \%$ & $100 \%$ & 4.0 \\
\hline Variation by pressure, head-speed and coverage & & & 50 \\
\hline Viscosity (root function) & $50 \mathrm{cps}$ & $200 \mathrm{cps}$ & $\mathbf{1 0 0}$ \\
\hline Variation by pressure, head-speed, coverage and viscosity & & & 5 \\
\hline Nozzle diameter (square function) & $120 \mu \mathrm{m}$ & $280 \mu \mathrm{m}$ & $1: 500$ \\
\hline Theoretical variation and range of pick-up & & & 2 \\
\hline
\end{tabular}

\section{Fig (13 ) Pick-up Ranges using in chromojet printer}

\section{Advantages of ChromoJET400}

- No screens - no limitation in pattern repeats

- Design change „on the fly“

- Full penetration

- Pile weight from 250 up to $1,500 \mathrm{~g} / \mathrm{m} 2$

- For polyamide, wool, acrylic and (up to a certain extent)

Polyester yarns

- Complete print line from one supplier

- High Resolution 


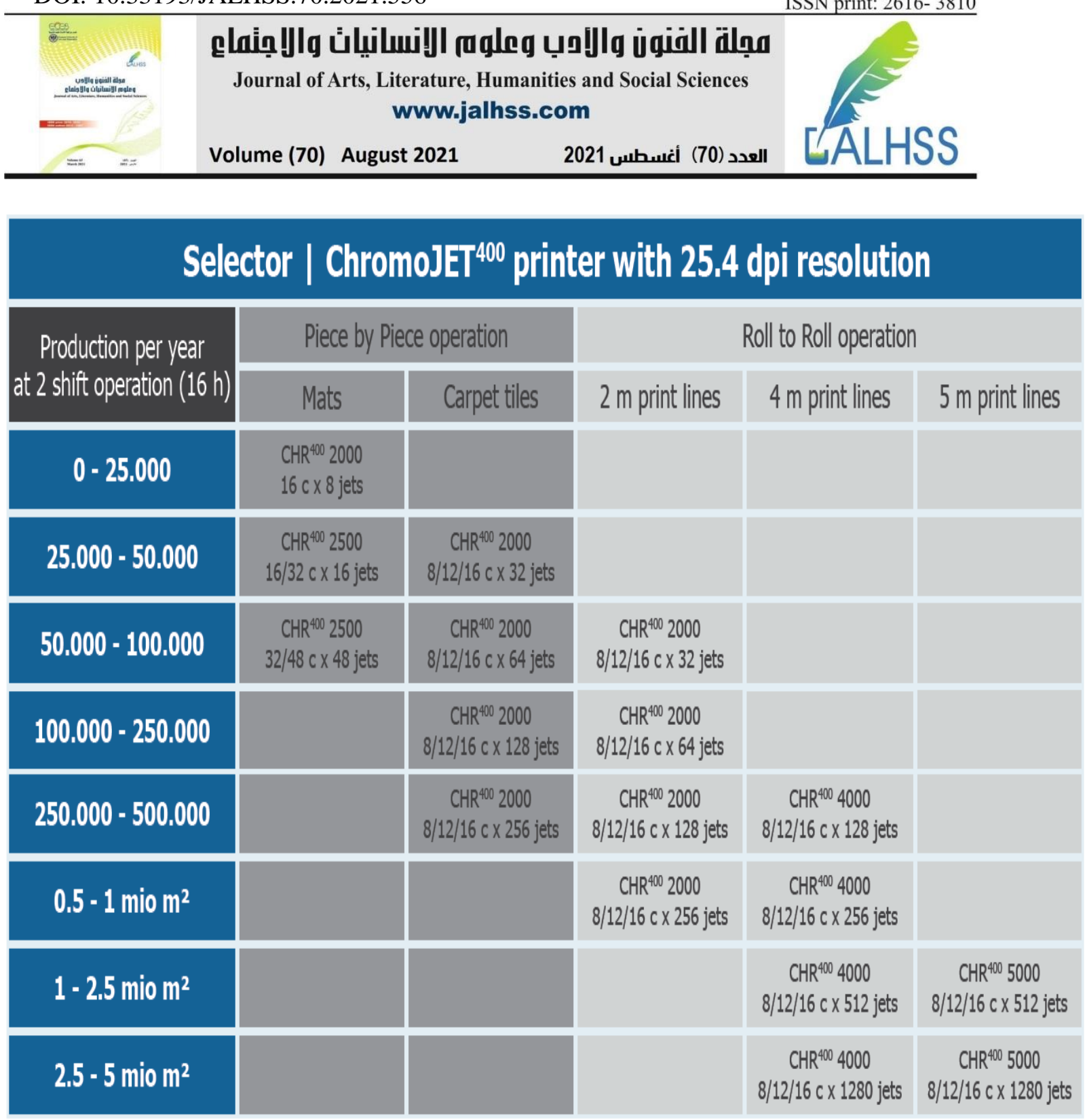

Fig ( 14) Chromo jet production, width, number of color and jets per color 


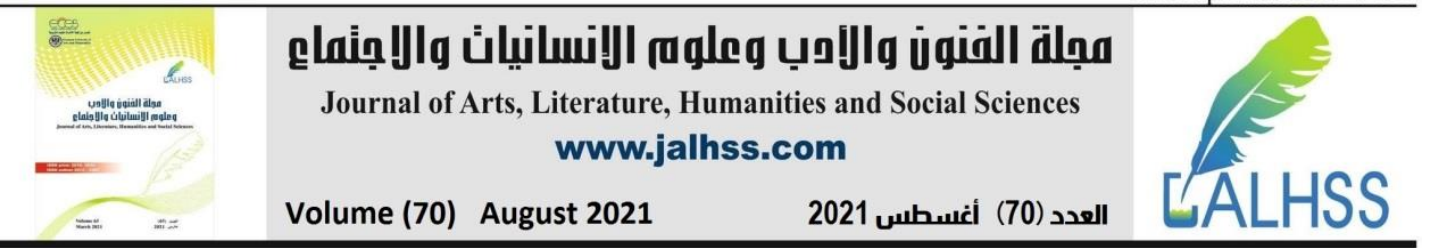
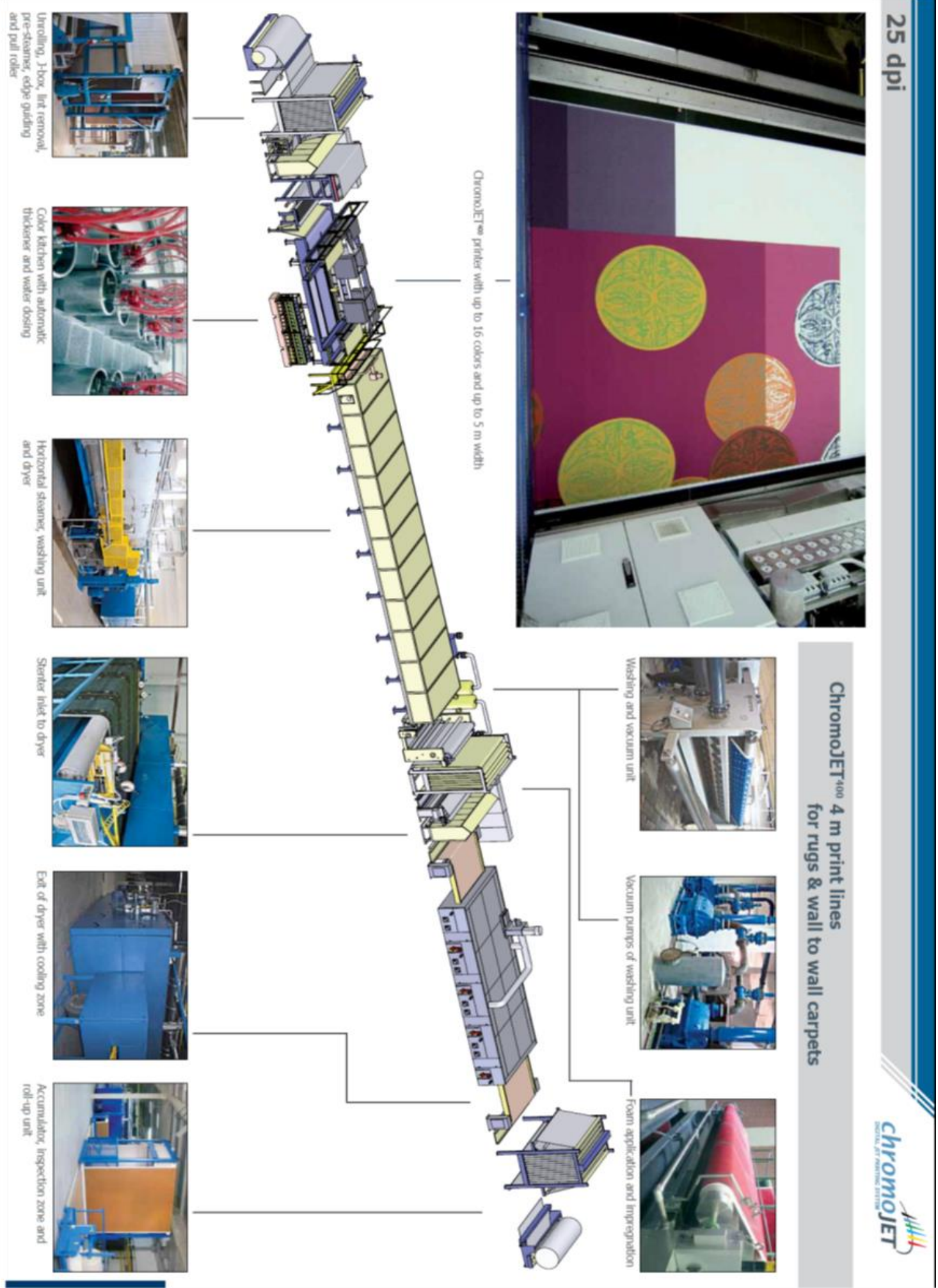

Fig (15) full line chromo-jet carpet printer 


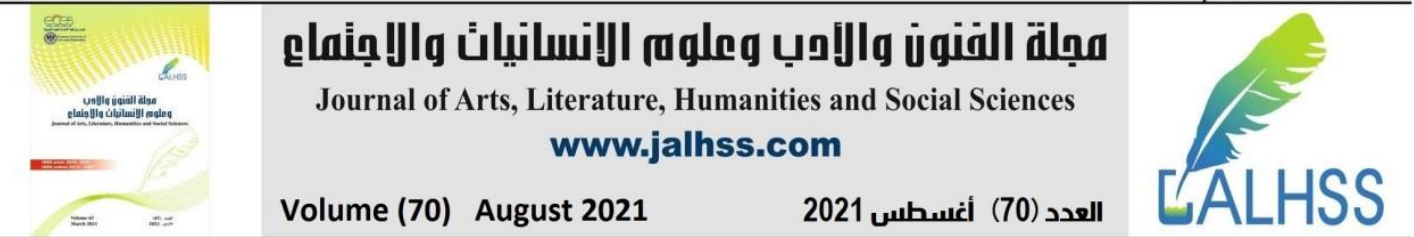

The next is chromojet machine process parts

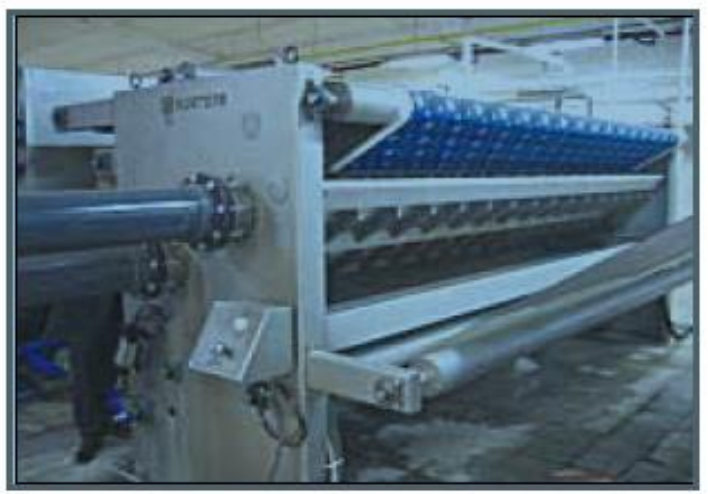

Washing and vacuum unit

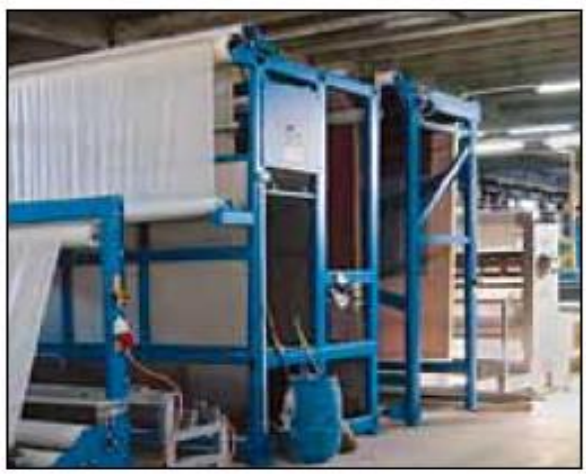

Unrolling, J-box, lint removal, pre-steamer, edge guiding and pull roller

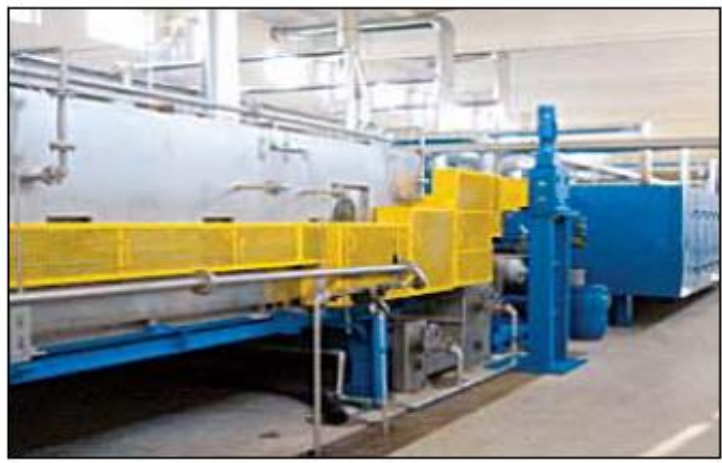

Horizontal steamer, washing unit and dryer

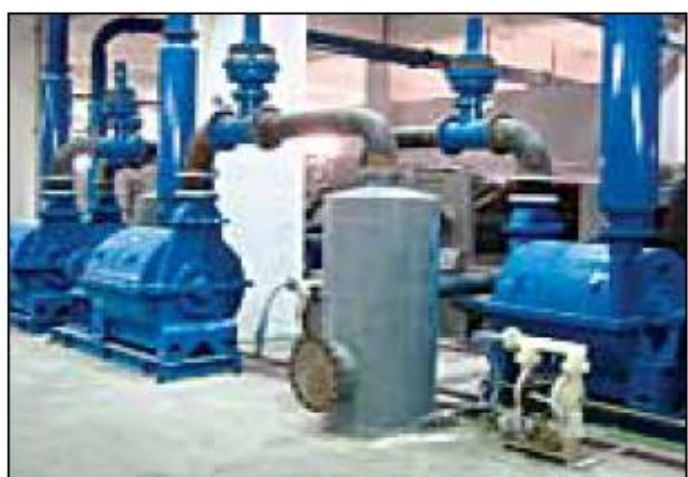

Vacuum pumps of washing unit

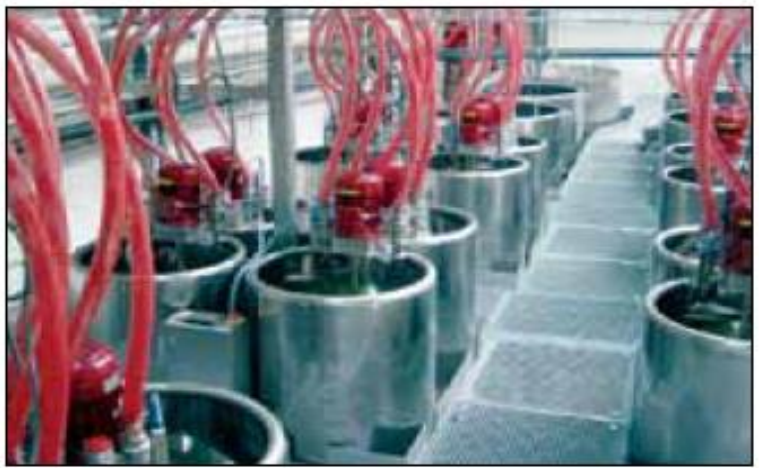

Color kitchen with automatic thickener and water dosing

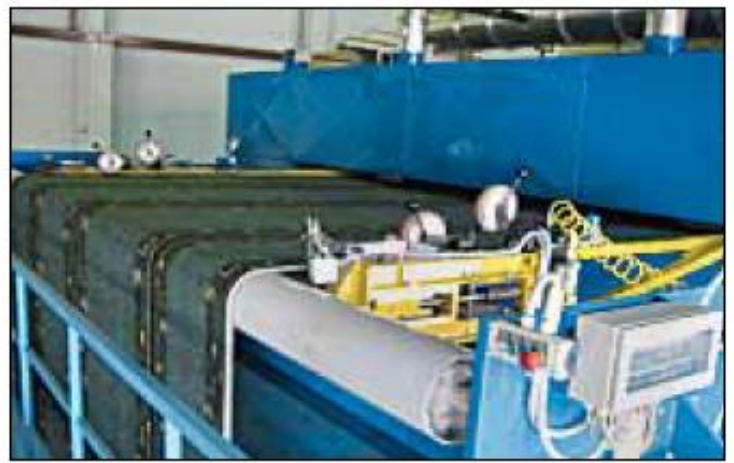

Stenter inlet to dryer 


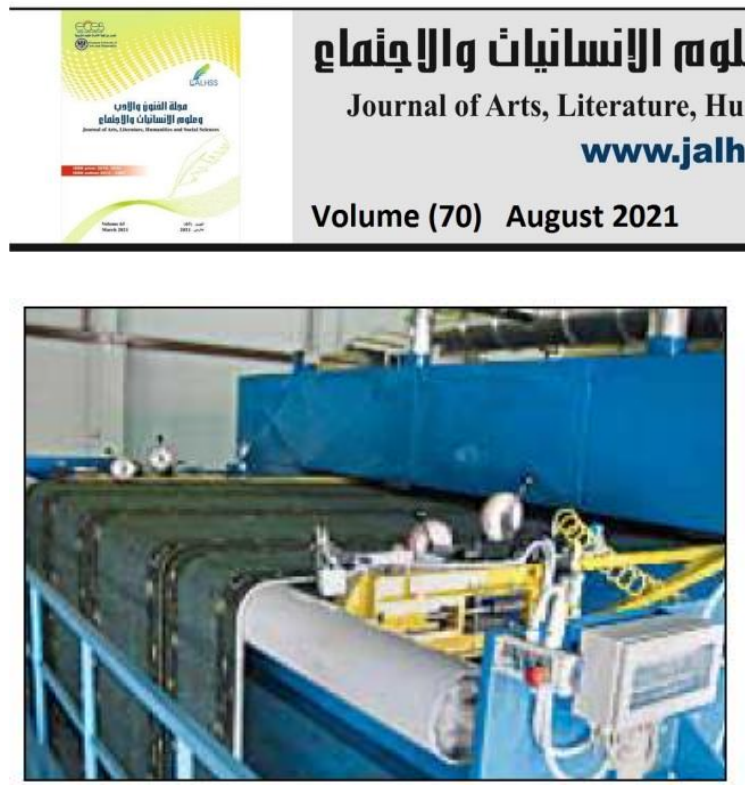

Stenter inlet to dryer

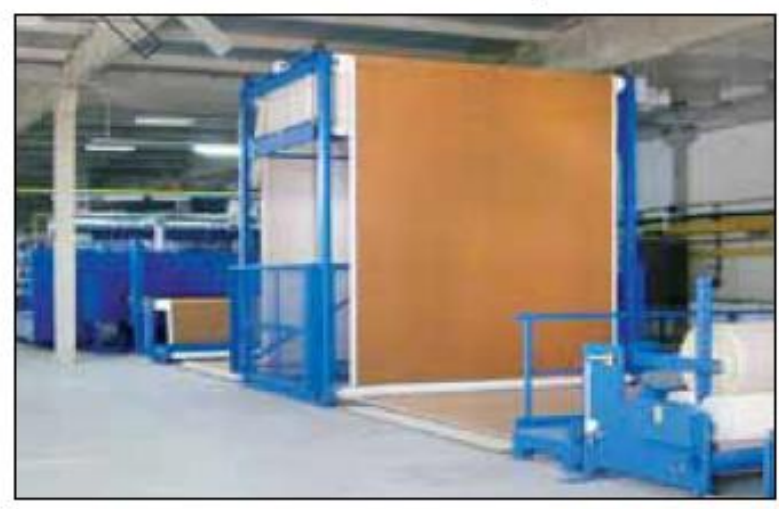

Accumulator, inspection zone and roll-up unit

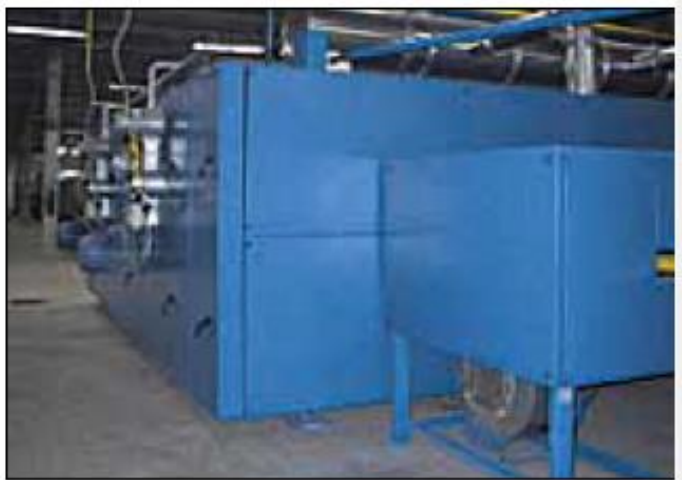

Exit of dryer with cooling zone

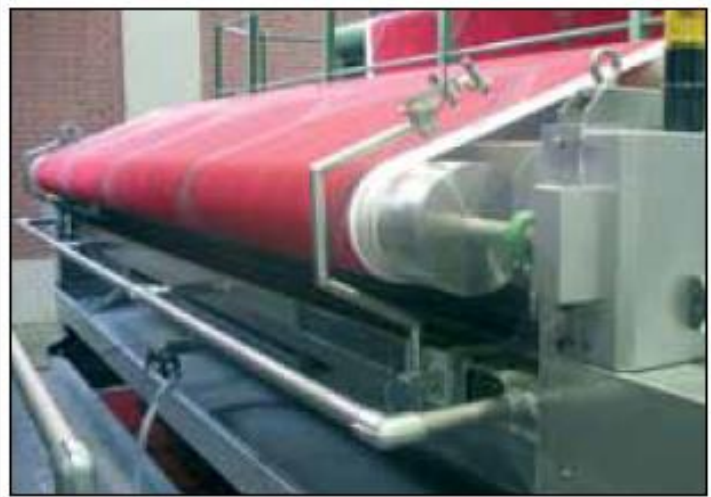

Foam application and impregnation

\section{Spot color printing with pre-mixed dyes:}

Dye shades are pre-mixed according to the recipes. One tank for each color shade used in the print. Amount of dye paste must match the actual consumption. System must be washed for a color change

\section{DESIGN PREPARATION}

The design done by using graphic design program by computer and one of the famous design program use

Adobe Photoshop, NedGraphics, Adobe Illustrator; Corel Draw 


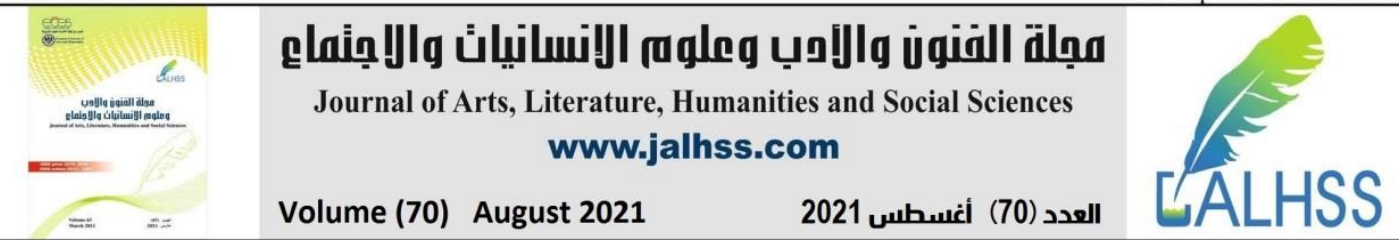

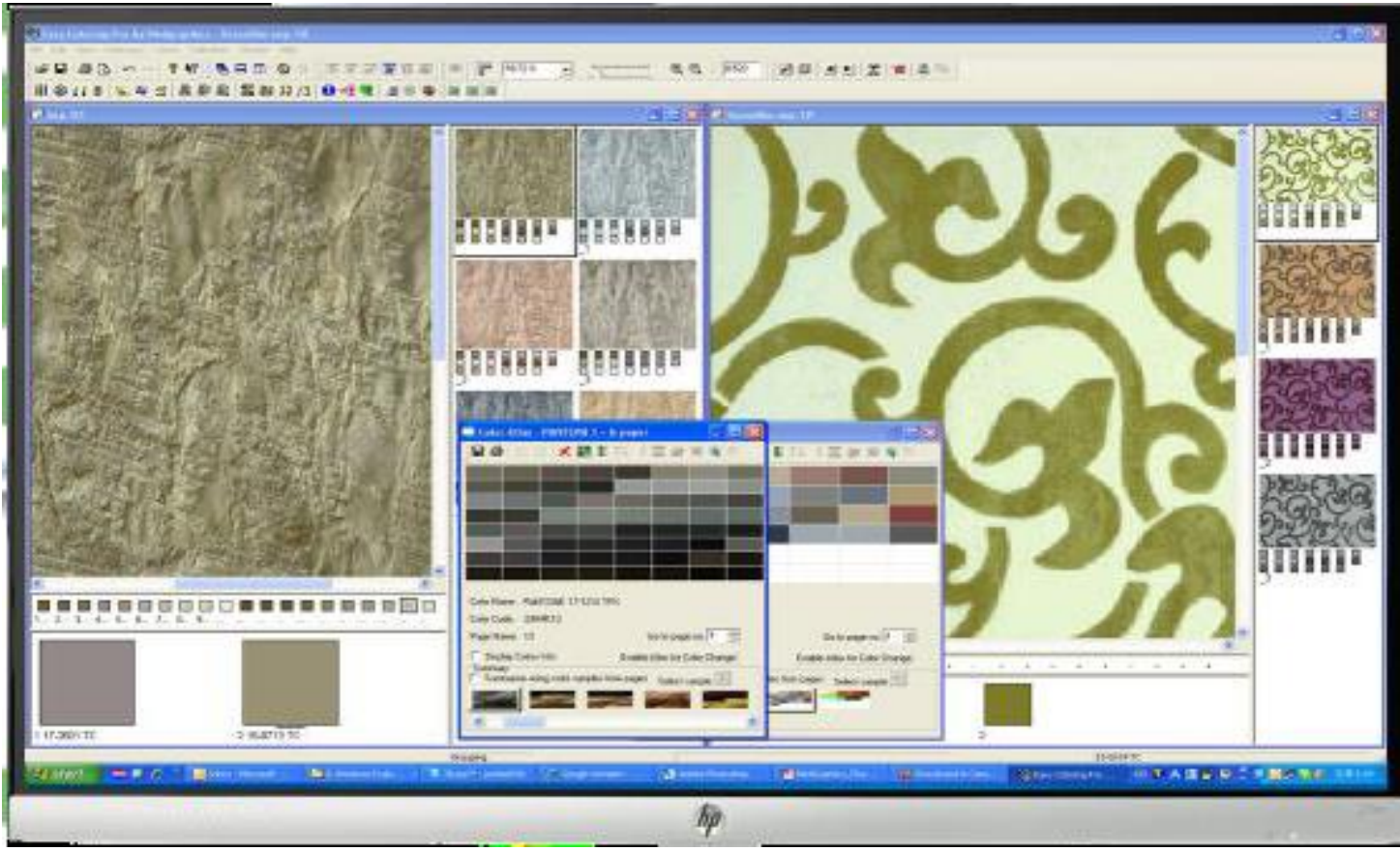

Fig (16) Screenshot NedGraphics

The design system has these basic functions:

- Create, match and combine patterns and designs

- Bring patterns into repeat

- Reduce number of colors

- Coloration - to show a design in several colorways

RASTER- OR VECTOR- FORMAT?

Each file format has its pros and cons:

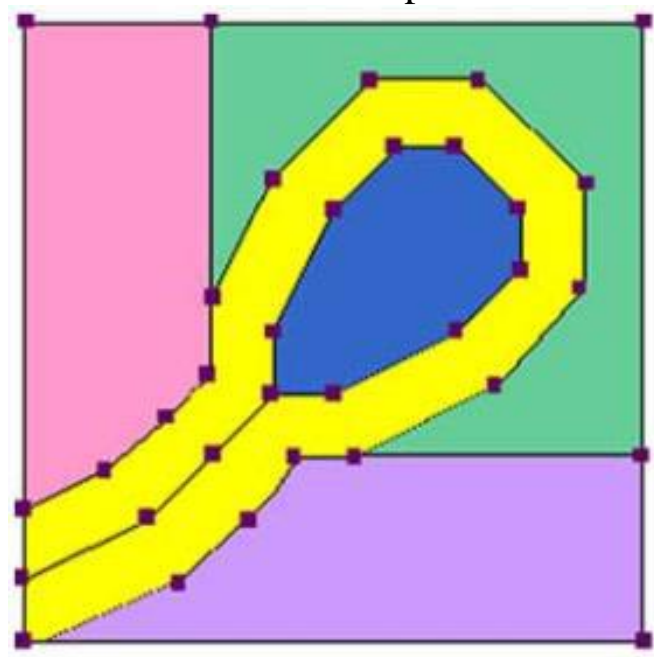

Vector

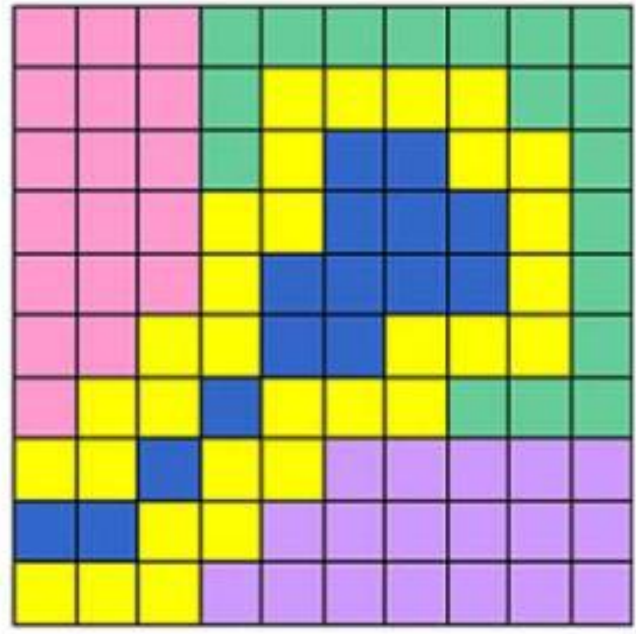

Raster 

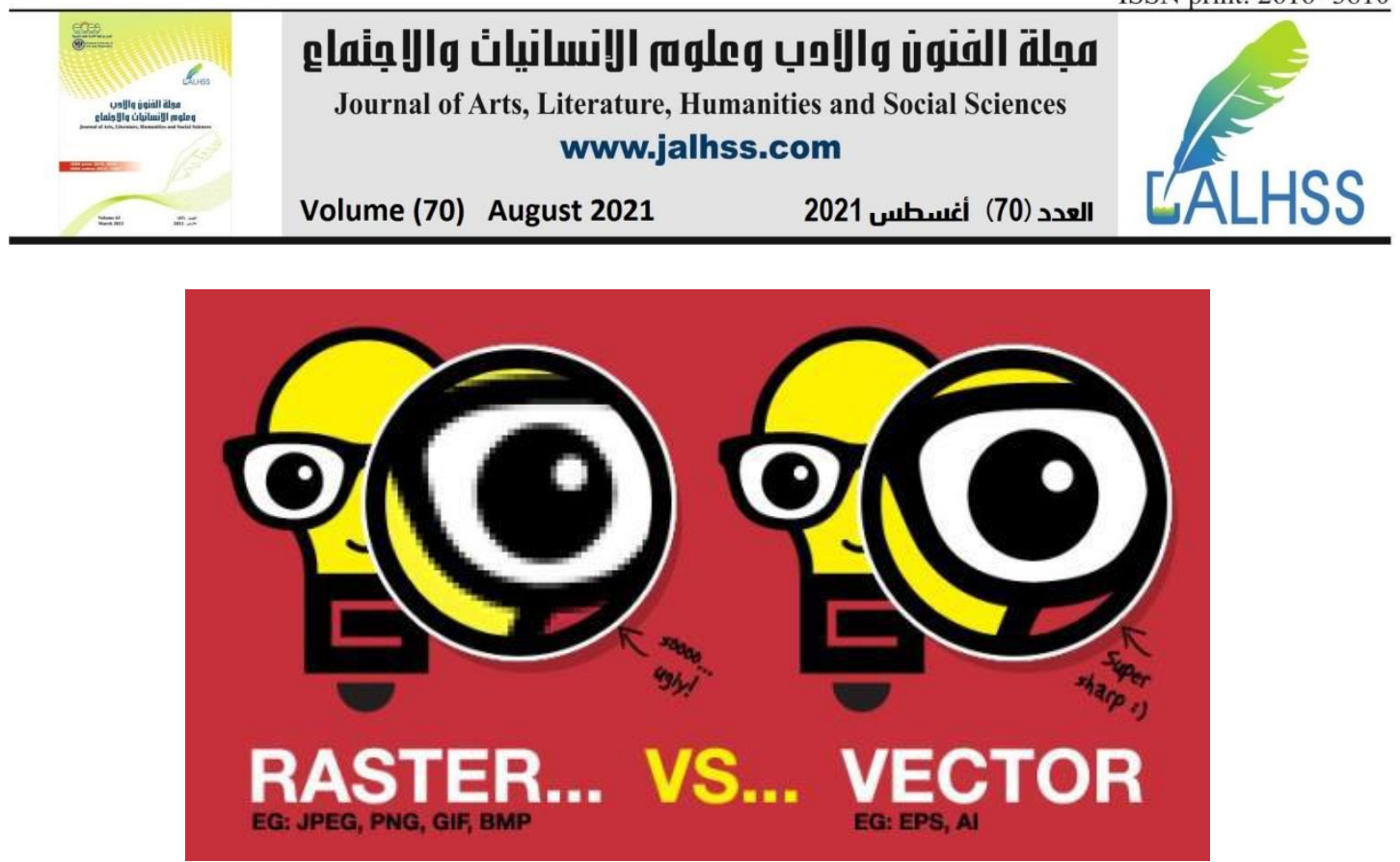

Fig (17) RASTER and VECTOR- FORMAT

RASTER or Pixel Format can show more details and is the most common format in the carpet industry. The disadvantage is its high memory demand and its limited scalability.it save format EG - JPEG - PNG - GIF - BMP.

Common platforms: Adobe Photoshop, NedGraphics.

VECTOR Format has the advantage that the memory demand is much lower and the designs can be zoomed and scaled without losing details. It save format EG - EPS AI.

Common platforms: Adobe Illustrator; Corel Draw.

COMBINED RASTER AND VECTOR FORMATS There are also programs available which combine raster and vector files.

Typical software platform: Adobe InDesign.

\section{Digital Printing}

Digital Textile floor coverings printing is a process of printing on carpet fabric using inkjet technology to print colorants onto fabric. This process allows for single pieces, mid to small-run cycle production and even long-runs as an alternative option to screen printed fabric. The first step in digital textile printing is to pretreat the fabric with liquid solutions that prepare it to accept the dye and better absorb the color. Then it is fed through the printer, which sprays the dye onto the textile with tiny droplets. The final step is fixing the fabric, a process that ensures the permanency of the design. Depending on the type of textile and type of dye, fixing may involve steam, dry heat, or pressure. Sometimes it requires a combination of two or more of those. Now Manufactures printing solutions provide a quick and easy digital printing process, requiring no pre or post treatment. Makes printing so simple. Zimmer's DTG printing solutions allow for unparalleled printing quality, speed and performance.

\section{There are two types of Digital printing process}

- $\quad$ Direct to Fabric printing

$>\quad$ Roll to roll 


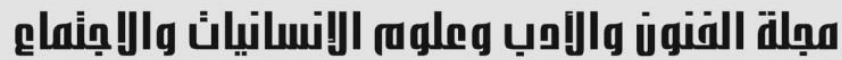 \\ Journal of Arts, Literature, Humanities and Social Sciences www.jalhss.com}

Volume (70) August 2021

العدد (70) أغسطس 2021

$>\quad$ Piece printing

- $\quad$ Paper Heat transfer printing

$>\quad$ Roll to roll

$>\quad$ Piece printing

Direct to Fabric printing, Roll to roll

The next direct printed carpet line from Zimmer

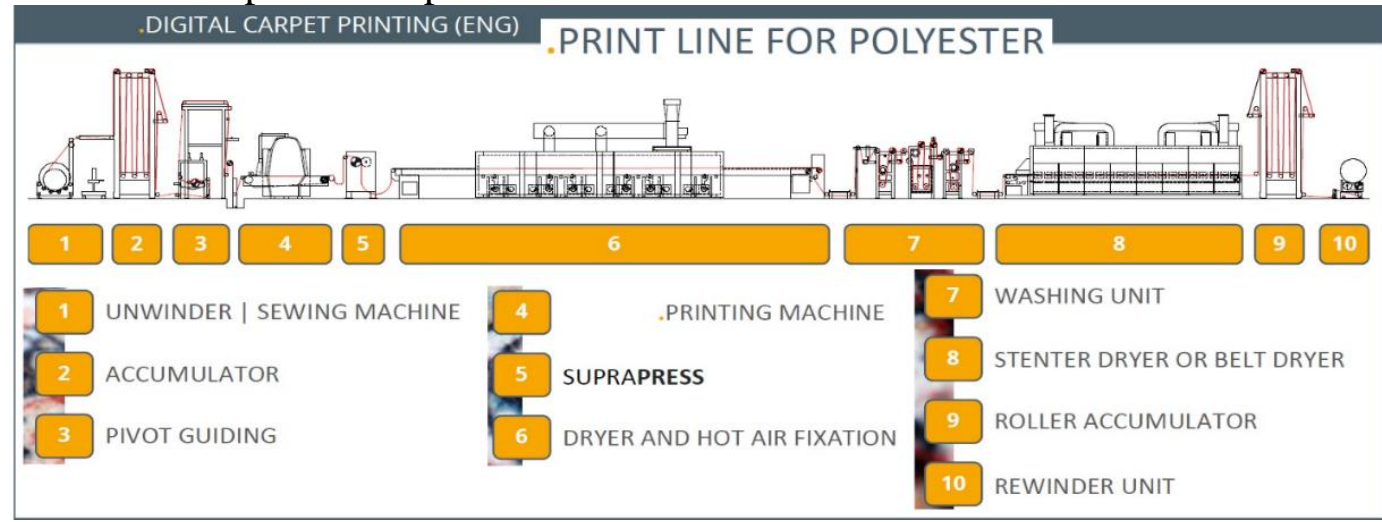

Fig (18) Zimmer digital carpet printing line.

China manufactures carpet printer line for Polyester

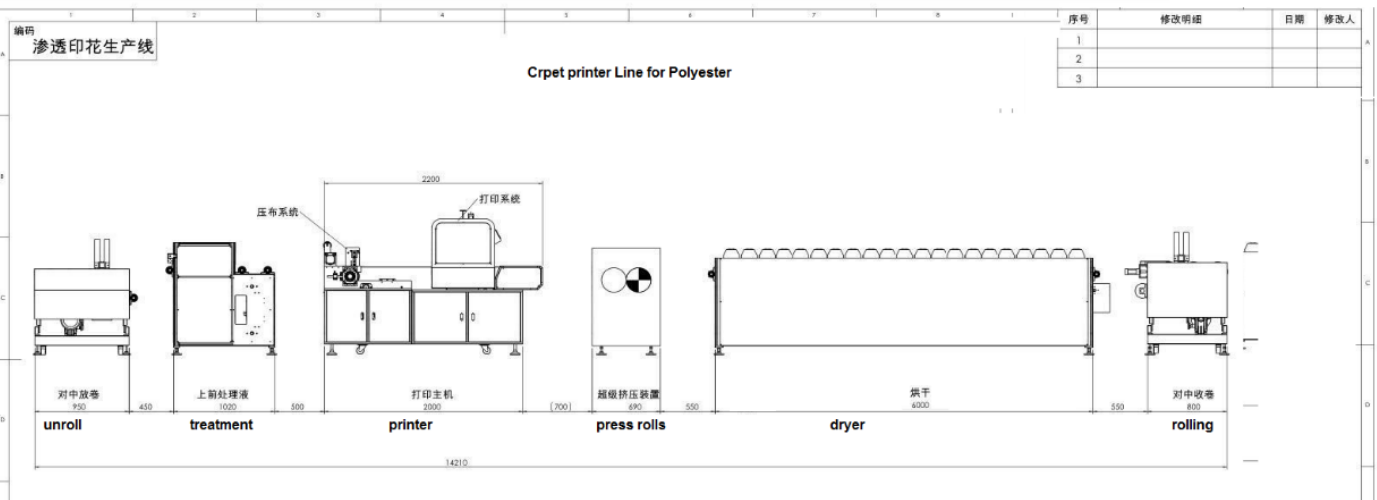

Fig (19) China manufactures carpet printer line for Polyester 


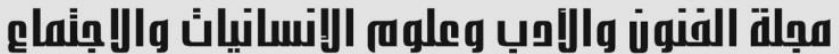

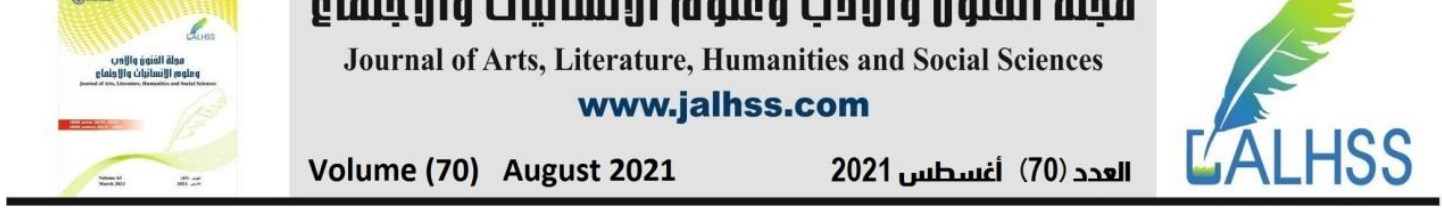

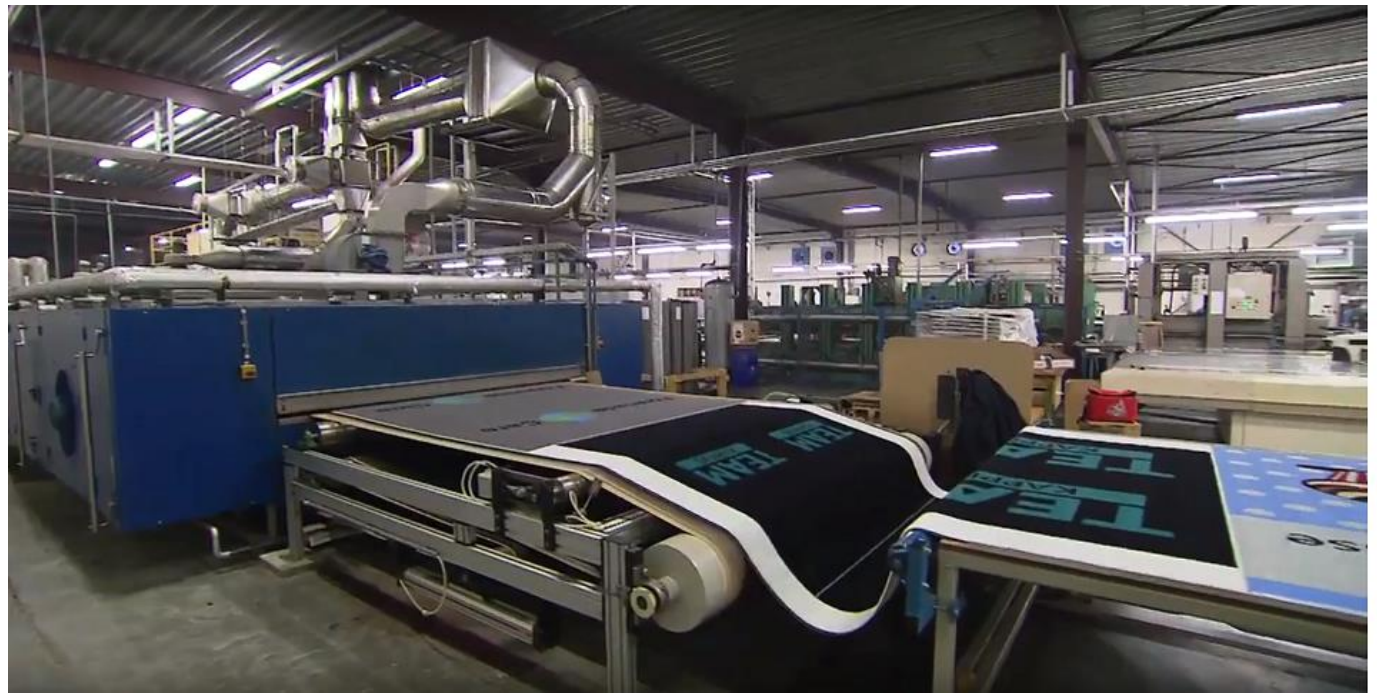

Photo (20) roll to roll direct printing to fabric

Direct to Fabric printing, Pieces printing

Found different type different size according customer carpet size and price of machine Small, medium and large flatbed printing machine
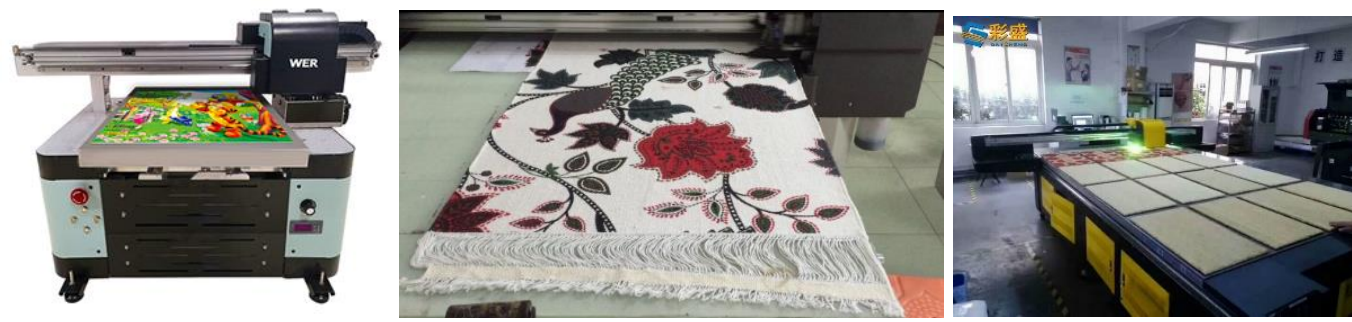

Photo (18 ) Direct to Fabric printing Pieces carpet printing machine

Piece printing dryer

After printing need to fix color by steaming or heating use for that different type of dryers for piece printing, the next one of this type

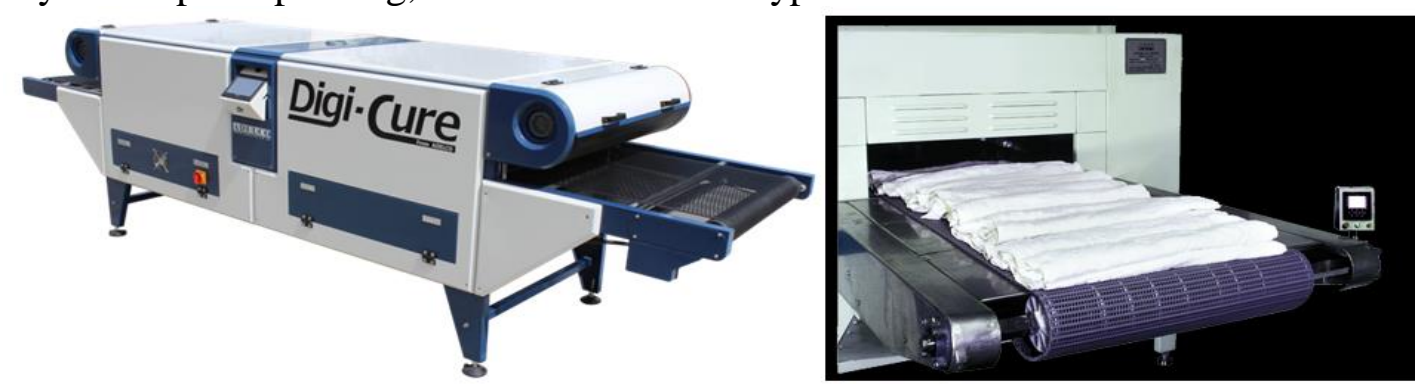

Photo (21) Pieces textile dryer 


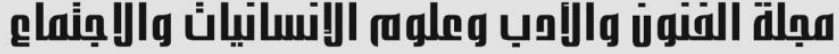 \\ Journal of Arts, Literature, Humanities and Social Sciences www.jalhss.com}

\section{Inkjet Print head Technology Overview}

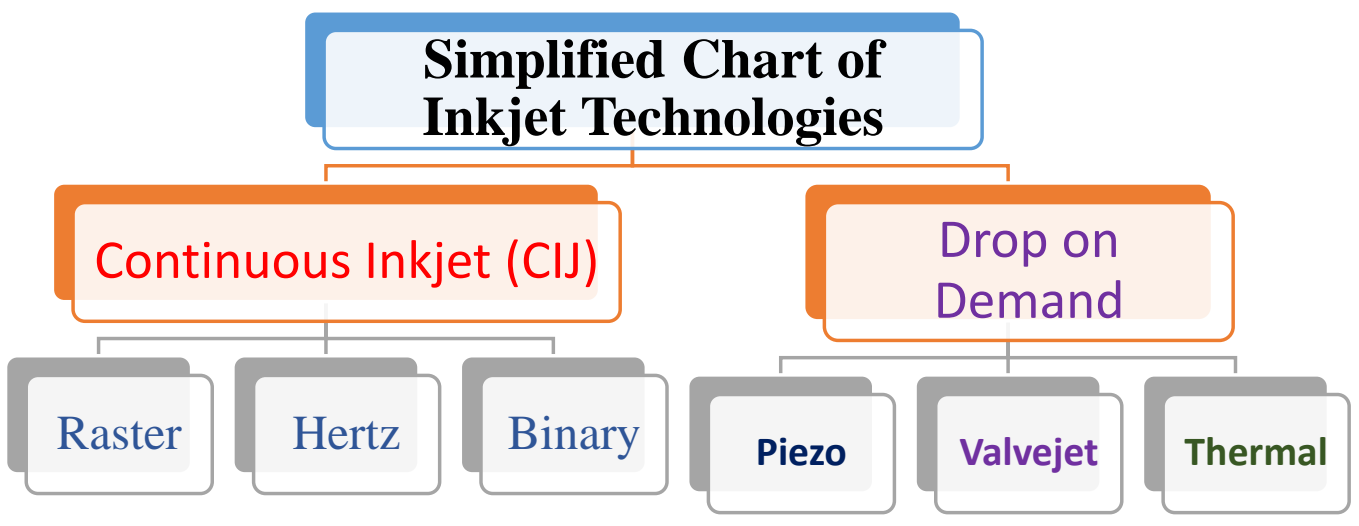

Fig (22) Simplified Chart of Inkjet Technologies

There are many sub-categories of ink jet and some other technologies, but this presentation will

-Provide an overview of technologies and terminology of inkjet

-Concentrate on key technologies being used today in production systems

- Primarily drop on demand piezo inkjet

The inkjet use in carpet printing are

- $\quad$ Drop on Demand - velvet jet

- $\quad$ Drop on Demand - Piezo 


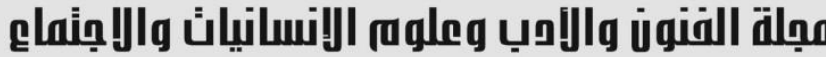 \\ Journal of Arts, Literature, Humanities and Social Sciences www.jalhss.com}

\section{Drop On Demand - Valvejet}
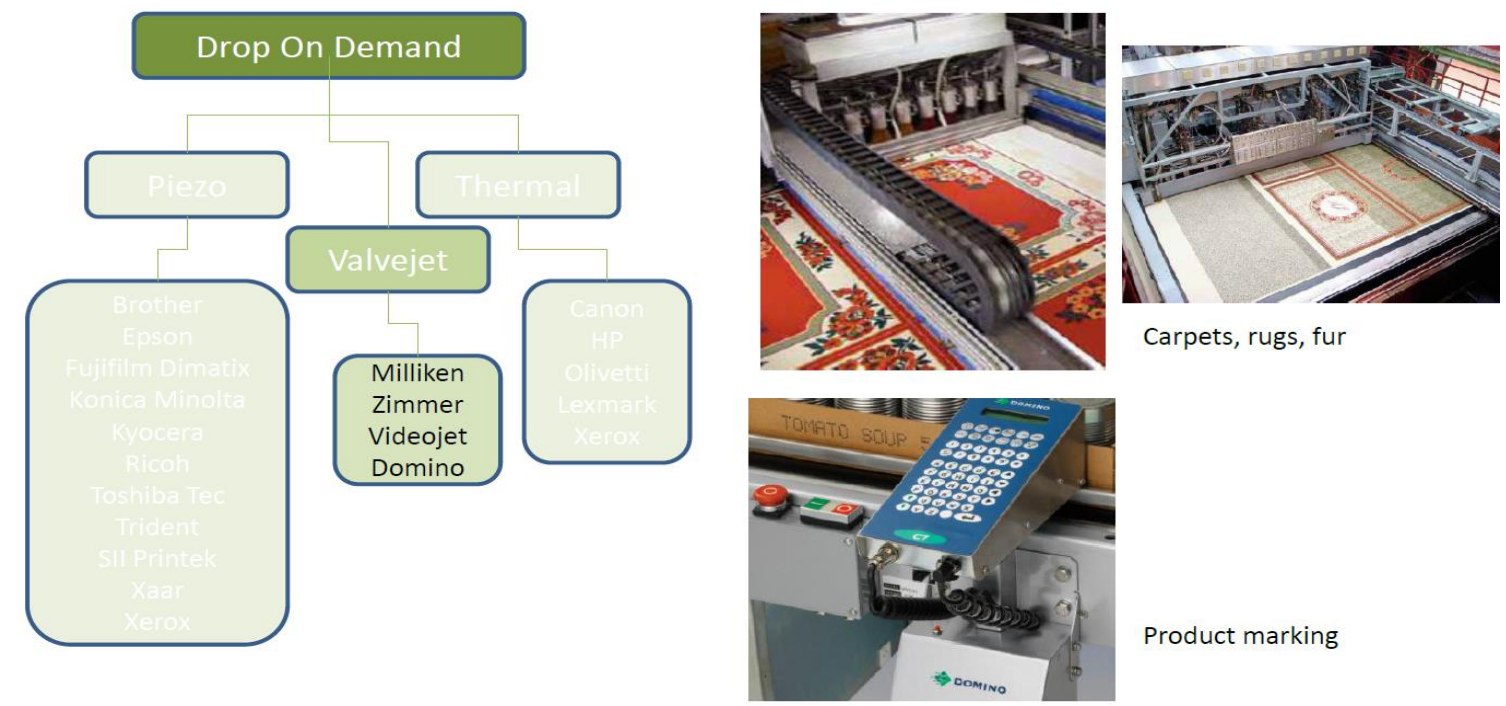

Carpets, rugs, fur

Product marking

Fig (23) drop on demand - velvet jet

Which are manufacture and used by:

Milliken - Zimmer - Videojet - Domino

\section{- Valvejet}

\section{Drop On Demand - Valvejet}
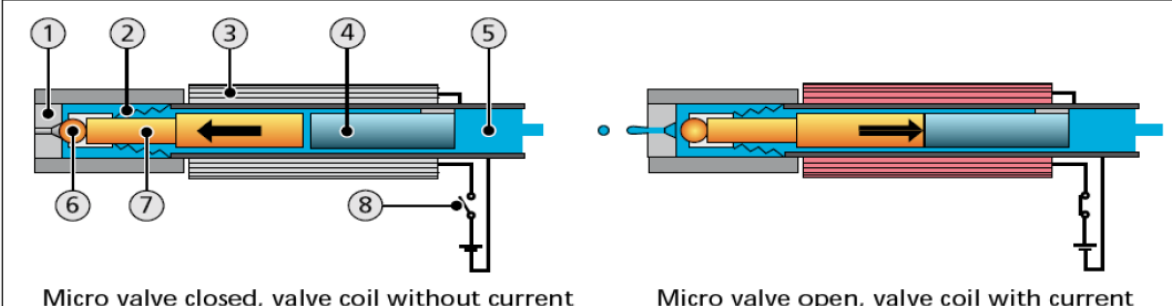

Valve seat, valve nozzle

2. Closing spring

Micro valve open, valve coil with current

3. Valve coil

4. Stationary anchor

5. Medium

6. Valve ball

7. Mobile anchor

8. Switch

The micro valve is actuated electromagnetically and medium flows through it directly. When there is no current, the micro valve is closed.

The closing spring acts on the mobile anchor

When there is a current feed through the valve coil, the mobile anchor with the valve ball is magnetically pulled by the magnetic field of the stationary anchor. The micro valve opens and the medium emerges.

Fig (24) velvet jet 


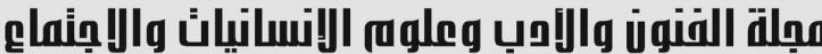 \\ Journal of Arts, Literature, Humanities and Social Sciences www.jalhss.com}

www.jalhss.com
Volume (70) August 2021

\section{Drop On Demand - Piezo}
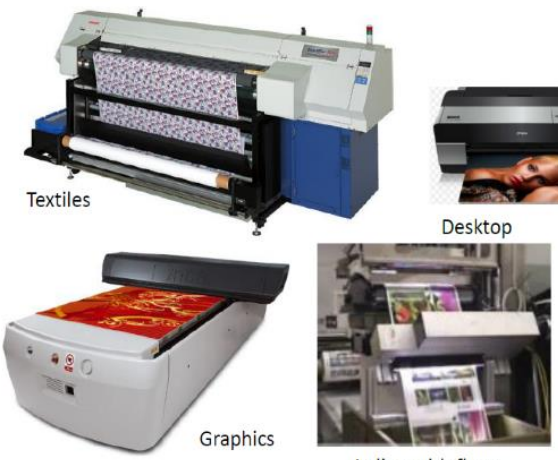

In line with flexo
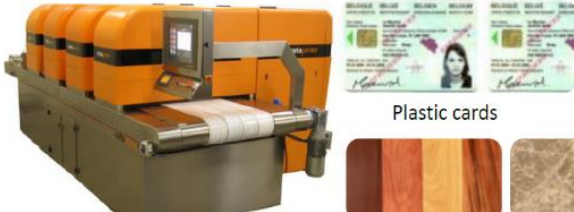

Plastic cards

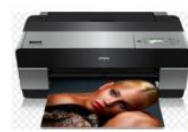

Drop on Demand
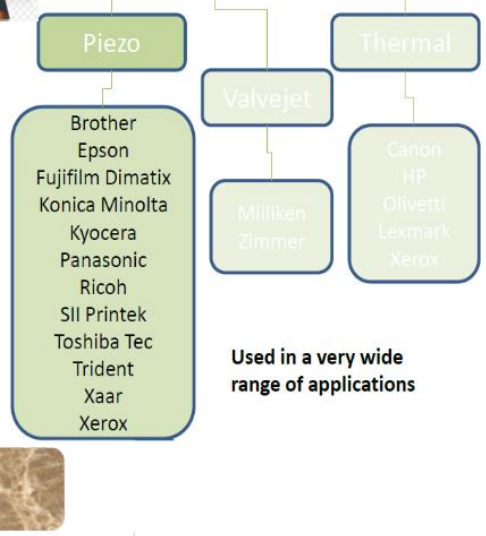

Used in a very wide

range of applications

\section{Piezo}

Fig (25) drop on demand - Piezo

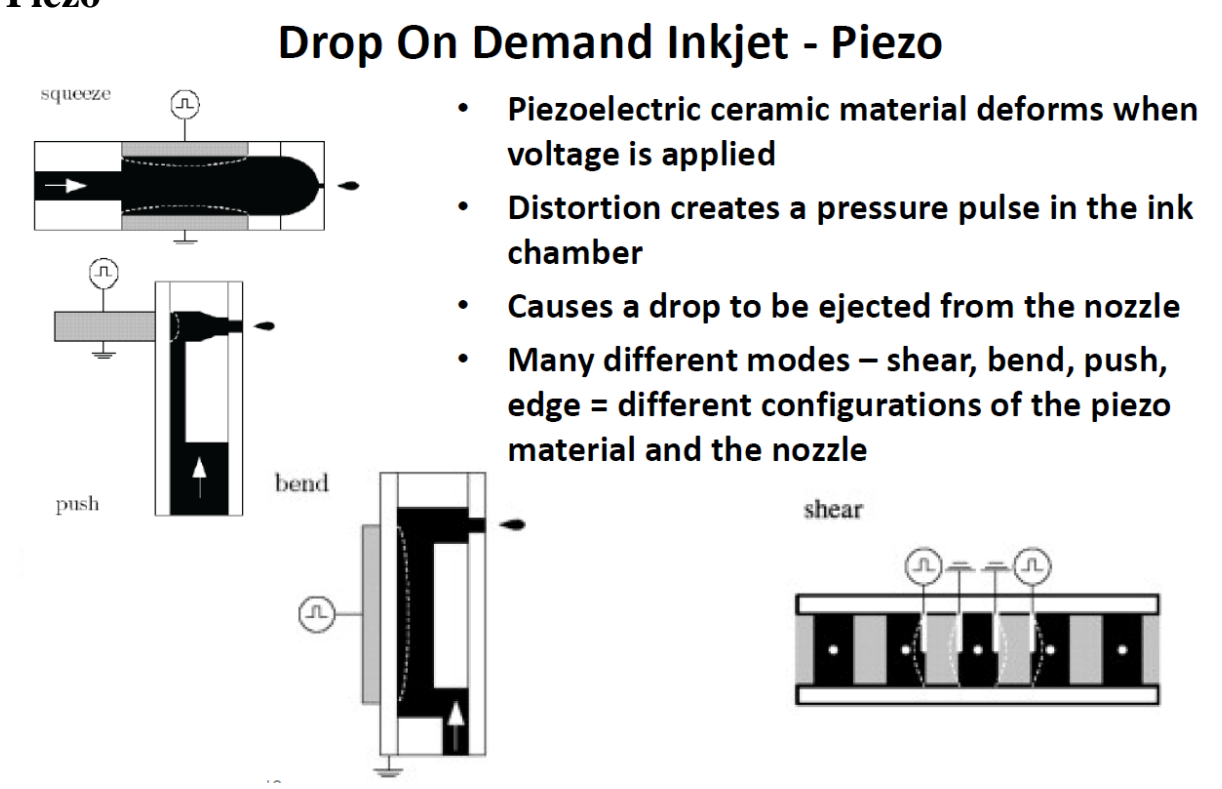

Fig (26) Piezo

Which are manufacture and used by

Brother - Epson - Fujifilm - Dimatix - Konica - Minolta - Kyocera Panasonic - Ricoh -

SII Printek - Toshiba Tec - Trident - Xaar - Xerox

Ink Jet Technologies - Summary

-Continuous $(\mathbf{C I J})=$ continuous flow of ink

- $\quad$ Method to produce drops 


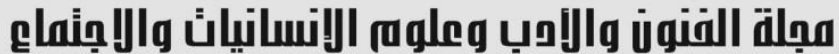 \\ Journal of Arts, Literature, Humanities and Social Sciences www.jalhss.com \\ Volume (70) August 2021 \\ العدد (70) أغسطس 2021}

- $\quad$ Method to select drops

- $\quad$ Method to recover and control the ink

$>\quad$ High speed capability

$>\quad$ Typically low resolution, but high resolution capable

-Drop On Demand (DOD) $=$ drop of ink only generated when needed

- $\quad$ No drop selection or deflection required

- $\quad$ Each nozzle fires only as required - nozzles can be inactive

$>\quad$ Nozzle maintenance and good ink formulation required

- $\quad$ Actuation mechanism required with enough energy to generate drop at required velocity to eject and reach substrate successfully

$>\quad$ Actuation methods - most common are thermal and piezo

- $\quad$ Piezo dominant technology in textile printers

Binary vs. Greyscale

- Binary

- $\quad$ One drop size

- $\quad$ On or off

- $\quad$ Multi-pulse binary

- $\quad$ Special mode offered by some printheads

- $\quad$ Ability to create larger drops (all same size)

- Greyscale

- $\quad$ Variable number of drops

- Drops coalesce in flight or at nozzle plate

- Directly vary drop volume

- Vary waveform according to drop size required

- $\quad$ Apply different waveforms to each bank of piezo

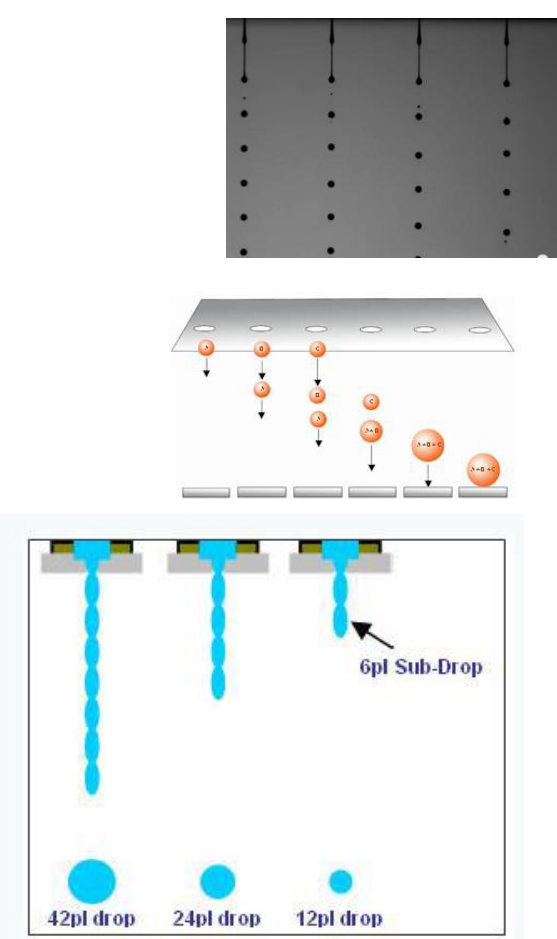




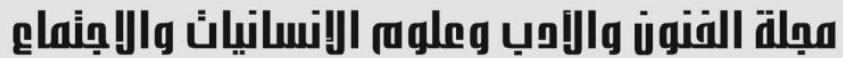 \\ Journal of Arts, Literature, Humanities and Social Sciences www.jalhss.com}

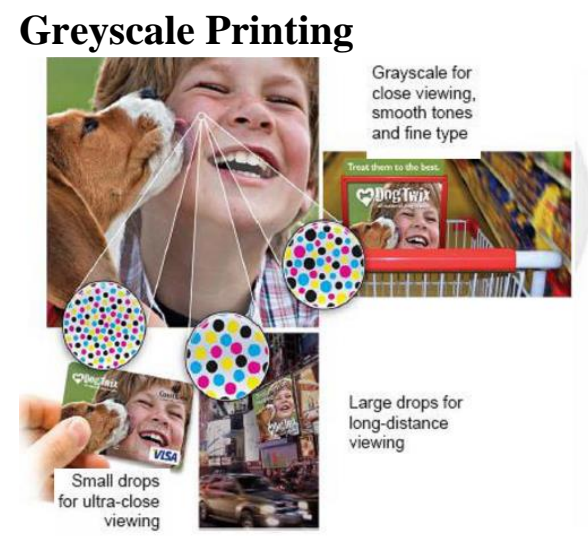

Fig (27) Greyscale Printing

Ink Flow

- $\quad$ End shooter/single ended

- Ink flows into the channel and exits only through the nozzle

- $\quad$ Recirculating/through flow

- $\quad$ Ink flows continuously through the channel and exits the nozzle only when required

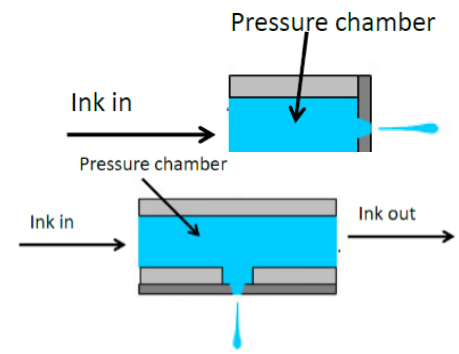

Piezo Inkjet Print heads for Textile floor coverings printing

- $\quad$ Fujifilm Dimatix Q-Class Polaris Series

$>\quad 512$ nozzles -4 rows of nozzles

$>\quad 200$ dpi one-color (all 4 rows)

$>\quad 100$ dpi two-color (2 rows per color)

$>\quad$ Versa Drop binary jetting capability

- $\quad 15 \mathrm{pl}$ drop $(40 \mathrm{kHz}) \&$ up to $30 \mathrm{pl}(25 \mathrm{kHz})$

- $\quad 35 \mathrm{pl}$ drop $(30 \mathrm{kHz}) \&$ up to $90 \mathrm{pl}(13 \mathrm{kHz})$

- $\quad 85 \mathrm{pl}$ drop $(20 \mathrm{kHz}) \&$ up to $150 \mathrm{pl}(10 \mathrm{kHz})$

- $\quad$ Fujifilm Dimatix Star Fire SG1024 Series

$>1024$ nozzles

$>\quad$ 400dpi 4 grey levels

$>\quad$ Incorporates Versa Drop binary and greyscale jetting

$>$ RediJet - continuous ink circulation at the nozzle 


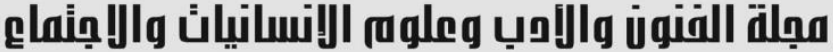 \\ Journal of Arts, Literature, Humanities and Social Sciences www.jalhss.com}

Volume (70) August 2021

العدد (70) أغسطس 2021
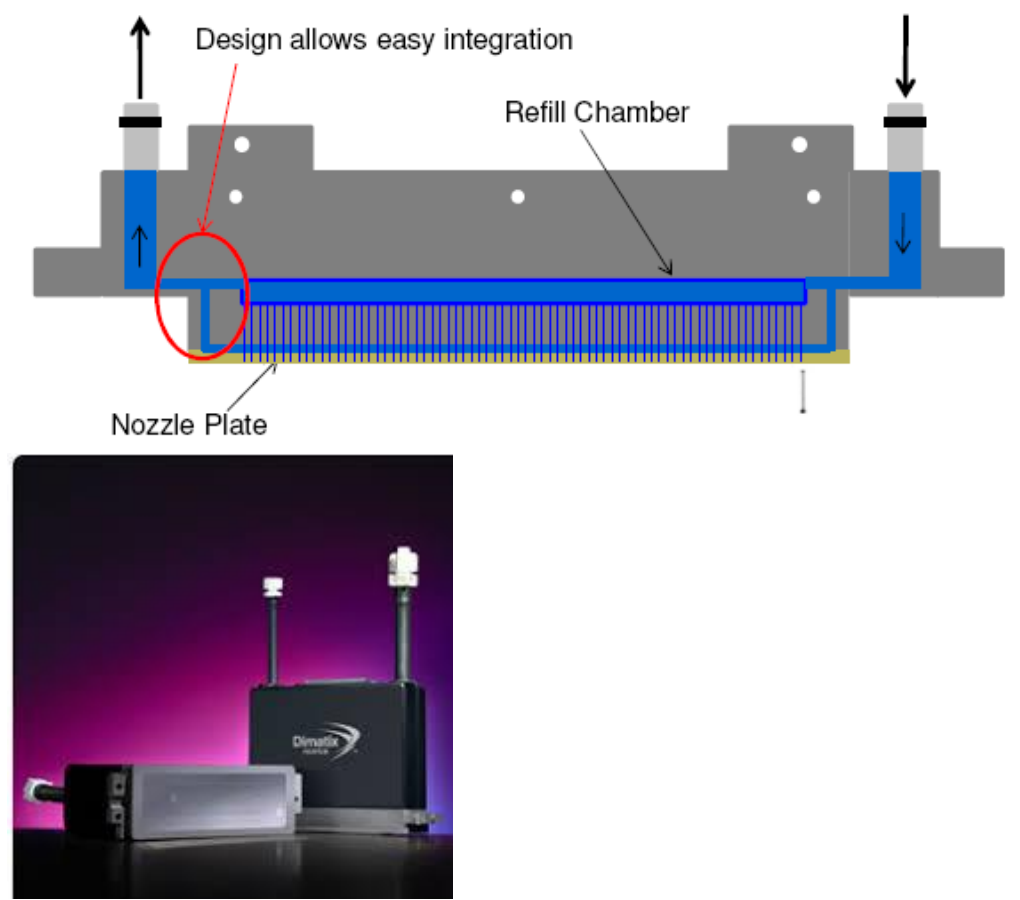

$>\quad$ Removable/replaceable coated metal nozzle plate

$>\quad$ Precise registration points

- $\quad$ Allows multiple printheads to be accurately arrayed into print bars

- $\quad$ Reduces set-up and alignment costs during nozzle replacement or printhead exchange

\section{Carpet solution}

Table (1) ink used and carpet material solution

\begin{tabular}{|c|c|c|c|c|}
\hline $\begin{array}{l}\text { Fiber } \\
\text { type }\end{array}$ & Polyamide/Nylon & Wool & Polyester & Cotton \\
\hline Acid & $\begin{array}{l}\text { Steaming } \\
3 \sim 6 \mathrm{~m} / 100^{\circ} \mathrm{C} \\
\text { spraying } \\
\text { vacuuming } \\
\text { spraying } \\
\text { vacuuming } \\
\text { drying }\end{array}$ & $\begin{array}{l}\text { Steaming } \\
8 \sim 10 \mathrm{~m} / 100^{\circ} \mathrm{C} \\
\text { spraying } \\
\text { vacuuming } \\
\text { spraying } \\
\text { vacuuming } \\
\text { drying }\end{array}$ & & \\
\hline Disperse & & & $\begin{array}{l}\text { Drying } \\
\text { hot air fix } 1 \mathrm{~min} \\
\text { from } 170 \sim 190^{\circ} \mathrm{C} \\
\text { spraying } \\
\text { vacuuming } \\
\text { reductive washing }\end{array}$ & \\
\hline
\end{tabular}




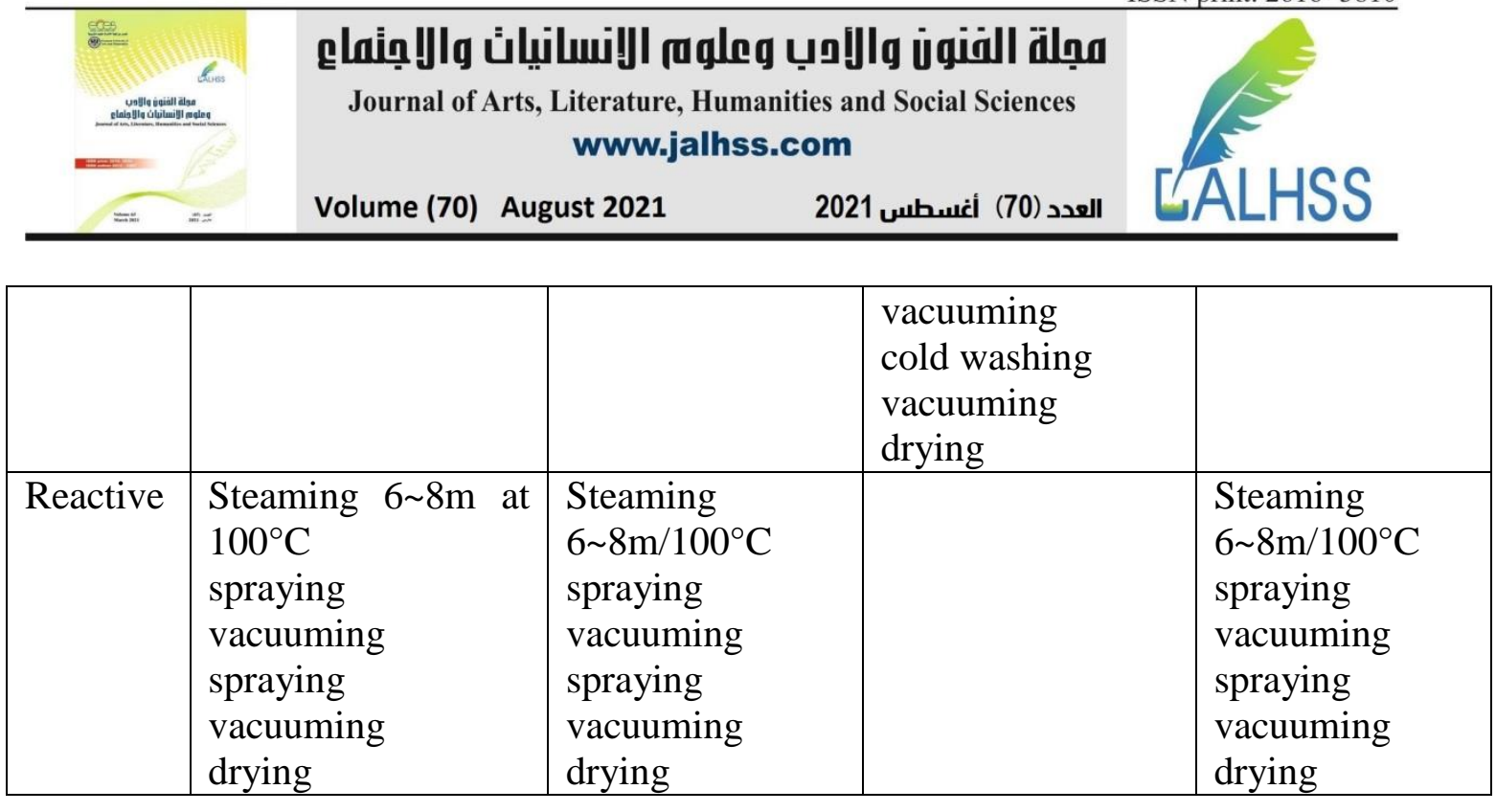

\section{Guidelines for preparing your artwork and files for production}

1. Provide all files in one of the appropriate formats listed below, including all support files used.

2. Layout all files in the correct resolution, proportions or scale (usually $1 / 4$ scale) to the final carpet size. Your page size must exactly match your final carpet size or scale.

3. Convert all fonts to Outlines and remove any stray text that has not been converted. If using Photoshop Rasterize* all text and remove any text layers not rasterized.

4. A Hard Copy Color proof MUST be submitted with the electronic files. Also any indications for PMS Color Match, size, and FPO's must be clearly marked on the hard copy. Color proofs accepted are: Iris print, Kodak Approval, Match print and similar calibrated quality proofs. Color lasers are not acceptable.

\section{Applications Supported}

- $\quad$ Adobe Illustrator 10 or Greater

(Saved in AI or EPS Formats) PC or Mac

- $\quad$ Adobe Photoshop 7.0 or Greater

(Saved in PSD, TIFF, or EPS Formats) PC or Mac

- $\quad$ Adobe Freehand 8.0 or Greater

(MUST be saved in EPS Format) PC or Mac

\section{Formats Supported}

\section{Vector:}

- $\quad$ AI - (Adobe Illustrator native format) this is the Adobe Illustrator native format. This type of file is usually created in Adobe Illustrator 10 or greater. All fonts used must be converted to outlines. Please provide support files for any embedded graphics used in your design. Illustrator should be used when combining Text, Logos, Illustrations, and Photographic Images in your design.

- $\quad$ EPS- (Encapsulated Post Script) also known as Vector Files or Outline Files. This type of file is usually created in Adobe Illustrator 10 or greater. All fonts used must be converted to outlines. Please provide support files for any embedded 


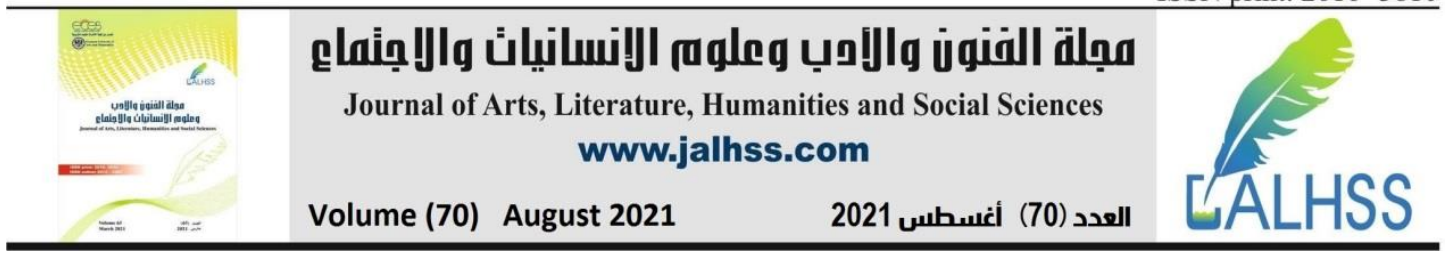

graphics used in your design. Designs that use text and logos reproduce much better when produced from EPS Outline files.

\section{Raster:}

- $\quad$ PSD- (Photoshop Layered Files) also known as Layered Files. This type of file is created in Adobe Photoshop 7.0 or greater, and has all layers intact. This can be helpful if the design ever needs to be edited or changed. All fonts used must be *rasterized (converted to pixels) in your design. Remove any text layers that have not been rasterized. *Rasterize - Convers text layers into pixel images so font support files are not necessary.

- $\quad$ TIFF- (Tagged Image File Format) This type of file is created in Adobe Photoshop 7.0 or greater. Typically a single layer (or Flattened) file. Photographic Images can be saved in this format.

- EPS- (Encapsulated Post Script) this type of file is created in Adobe Photoshop 7.0 or greater. Photographic Images can be saved as EPS files as well.

- JPEG- (compressed file) this format is not recommended for final production files.

\section{Color Mode}

- $\quad$ CMYK- (Cyan, Magenta, Yellow, Black). Please set up all files for CMYK color mode. Illustrator files must have all colors used converted to CMYK. All photographic support files used in Illustrator must be CMYK and prepared to the proper resolution and format for the project.

- $\quad$ BLACK- (in Illustrator) All Blacks should be composed of 85c, 70m, 75y, and 100k. This will produce a richer shade of black when your design is ink jetted onto the carpet surface.

\section{Resolution}

All photographic (pixel) graphics MUST be designed to have 72 DPI of resolution at final finish size, and in CMYK Mode. Images MUST not be interpolated (sized up); this will greatly affect the resolution and quality of the final printed carpet. Example: A 10ft. $x$ 10ft. carpet at $72 \mathrm{DPI}=284 \mathrm{mb}$ file

\section{Converting Fonts to Outlines}

Converting Fonts to Outlines eliminates the need to provide support fonts. It also reduces the risk of having a font re-wrap or change appearance when opened on different computer platforms (PC, MAC) and software versions.

\section{Practical experiments}

1-We choose customize items Textile floor covering as next table.

\begin{tabular}{|l|l|l|l|l|}
\hline Ser. & \multicolumn{1}{|c|}{$\begin{array}{c}\text { Textile floor covering } \\
\text { Type }\end{array}$} & $\begin{array}{c}\text { Size } \\
\text { Width x length }\end{array}$ & $\begin{array}{c}\text { Number of } \\
\text { colors }\end{array}$ & Number of $\mathrm{mt} 2$ \\
\hline 1 & Wall to Wall & & & \\
\hline 2 & Area rug & & & \\
\hline 3 & Bath Mat & & & \\
\hline 4 & Kitchen Mat & & & \\
\hline 5 & Children mat & & \\
\hline
\end{tabular}




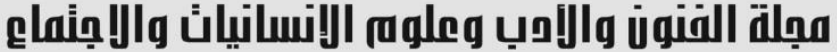

Journal of Arts, Literature, Humanities and Social Sciences www.jalhss.com

Volume (70) August 2021

العدد (70) أغسطس 2021

\begin{tabular}{|l|l|l|l|l|}
\hline 6 & Door Mat & & & \\
\hline 7 & Sports Mat & & & \\
\hline 8 & Advertising Carpet & & & \\
\hline 9 & Car Mat & & & \\
\hline 10 & prayer mat & & \\
\hline
\end{tabular}

2- We sent order of this designs to 10 manufacture printed Textile floor

3- Collect reply from each supplier if can printed this designs or not.

\begin{tabular}{|l|c|c|c|c|}
\hline \multirow{2}{*}{$\begin{array}{c}\text { Design } \\
\text { number }\end{array}$} & $\begin{array}{c}\text { Number of } \\
\text { colors }\end{array}$ & $\begin{array}{c}\text { Wize } \\
\text { Width } \mathrm{cm} \text { length } \\
\mathrm{cm}\end{array}$ & $\begin{array}{c}\text { Number of } \\
\mathrm{mt} 2\end{array}$ & Final result \\
\cline { 2 - 5 } & Yes / No & Yes / No & Yes / No & Yes / No \\
\hline & & & & \\
\hline & & & & \\
\hline & & & & \\
\hline & & & & \\
\hline
\end{tabular}




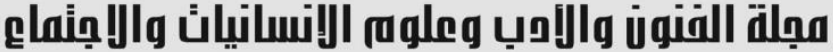

Journal of Arts, Literature, Humanities and Social Sciences www.jalhss.com

Volume (70) August 2021

العدد (70) أغسطس 2021

Design sent to Manufacture of printed textile floor covering

\begin{tabular}{|c|c|c|c|c|}
\hline \multirow{2}{*}{ Item Type } & \multirow{2}{*}{ Design number } & \multirow{2}{*}{$\begin{array}{c}\text { Number of } \\
\text { colors }\end{array}$} & Size & \multirow{2}{*}{ Number of $\mathrm{mt} 2$} \\
\hline & & & Width $\mathrm{cm} x$ length $\mathrm{cm}$ & \\
\hline \multirow{3}{*}{ 1- Wall to wall designs } & $1-1$ & 5 & $97.54 \times 97,54$ & 12 \\
\hline & $1-2$ & 2 & $400 \times 350$ & 14 \\
\hline & $1-3$ & 256 & $400 \times 350$ & 14 \\
\hline \multirow{3}{*}{ 2- Area Rug } & $2-1$ & 4 & $160 \times 230$ & 18.4 \\
\hline & $2-2$ & 12 & $180 \times 235$ & 18.8 \\
\hline & $2-3$ & 256 & $200 \times 300$ & 12 \\
\hline \multirow{3}{*}{ 3- Bath Mat } & $3-1$ & 8 & $50 \times 80+50 \times 45$ & 13.6 \\
\hline & $3-2$ & 8 & $60 \times 90+60 \times 45$ & 14.4 \\
\hline & $3-3$ & 256 & $60 \times 90+60 \times 45$ & 14.4 \\
\hline \multirow{3}{*}{ 4- Kitchen Mat } & $4-1$ & 8 & $57 \times 120+57 \times 200$ & 12.8 \\
\hline & $4-2$ & 13 & $57 \times 120+57 \times 200$ & 12.8 \\
\hline & 4-3 & 256 & $57 \times 120+57 \times 200$ & 12.8 \\
\hline \multirow{3}{*}{ 5- Children Mat } & $5-1$ & 12 & $100 \times 150$ & 12 \\
\hline & $5-2$ & 10 & $133 \times 190$ & 15.2 \\
\hline & 5-3 & 256 & $133 \times 190$ & 15.2 \\
\hline \multirow{3}{*}{ 6- Door Mat } & 6-1 & 8 & $50 \times 80$ & 12.8 \\
\hline & $6-2$ & 8 & $57 \times 90$ & 14.4 \\
\hline & $6-3$ & 256 & $57 \times 90$ & 14.4 \\
\hline \multirow{3}{*}{ 7- Sports Mat } & $7-1$ & 6 & $80 \times 120$ & 14.4 \\
\hline & $7-2$ & 4 & $160 \times 230$ & 18.4 \\
\hline & $7-3$ & 256 & $160 \times 230$ & 18.4 \\
\hline \multirow{3}{*}{ 8- Advertising Carpet } & $8-1$ & 6 & $80 \times 120$ & 14.4 \\
\hline & $8-2$ & 4 & $133 \times 400$ & 12 \\
\hline & $8-3$ & 256 & $133 \times 400$ & 12 \\
\hline \multirow{3}{*}{ 9- Car Mat } & $9-1$ & 3 & $2(44 \times 68)+2(44 \times 34)$ & 14.4 \\
\hline & $9-2$ & 12 & $2(44 \times 68)+2(44 \times 34)$ & 12.69 \\
\hline & $9-3$ & 256 & $2(44 \times 68)+2(44 \times 34)$ & 12.69 \\
\hline \multirow{3}{*}{10 - prayer mat } & $10-1$ & 9 & $67 \times 113$ & 13.56 \\
\hline & $10-2$ & 7 & $67 \times 113$ & 13.56 \\
\hline & $10-3$ & 256 & $80 \times 120$ & 14.4 \\
\hline
\end{tabular}




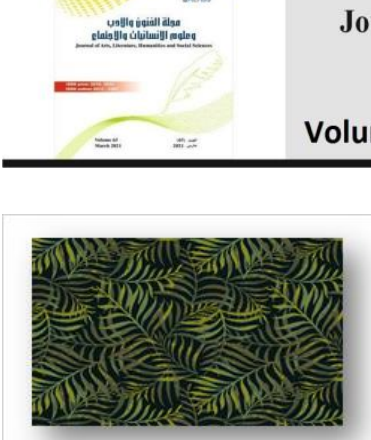

1-1
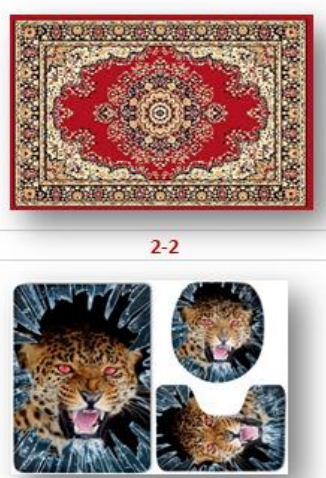

3-3

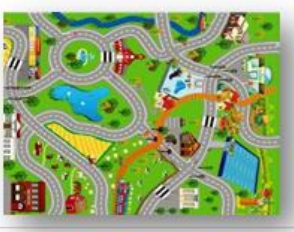

5-1

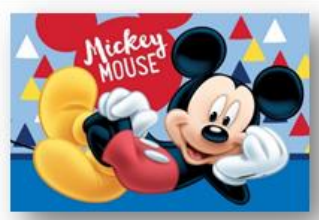

6-2
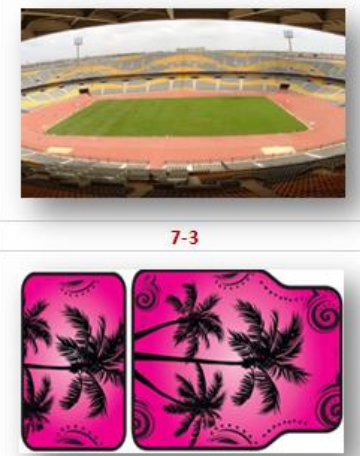

9-1

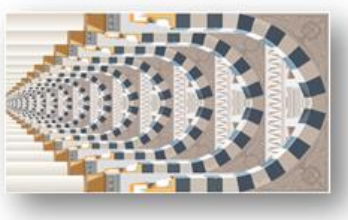

$10-2$

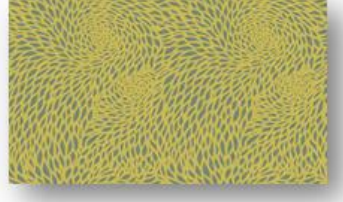

1-2

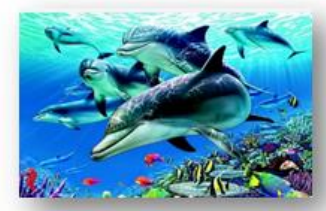

$2-3$

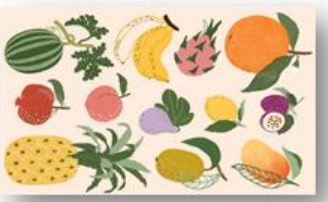

4-1

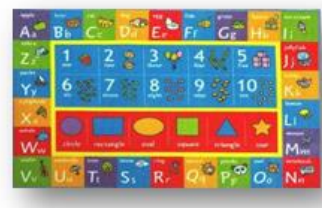

5-2

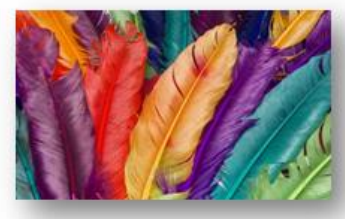

6-3

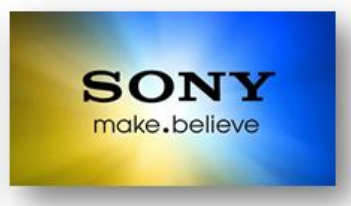

8-1
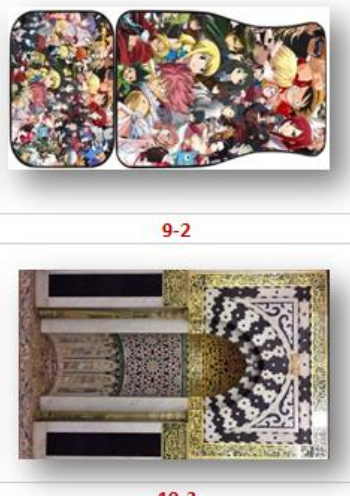

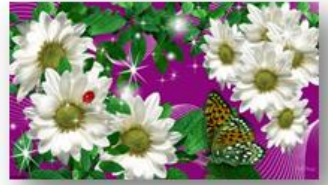

1-3
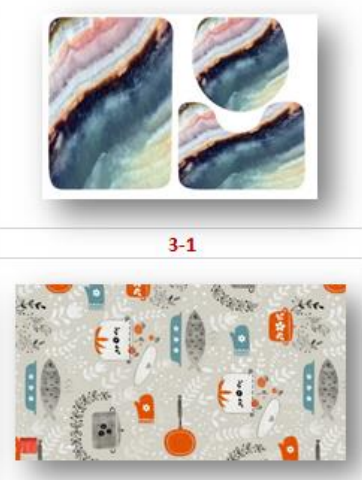

4-2

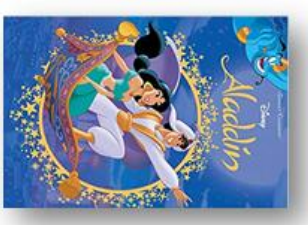

$5-3$

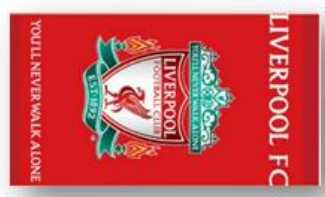

7-1

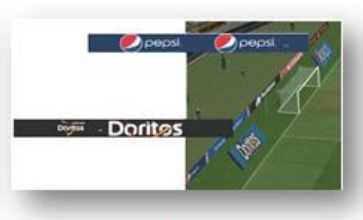

8-2
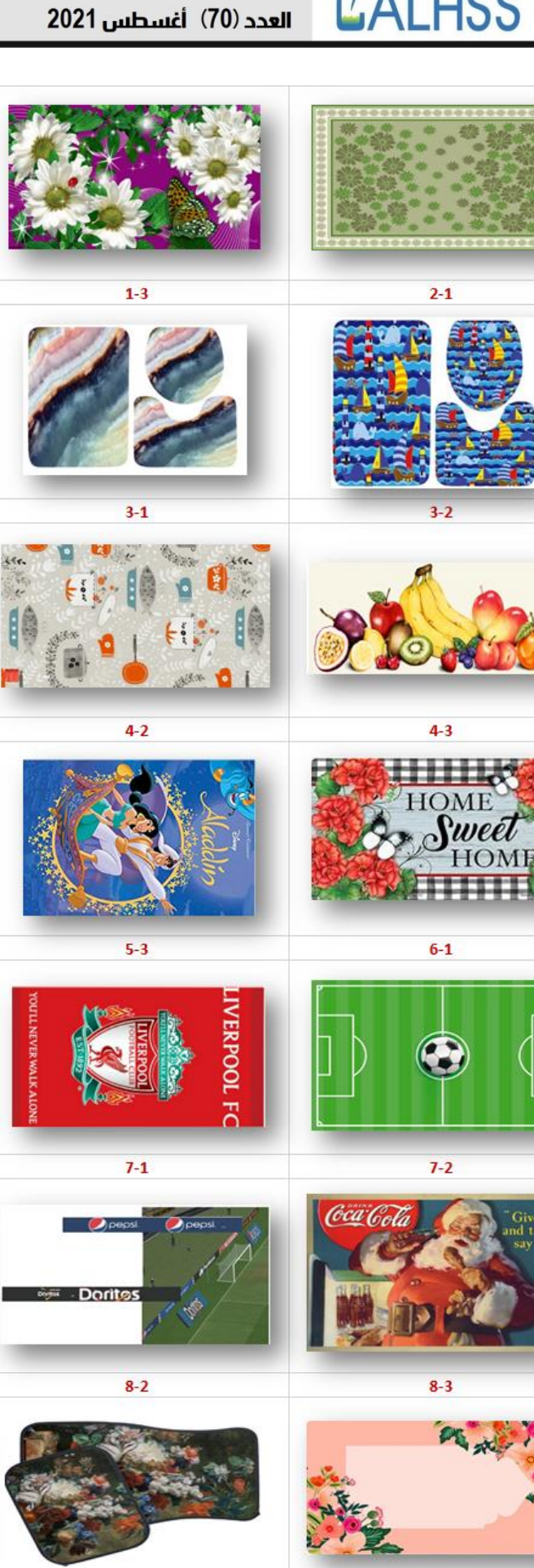

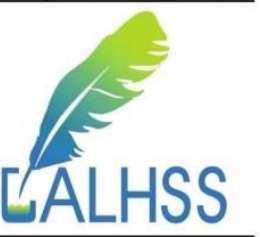




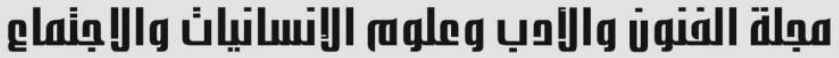

\section{RESULTS AND DISCUSSION:}

Table (2) show capability produce each design on printing machine type

We will give (Yes) 5 points and (NO) 0 Point and submet total point for each design as next

\begin{tabular}{|c|c|c|c|c|c|c|c|c|c|c|c|c|c|c|c|c|c|c|c|c|c|c|c|c|c|c|c|c|c|}
\hline & 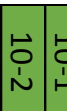 & $\vec{i}$ & $i$ & $\begin{array}{l}\mathcal{L} \\
\mathcal{L}\end{array}$ & 离 & i & 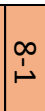 & 岀 & & $\dot{U}$ & & i) & $\begin{array}{c}\vec{\omega} \\
\dot{\omega}\end{array}$ & $\stackrel{\sim}{\sim}$ & & & $\stackrel{\sim}{\sim} \vec{i}$ & $\mid \begin{array}{l}\omega \\
\dot{\omega}\end{array}$ & $\underset{\dot{\sim}}{\dot{w}}$ & $\begin{array}{c}\omega \\
⿱ \\
\sim\end{array}$ & & & & & & & \multicolumn{3}{|c|}{ 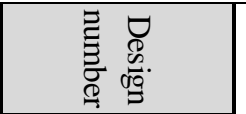 } \\
\hline & 8 & & 8 & $\mathbb{S}^{2}$ & z & 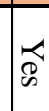 & $\widetilde{\&}$ & z & & $\widehat{\varnothing}$ & 8 & $\widehat{\Phi}$ & z & 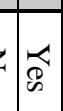 & 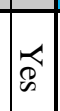 & & $z$ & 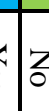 & $\sqrt{\mathscr{2}}$ & 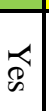 & & & & & 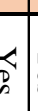 & & za & 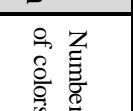 & \\
\hline & 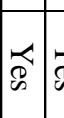 & 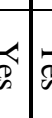 & $b_{0}^{\infty}$ & $\underset{D}{4}$ & z & z & $\widetilde{\varnothing}$ & z & $z$ & 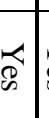 & $\widehat{d}$ & $\widehat{\varnothing}$ & z & $z$ & $z$ & z & z & 3 & a & $z$ & $z^{\prime}$ & & $\frac{7}{b}$ & z & b & & $z \underset{0}{\sigma}$ & 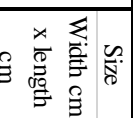 & 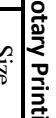 \\
\hline & & & z & $z$ & z & z & z & z & z & z & zalz & $z \mid z$ & z & 7 & $z$ & $z$ & $z \mid z$ & t & $z$ & $z$ & $Z$ & & z & $z$ & & & $z_{0}$ & 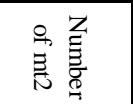 & \\
\hline & & & & & $D$ & & & 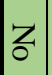 & z & z & & za & & $z$ & $z$ & $z=$ & $z$ & 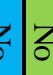 & & & & & & & & & $z \underset{0}{\sigma}$ & 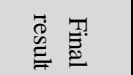 & \\
\hline
\end{tabular}

\begin{tabular}{|c|c|c|c|c|c|c|c|c|c|c|c|c|c|c|c|c|c|c|c|c|c|c|c|c|c|c|c|}
\hline & 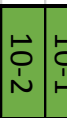 & $\begin{array}{l}\dot{0} \\
\dot{\varphi}\end{array} \mid \begin{array}{l}\dot{L} \\
\dot{u}\end{array}$ & $\begin{array}{l}\dot{\omega} \\
\dot{L}\end{array}$ & ம & $\mid \begin{array}{l}\infty \\
\dot{\omega}\end{array}$ & $\begin{array}{c}\infty \\
\dot{\sim} \\
\end{array}$ & $\begin{array}{l}\infty \\
\stackrel{\bullet}{\bullet}\end{array}$ & $\dot{\omega} \mid \dot{n}$ & $i$ & & $\dot{\sim} \underset{\sim}{i}$ & $\dot{u}$ & & 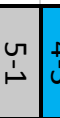 & $\stackrel{\vec{\sim}}{\sim}$ & $\stackrel{\vec{t}}{\dot{1}}$ & $\begin{array}{cc}\omega \\
\omega \\
\omega\end{array}$ & 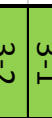 & & I & & & & & \multicolumn{3}{|c|}{ 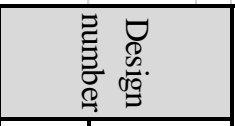 } \\
\hline & 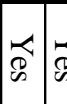 & & & $\overparen{\&}$ & z & 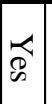 & 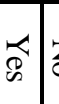 & $z$ & $\sqrt{\varnothing}$ & $z$ & 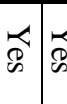 & z & $\widehat{\infty}$ & 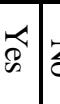 & $z$ z & 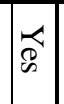 & & 8 & & 8 & $\checkmark$ & & & 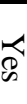 & $z$ & 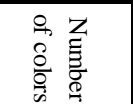 & \\
\hline & $\widehat{d}$ & 8 & $\stackrel{8}{\vec{\Omega}}$ & 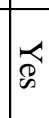 & $\widehat{\wp}$ & 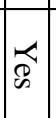 & 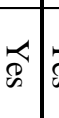 & 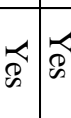 & $\mathscr{\infty}$ & 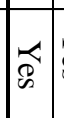 & $\widehat{Q}$ & $\sqrt{\infty}$ & $\widetilde{\delta}$ & $\widehat{\delta}$ & 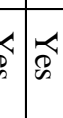 & $\widehat{\infty}$ & $\mathbb{8}$ & 8 & $\theta$ & 6 & 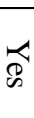 & 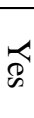 & 6 & $\vec{\sigma}$ & zo & 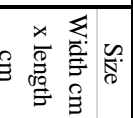 & 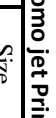 \\
\hline & $z$ & $z$ & $z$ & z & $z$ & $z$ & z & $z \mid z$ & $z$ & $z$ & $z \mid z$ & $z$ & $z$ & z & $z=z$ & za & z & & & & & & & & z & 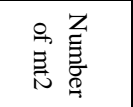 & \\
\hline & & & & & $z_{0}$ & & 0 & z & 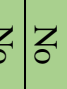 & & & & $z$ & 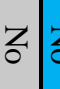 & & za & & & & & & & & & ż & $E$ & \\
\hline
\end{tabular}

\begin{tabular}{|c|c|c|c|c|c|c|c|c|c|c|c|c|c|c|c|c|c|c|c|c|c|c|c|c|c|c|c|c|}
\hline 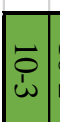 & 휭 & 5 & ĩ & 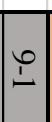 & $\stackrel{\infty}{\dot{\omega}}$ & $\begin{array}{l}\infty \\
\text { ì }\end{array}$ & $\begin{array}{l}\infty \\
1 \\
\end{array}$ & $\dot{\omega}$ & & $I i$ & ì & I & $\ddot{\omega}$ & $\hat{n}$ & & $\dot{\omega}$ & \pm & $\underset{\omega}{\omega}$ & & & ט & $\underline{\underline{T}}$ & $\dot{\omega}$ & $\bar{n}$ & 1 & \multicolumn{2}{|c|}{ 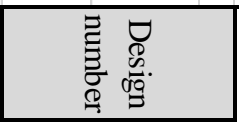 } & \\
\hline & $\overparen{\wp}$ & & $\widetilde{\varnothing}$ & $\widehat{\S}$ & $\overparen{\varnothing}$ & $\widehat{d}$ & 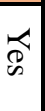 & 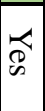 & 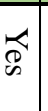 & $\underset{\bigotimes}{\diamond}$ & 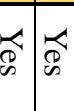 & 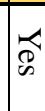 & $\mathbb{E}^{2}$ & $\widehat{d}$ & E & $\widehat{d}$ & $\widehat{\Xi}$ & 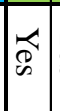 & 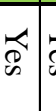 & & $\begin{array}{l}6 \\
b\end{array}$ & 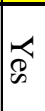 & 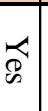 & 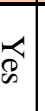 & 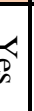 & $z \underset{\sigma}{z}$ & 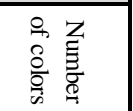 & \\
\hline & 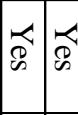 & 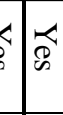 & 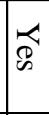 & $\mid \precsim$ & 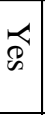 & 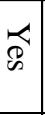 & 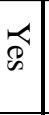 & 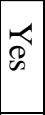 & 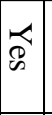 & 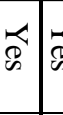 & $\underset{\phi}{\triangleleft}$ & 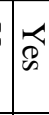 & 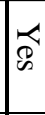 & $\overleftarrow{d}$ & 8 & $\overleftrightarrow{\mathbb{R}}$ & $\widehat{\&}$ & $\widehat{\bigotimes}$ & 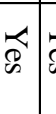 & & 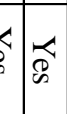 & $\underset{\wp}{\infty}$ & $\widetilde{8}$ & 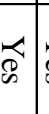 & 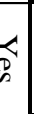 & $z \underset{0}{a}$ & 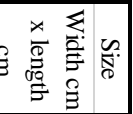 & \\
\hline & 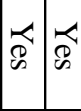 & 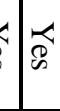 & 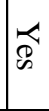 & 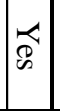 & 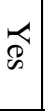 & $\overparen{\infty}$ & $\underset{\wp}{\swarrow}$ & 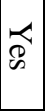 & 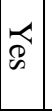 & 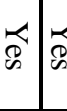 & $\overleftarrow{\wp}$ & 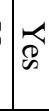 & 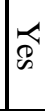 & $\overleftrightarrow{\infty}$ & 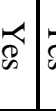 & $\underset{\infty}{\infty}$ & 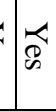 & 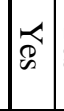 & $\widetilde{0}$ & & $\begin{array}{l}\qquad \\
b\end{array}$ & $\widehat{\sigma}$ & 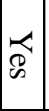 & 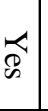 & & $\begin{array}{c}z \\
0\end{array}$ & 总总 & \\
\hline & $\precsim$ & 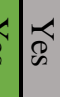 & & 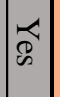 & 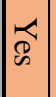 & $\approx$ & $\approx$ & 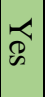 & 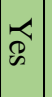 & $\overparen{\infty}$ & ৫্চ & & & 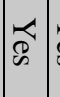 & 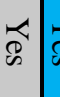 & 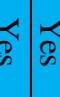 & 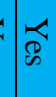 & $\widehat{\diamond}$ & & & & & & & & $\begin{array}{lll}z & 0 \\
0\end{array}$ & $\begin{array}{l}\vec{\infty} \\
\stackrel{D}{E}\end{array}$ & \\
\hline
\end{tabular}




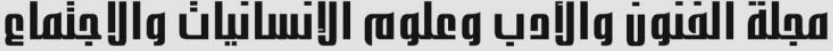

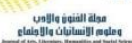

Journal of Arts, Literature, Humanities and Social Sciences www.jalhss.com

Volume (70) August 2021

العدد (70) أغسطس 2021

Table ( 3) show capability produce each design on printing machine type

\begin{tabular}{|c|c|c|c|c|c|c|c|c|c|c|c|c|c|c|}
\hline \multicolumn{5}{|c|}{ Rotary Printing } & \multicolumn{5}{|c|}{ chromo jet Printing } & \multicolumn{5}{|c|}{ Digital Printing } \\
\hline $\begin{array}{l}\text { Design } \\
\text { number }\end{array}$ & $\begin{array}{l}\text { Number } \\
\text { of colors }\end{array}$ & \begin{tabular}{|c|} 
Size \\
Width cm \\
$\mathrm{x}$ length \\
$\mathrm{cm}$ \\
\end{tabular} & $\begin{array}{c}\text { Number } \\
\text { of mt2 }\end{array}$ & Rotary & $\begin{array}{l}\text { Design } \\
\text { number }\end{array}$ & $\begin{array}{l}\text { Number } \\
\text { of colors }\end{array}$ & \begin{tabular}{|c|} 
Size \\
Width $\mathrm{cm}$ \\
$\mathrm{x}$ length \\
$\mathrm{cm}$ \\
\end{tabular} & $\begin{array}{c}\text { Number } \\
\text { of } m t 2\end{array}$ & $\begin{array}{c}\text { Chromo } \\
\text { jet }\end{array}$ & $\begin{array}{l}\text { Design } \\
\text { number }\end{array}$ & $\begin{array}{l}\text { Number } \\
\text { of colors }\end{array}$ & \begin{tabular}{|c|} 
Size \\
Width $\mathrm{cm}$ \\
$\mathrm{x}$ length \\
$\mathrm{cm}$ \\
\end{tabular} & $\begin{array}{c}\text { Number } \\
\text { of } m t 2\end{array}$ & Digital \\
\hline $1-1$ & 5 & 5 & 0 & 10 & $1-1$ & 5 & 5 & 0 & 10 & $1-1$ & 5 & 5 & 5 & 15 \\
\hline $1-2$ & 5 & 0 & 0 & 5 & $1-2$ & 5 & 5 & 0 & 10 & $1-2$ & 5 & 5 & 5 & 15 \\
\hline $1-3$ & 0 & 0 & 0 & 0 & $1-3$ & 0 & 5 & 0 & 5 & $1-3$ & 5 & 5 & 5 & 15 \\
\hline $2-1$ & 5 & 0 & 0 & 5 & $2-1$ & 5 & 5 & 0 & 10 & $2-1$ & 5 & 5 & 5 & 15 \\
\hline $2-2$ & 5 & 0 & 0 & 5 & $2-2$ & 5 & 5 & 0 & 10 & $2-2$ & 5 & 5 & 5 & 15 \\
\hline $2-3$ & 0 & 0 & 0 & 0 & $2-3$ & 0 & 5 & 0 & 5 & $2-3$ & 5 & 5 & 5 & 15 \\
\hline 3-1 & 5 & 0 & 0 & 5 & $3-1$ & 5 & 5 & 0 & 10 & 3-1 & 5 & 5 & 5 & 15 \\
\hline $3-2$ & 5 & 0 & 0 & 5 & $3-2$ & 5 & 5 & 0 & 10 & $3-2$ & 5 & 5 & 5 & 15 \\
\hline 3-3 & 0 & 0 & 0 & 0 & $3-3$ & 0 & 5 & 0 & 5 & 3-3 & 5 & 5 & 5 & 15 \\
\hline 4-1 & 5 & 0 & 0 & 5 & 4-1 & 5 & 5 & 0 & 10 & 4-1 & 5 & 5 & 5 & 15 \\
\hline $4-2$ & 0 & 0 & 0 & 0 & $4-2$ & 0 & 5 & 0 & 5 & $4-2$ & 5 & 5 & 5 & 15 \\
\hline 4-3 & 0 & 0 & 0 & 0 & $4-3$ & 0 & 5 & 0 & 5 & 4-3 & 5 & 5 & 5 & 15 \\
\hline $5-1$ & 5 & 0 & 0 & 5 & $5-1$ & 5 & 5 & 0 & 10 & $5-1$ & 5 & 5 & 5 & 15 \\
\hline $5-2$ & 5 & 0 & 0 & 5 & $5-2$ & 5 & 5 & 0 & 10 & $5-2$ & 5 & 5 & 5 & 15 \\
\hline $5-3$ & 0 & 0 & 0 & 0 & $5-3$ & 0 & 5 & 0 & 5 & $5-3$ & 5 & 5 & 5 & 15 \\
\hline $6-1$ & 5 & 5 & 0 & 10 & $6-1$ & 5 & 5 & 0 & 10 & $6-1$ & 5 & 5 & 5 & 15 \\
\hline $6-2$ & 5 & 5 & 0 & 10 & $6-2$ & 5 & 5 & 0 & 10 & $6-2$ & 5 & 5 & 5 & 15 \\
\hline $6-3$ & 0 & 5 & 0 & 5 & $6-3$ & 0 & 5 & 0 & 5 & $6-3$ & 5 & 5 & 5 & 15 \\
\hline $7-1$ & 5 & 5 & 0 & 10 & $7-1$ & 5 & 5 & 0 & 10 & $7-1$ & 5 & 5 & 5 & 15 \\
\hline $7-2$ & 5 & 0 & 0 & 5 & $7-2$ & 5 & 5 & 0 & 10 & $7-2$ & 5 & 5 & 5 & 15 \\
\hline $7-3$ & 0 & 0 & 0 & 0 & $7-3$ & 0 & 5 & 0 & 5 & $7-3$ & 5 & 5 & 5 & 15 \\
\hline $8-1$ & 5 & 5 & 0 & 10 & $8-1$ & 5 & 5 & 0 & 10 & $8-1$ & 5 & 5 & 5 & 15 \\
\hline $8-2$ & 5 & 0 & 0 & 5 & $8-2$ & 5 & 5 & 0 & 10 & $8-2$ & 5 & 5 & 5 & 15 \\
\hline $8-3$ & 0 & 0 & 0 & 0 & $8-3$ & 0 & 5 & 0 & 5 & $8-3$ & 5 & 5 & 5 & 15 \\
\hline $9-1$ & 5 & 5 & 0 & 10 & $9-1$ & 5 & 5 & 0 & 10 & $9-1$ & 5 & 5 & 5 & 15 \\
\hline $9-2$ & 5 & 5 & 0 & 10 & $9-2$ & 5 & 5 & 0 & 10 & $9-2$ & 5 & 5 & 5 & 15 \\
\hline $9-3$ & 0 & 5 & 0 & 5 & $9-3$ & 0 & 5 & 0 & 5 & $9-3$ & 5 & 5 & 5 & 15 \\
\hline $10-1$ & 5 & 5 & 0 & 10 & $10-1$ & 5 & 5 & 0 & 10 & $10-1$ & 5 & 5 & 5 & 15 \\
\hline $10-2$ & 5 & 5 & 0 & 10 & $10-2$ & 5 & 5 & 0 & 10 & $10-2$ & 5 & 5 & 5 & 15 \\
\hline $10-3$ & 0 & 0 & 0 & 0 & $10-3$ & 0 & 5 & 0 & 5 & $10-3$ & 5 & 5 & 5 & 15 \\
\hline
\end{tabular}

The next Diagram show number of Points take for each design 


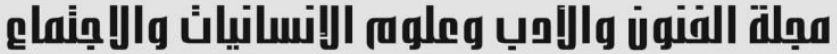

Journal of Arts, Literature, Humanities and Social Sciences www.jalhss.com

Volume (70) August 2021

العدد (70) أغسطس 2021

Diagram (1) points of each design on types of printing

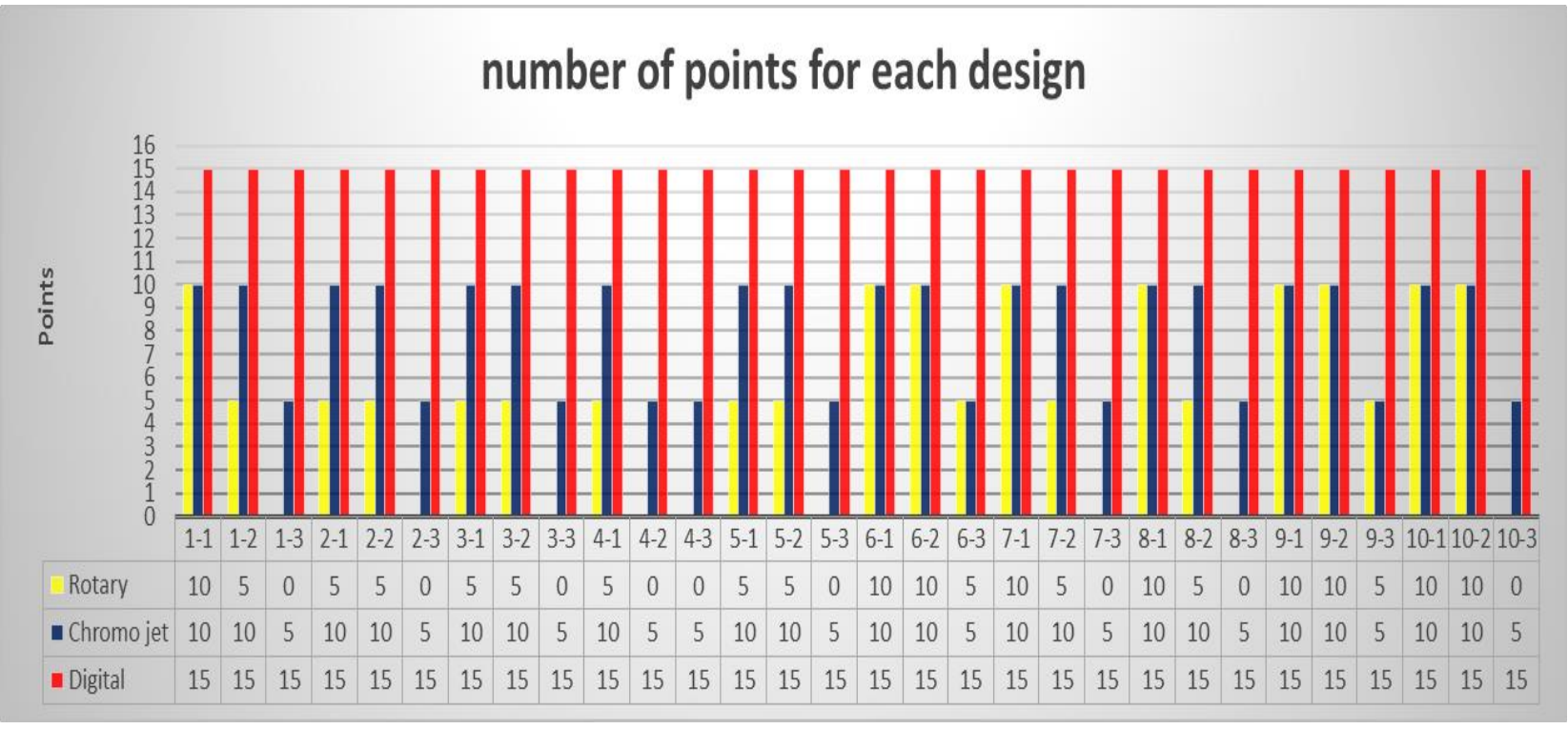

Table (4) show points for each design according number of colors

\begin{tabular}{|c|c|c|c|c|c|c|c|}
\hline Design number & $\begin{array}{l}\text { Number of } \\
\text { colors Rotary }\end{array}$ & $\begin{array}{l}\text { Number of colors } \\
\text { Chromo Jet }\end{array}$ & $\begin{array}{l}\text { Number of } \\
\text { colors Digital }\end{array}$ & Design number & $\begin{array}{l}\text { Number of } \\
\text { colors Rotary }\end{array}$ & $\begin{array}{l}\text { Number of colors } \\
\text { Chromo Jet }\end{array}$ & $\begin{array}{l}\text { Number of } \\
\text { colors Digital }\end{array}$ \\
\hline $1-1$ & 5 & 5 & 5 & $2-1$ & 5 & 5 & 5 \\
\hline $1-2$ & 5 & 5 & 5 & $2-2$ & 5 & 5 & 5 \\
\hline $1-3$ & 0 & 0 & 5 & $2-3$ & 0 & 0 & 5 \\
\hline $3-1$ & 5 & 5 & 5 & $4-1$ & 5 & 5 & 5 \\
\hline $3-2$ & 5 & 5 & 5 & $4-2$ & 0 & 0 & 5 \\
\hline $3-3$ & 0 & 0 & 5 & $4-3$ & 0 & 0 & 5 \\
\hline $5-1$ & 5 & 5 & 5 & $6-1$ & 5 & 5 & 5 \\
\hline $5-2$ & 5 & 5 & 5 & $6-2$ & 5 & 5 & 5 \\
\hline $5-3$ & 0 & 0 & 5 & $6-3$ & 0 & 0 & 5 \\
\hline $7-1$ & 5 & 5 & 5 & $8-1$ & 5 & 5 & 5 \\
\hline $7-2$ & 5 & 5 & 5 & $8-2$ & 5 & 5 & 5 \\
\hline $7-3$ & 0 & 0 & 5 & $8-3$ & 0 & 0 & 5 \\
\hline $9-1$ & 5 & 5 & 5 & $10-1$ & 5 & 5 & 5 \\
\hline $9-2$ & 5 & 5 & 5 & $10-2$ & 5 & 5 & 5 \\
\hline $9-3$ & 0 & 0 & 5 & $10-3$ & 0 & 0 & 5 \\
\hline
\end{tabular}




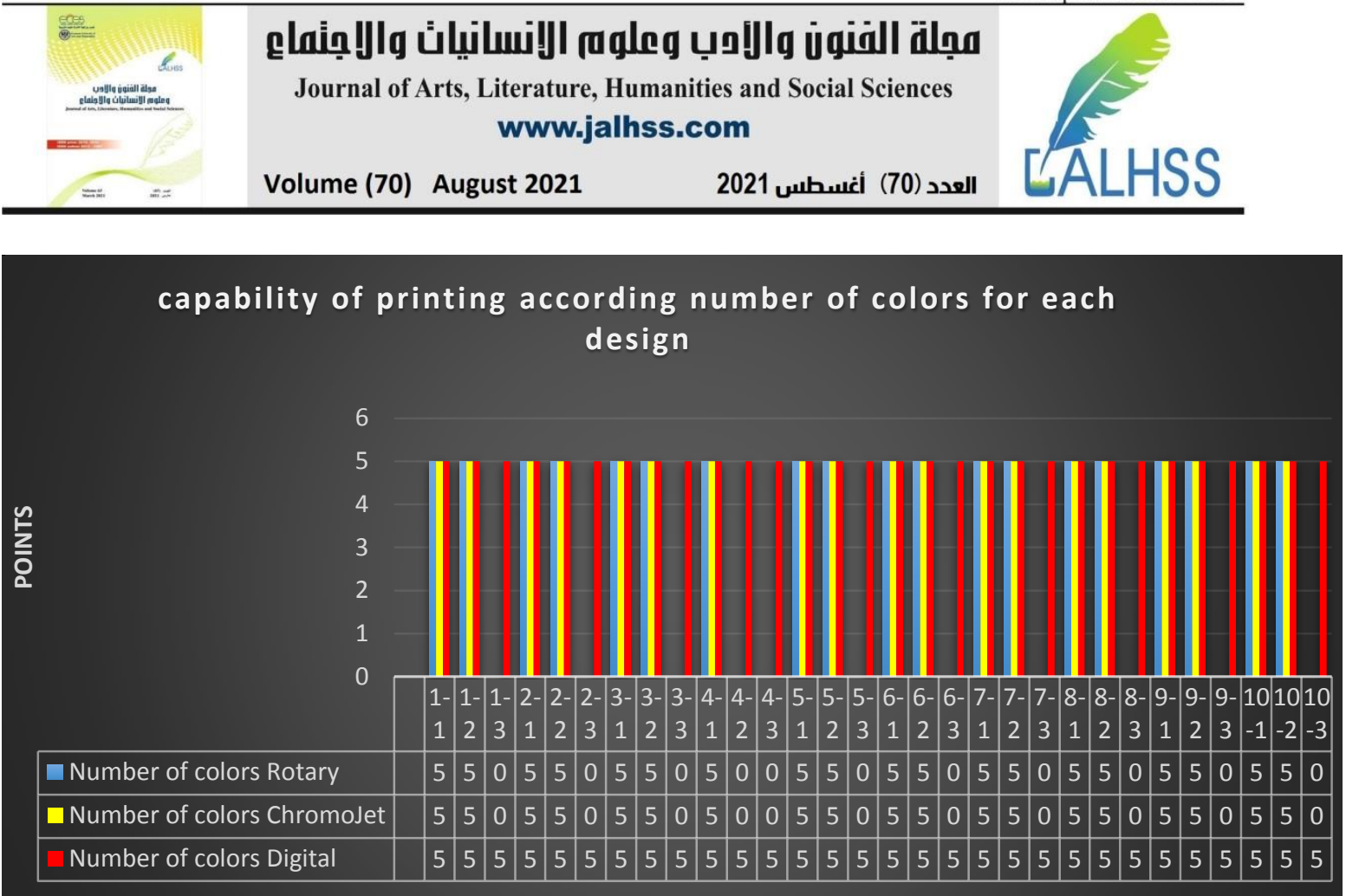

Diagram (2) capability of printing according number of colors for each design

Table (5) show points for each design according size of design

\begin{tabular}{|c|c|c|c|c|c|c|c|}
\hline design \# & $\begin{array}{c}\text { Width } \mathrm{cm} x \\
\text { length } \mathrm{cm} \text { Rotary }\end{array}$ & $\begin{array}{l}\text { Width } \mathrm{cm} \mathrm{x} \\
\text { length } \mathrm{cm} \\
\text { Chromo jet }\end{array}$ & $\begin{array}{c}\text { Width } \mathrm{cm} x \\
\text { length } \mathrm{cm} \text { digital }\end{array}$ & design \# & $\begin{array}{c}\text { Width } \mathrm{cm} x \\
\text { length } \mathrm{cm} \text { Rotary }\end{array}$ & $\begin{array}{l}\text { Width } \mathrm{cm} \mathrm{x} \\
\text { length } \mathrm{cm} \\
\text { Chromo jet }\end{array}$ & $\begin{array}{c}\text { Width } \mathrm{cm} \mathrm{x} \\
\text { length } \mathrm{cm} \text { digital }\end{array}$ \\
\hline $1-1$ & 5 & 5 & 5 & $2-1$ & 0 & 5 & 5 \\
\hline $1-2$ & 0 & 5 & 5 & $2-2$ & 0 & 5 & 5 \\
\hline $1-3$ & 0 & 5 & 5 & $2-3$ & 0 & 5 & 5 \\
\hline $3-1$ & 0 & 5 & 5 & $\overline{4-1}$ & 0 & 5 & 5 \\
\hline $3-2$ & 0 & 5 & 5 & $4-2$ & 0 & 5 & 5 \\
\hline 3-3 & 0 & 5 & 5 & $4-3$ & 0 & 5 & 5 \\
\hline $5-1$ & 0 & 5 & 5 & $6-1$ & 5 & 5 & 5 \\
\hline $5-2$ & 0 & 5 & 5 & $6-2$ & 5 & 5 & 5 \\
\hline $5-3$ & 0 & 5 & 5 & $6-3$ & 5 & 5 & 5 \\
\hline $7-1$ & 5 & 5 & 5 & $8-1$ & 5 & 5 & 5 \\
\hline $7-2$ & 0 & 5 & 5 & $8-2$ & 0 & 5 & 5 \\
\hline $7-3$ & 0 & 5 & 5 & $8-3$ & 0 & 5 & 5 \\
\hline 9-1 & 5 & 5 & 5 & $10-1$ & 5 & 5 & 5 \\
\hline $9-2$ & 5 & 5 & 5 & $10-2$ & 5 & 5 & 5 \\
\hline $9-3$ & 5 & 5 & 5 & $10-3$ & 0 & 5 & 5 \\
\hline
\end{tabular}




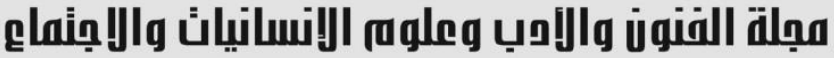

Journal of Arts, Literature, Humanities and Social Sciences www.jalhss.com

Volume (70) August 2021

العدد (70) أغسطس 2021

\section{¿ALHSS}

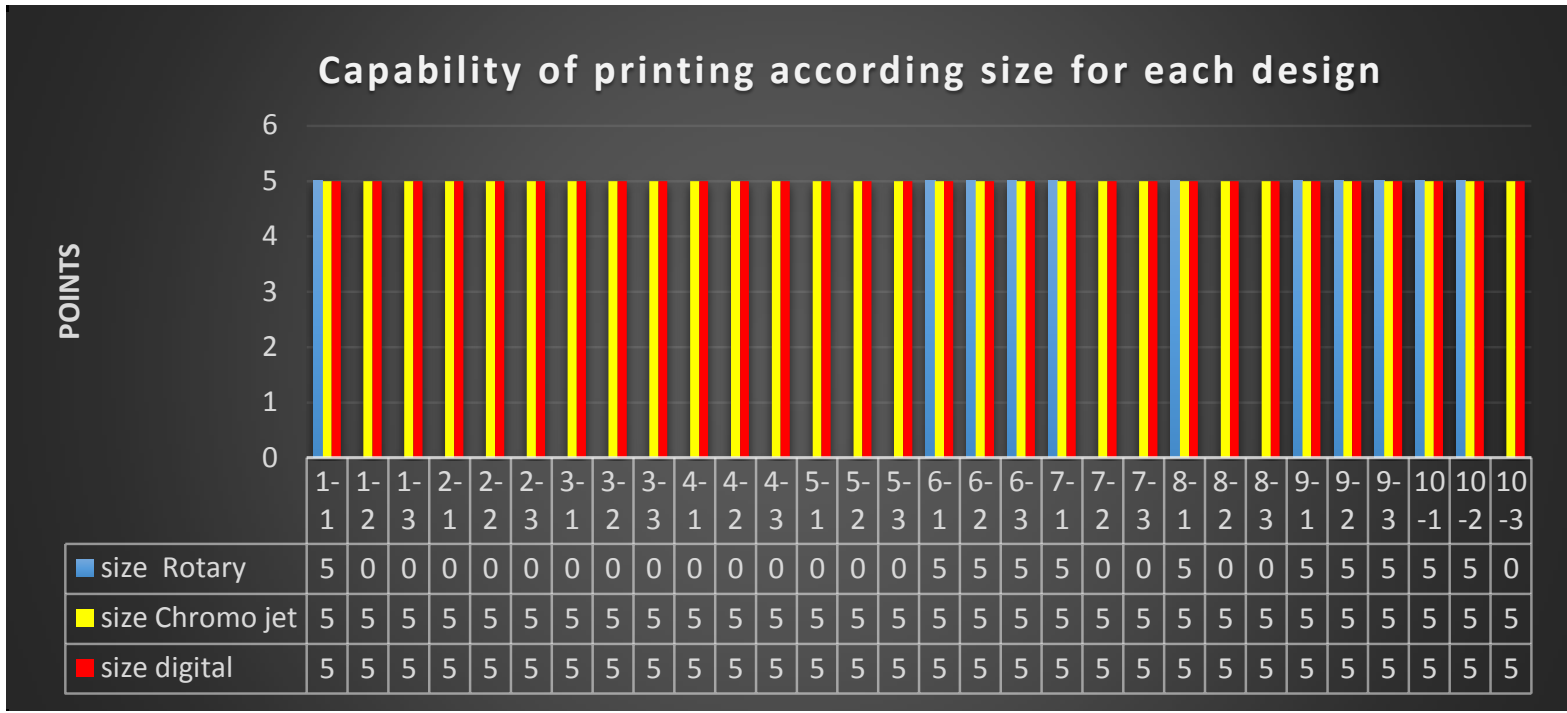

Diagram (3) capability of printing according size for each design

Table (6) show points for each design according quantity of design

\begin{tabular}{|c|c|c|c|}
\hline Design number & quantity Rotary & $\begin{array}{l}\text { quantity Chromo } \\
\text { jet }\end{array}$ & quantity digital \\
\hline $1-1$ & 0 & 0 & 5 \\
\hline $1-2$ & 0 & 0 & 5 \\
\hline $1-3$ & 0 & 0 & 5 \\
\hline $3-1$ & 0 & 0 & 5 \\
\hline $3-2$ & 0 & 0 & 5 \\
\hline $3-3$ & 0 & 0 & 5 \\
\hline $5-1$ & 0 & 0 & 5 \\
\hline $5-2$ & 0 & 0 & 5 \\
\hline $5-3$ & 0 & 0 & 5 \\
\hline $7-1$ & 0 & 0 & 5 \\
\hline $7-2$ & 0 & 0 & 5 \\
\hline $7-3$ & 0 & 0 & 5 \\
\hline $9-1$ & 0 & 0 & 5 \\
\hline $9-2$ & 0 & 0 & 5 \\
\hline $9-3$ & 0 & 0 & 5 \\
\hline
\end{tabular}

\begin{tabular}{|c|c|c|c|}
\hline Design number & quantity Rotary & $\begin{array}{l}\text { quantity Chromo } \\
\text { jet }\end{array}$ & quantity digital \\
\hline $2-1$ & 0 & 0 & 5 \\
\hline $2-2$ & 0 & 0 & 5 \\
\hline $2-3$ & 0 & 0 & 5 \\
\hline $4-1$ & 0 & 0 & 5 \\
\hline $4-2$ & 0 & 0 & 5 \\
\hline $4-3$ & 0 & 0 & 5 \\
\hline $6-1$ & 0 & 0 & 5 \\
\hline $6-2$ & 0 & 0 & 5 \\
\hline $6-3$ & 0 & 0 & 5 \\
\hline $8-1$ & 0 & 0 & 5 \\
\hline $8-2$ & 0 & 0 & 5 \\
\hline $8-3$ & 0 & 0 & 5 \\
\hline $10-1$ & 0 & 0 & 5 \\
\hline $10-2$ & 0 & 0 & 5 \\
\hline $10-3$ & 0 & 0 & 5 \\
\hline & & & \\
\hline
\end{tabular}



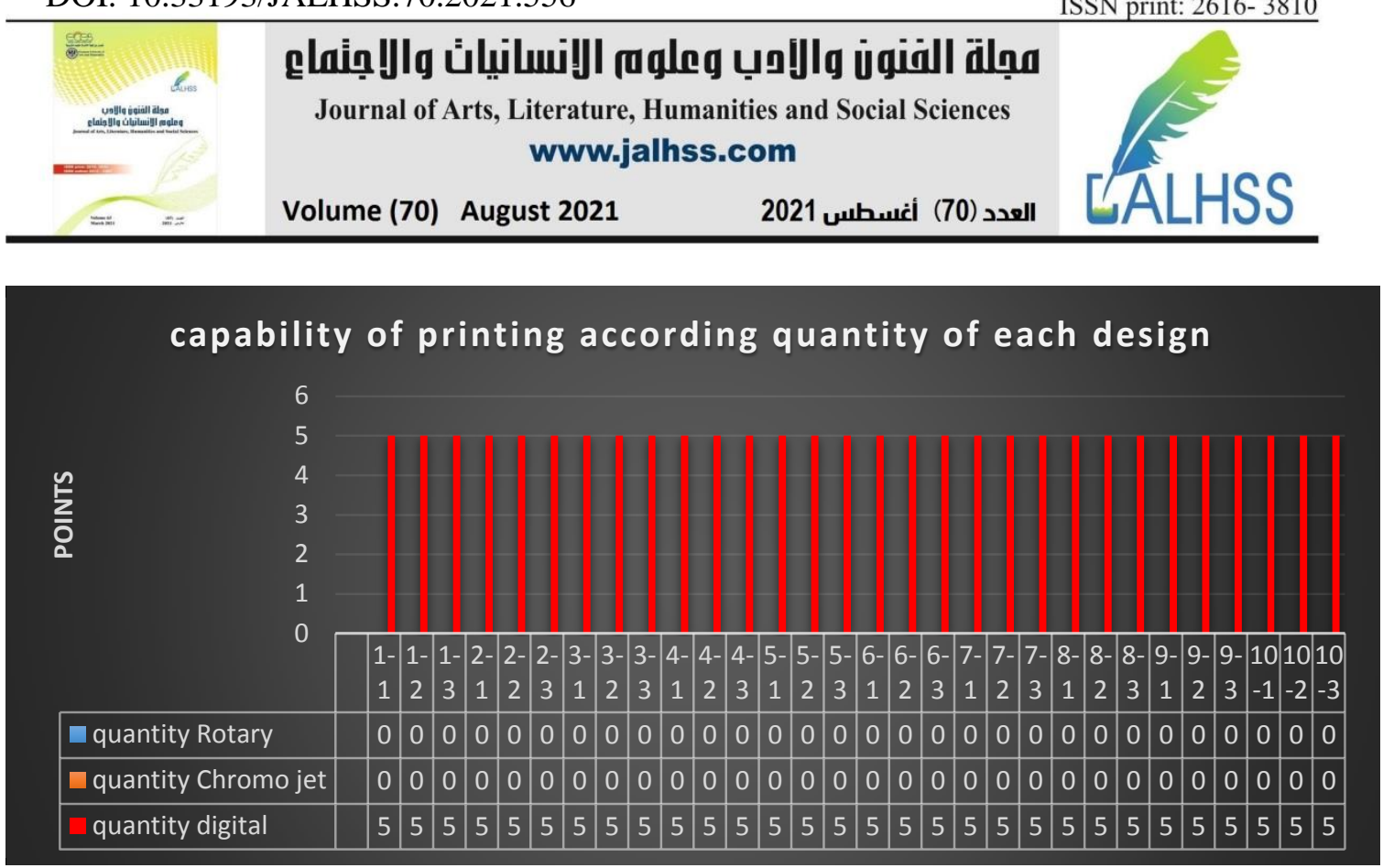

Diagram (4) capability of printing according quantity of each design

\section{SIGNIFICANT RESULTS:}

1- $\quad$ The Rotary Printing machine is very limited for printing different size, it is able only to print carpet length equal the circumference of the cylinder diameter . 2- $\quad$ The Chromo jet Printing machine can print any size of design which fit width of printing machine, and any length needed

3- $\quad$ The Digital Printing machine can print any size of design which fit width of printing machine, and any length needed

4- The Rotary Printing machine can't print design with more than 12 colors according numbers of rotary screens on machine, also can't print photo designs and 3D.

5- $\quad$ The Chromo Jet Printing machine can't print design with more than 12 colors according numbers of pump colors on machine, also can't print photo designs and $3 \mathrm{D}$.

6- The Digital Printing machine can print any design with any format and any numbers of colors, also can print photo designs and 3D.

7- $\quad$ The Rotary Printing machine not suitable for making customer design with less than 50000 square meter , and customer can order standard design of factory which make as stock.

8- The Chromo Jet printing machine minimum customer order 500 square meter.

9- $\quad$ The digital printing machine print minimum customer order 20 square meter, but can print less than 1 square meter with little more price

10- The delivery time for customer order not less than 60 days

11- The delivery time for customer order not less than 30 days

12- The delivery time for customer order around 2 days. 


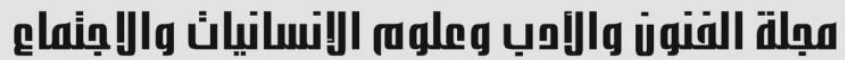 \\ Journal of Arts, Literature, Humanities and Social Sciences www.jalhss.com \\ Volume (70) August 2021 \\ العدد (70) أغسطس 2021}

By Digital printing machine can do any size, numbers of colors with minimum quantity in short time, That mean digital printing techniques suitable for create customize designs for Textile floor covering

\section{REFERENCES}

1- Caccia, Lucia, and Marco Nespeca. 2006. "Industrial production printers-

DReAM." In Digital printing of textiles, by Hitoshi Ujiie, 84-97. Cambridge:

Woodhead Publishing Limited.

2- Cahill, Vincent. 2006. "The evolution and progression of digital printing of textiles." In Digital printing of textiles, by Hitoshi Ujiie, 2. Cambridge: Woodhead Publishing Limited.

3- $\quad$ Carden, Susan. 2016. Digital Textile Printing. London; New York:

Bloomsbury Academic, An imprint of Bloomsbury Publishing Plc.

4- $\quad$ Carpet institute of Australia limited International Fiber center: carpet Manufacture.

5- $\quad$ The Carpet and Rug Institute: THE CARPET PRIMER, ISBN 0-89275-084-7, Copyright(c) 2003 update, - P. O. Box 2048 -Dalton, GA 30 722-2048 )

6- $\quad$ Chamberlain, Walter. 1978. The Thames\&Hudson Manual of Woodcut

Printing and Related Techniques. London:Thames\&Hudson.

7- Cooper-Hewitt Museum. 1987. "Printed Textiles 1760-1860 in the Collection of the Cooper-Hewitt Museum." Washington, DC: Smithsonian Institute.

8- Crossland : "Modern carpet Manufacture" First published, 1958.

9- $\quad$ Dawson, T.L. 2006a. "Digital colour management." In Digital printing of textiles, by Hitoshi Ujiie, 163-178. Cambridge: Woodhead Publishing Limited.

10- Dawson, T.L. 2006b. "Digital image design, data encoding and formation of printed images." In Digital printing of textiles, by Hitoshi Hjiie, 147-162. Cambridge: Woodhead Publishing Limited.

11- Elman Awad Seraj Aly: Comparison of functional performance for Blankets produced from different types of recycled fibers and Materials, Unpublished Ph.D. treatise- Faculty of Agriculture, Department of Home Economics- Alexandria University, 2006.

12- $\quad$ Fang, Kuanjun. 2011. "Current situation and development tendency of digital inkjet printing machines." China textile leader 65-67.

13- $\quad$ Fang, Kuanjun. 2006. "Digital ink jet printing technology." Dyeing and finishing 44-48.

14- $\quad$ Fralix, Michael. 2006. "Digital printing and mass customization." In Digital printing of textiles, by Hitoshi Ujiie, 293-310. Cambridge: Woodhead Publishing Limited.

15- Glenda Gilmore Andes: the Effect of Carpet fiber on the Growth of Dermato phogiodes farinae in a controlled Environment. 


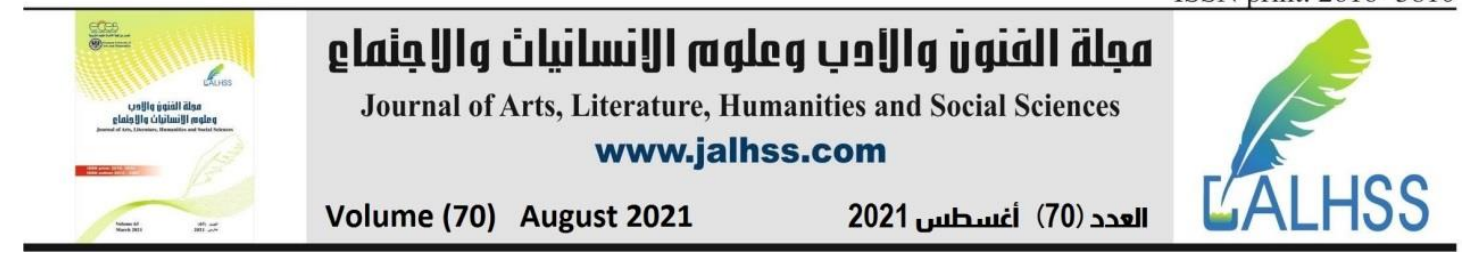

16- Gupta, Sanjay. 2001. "Inkjet printing-A revolutionary ecofriendly technique for textile printing." Indian Journal of Fibre \& Textile Research 156-161.

17- Hassan Omar Abdul-Aziz: Effect of blends raw materials (Wool - Nylon Poly Propylene) On the efficiency performance of mechanical carpets during end used, Unpublished Master treatise - Faculty of Applied Arts, Helwan University, 2001.

18- Hind Ahmed Amin: Effect of the different elements of structural composition of the carpeting (TUFT) on the properties of physical and mechanical, Unpublished Master treatise- Faculty of Applied Arts, Helwan University, 2000.

19- H.Ujiie: Digital Printing of Textiles, 1st Edition, Woodhead Publishing, 28th April 2006, Hardcover ISBN: $9781855739512-$ eBook ISBN: 9781845691585

20- Ibrahim Abdel Baki: Case Study for the patterns of folklore in El Sharkeya Province and Take advantage from them in the design of the floor covering non fluffy, Unpublished Ph.D. treatise -Faculty of Applied Arts, Helwan University, 1984.

21- Ismail Ibrahim Mahmoud: Identify selection criteria for non-woven floor covering Linked to functional performance for final product, Unpublished Ph.D. treatise - Faculty of Applied Arts, Helwan University, 1994

22- Invista (Canada) Company , Carpet and fiber Glossary, 2007.

23- Johnny Shell: Digital Textile Printing Technology Overview, SGIA vice President-Technical Services

24- Kasman Kasman * and Vasily G. Moshnyaga : New Technique for Posture Identification in Smart Prayer Mat, Faculty of Engineering, Fukuoka University, Fukuoka 814-0180, Japan ,Published: 23 August 2017

25- $\quad$ Keeling, R M. 1981. "Ink jet printing." Physics in Technology, 196-203.

26- Khalid el Sayed Mohammad Aly: Innovative designs of flowers motifs for printing Rug by using chromo jet printing machine, Unpublished Master treatise Faculty of Applied Arts, Helwan University, 2002.

27- King, Kerry Maguire. 2006. "Just-in-time printing." In Digital printing of textiles, by Hitoshi

28- Kobayashi, Hisayuki. 2006. "Industrial production printers-Mimaki's Tx series.” In Digital printing of textiles, by Hitoshi Ujiie, 98-120. Cambridge:

Woodhead Publishing Limited. Mimaki. n.d. Tx Series. http://www.mimakieurope.com/products/textile-printers/tx-series-category/.

29- Mona Mohamed Haggai: Study of the basic requirements for locally produced prayer rug and measuring the efficiency of its performance, published Ph.D. treatiseFaculty of Education for Home Economics in Makkah, 2008

30- Moser, Leon S. 2003. "ITMA 2003 Review: Textile Printing." Journal of Textile and Apparel, Technology and Manufacturing 3.

31- Najwa Abdel-Rahman Abdel-Al Ammar: Study methods of production for floor covering non fluffy and comparison between them, Unpublished Master treatise- Faculty of Applied Arts, Helwan University, 1991. 


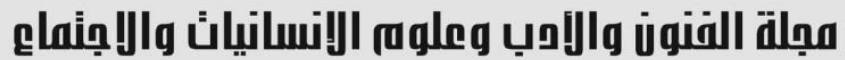 \\ Journal of Arts, Literature, Humanities and Social Sciences www.jalhss.com \\ Volume (70) August 2021 \\ العدد (70) أغسطس 2021}

32- Notermans, Jos. 2012. 25 years of digital textile printing. 11.

http://www.ifai.com/2012/01/01/25-years-of-digital-printing/.

33- Raymond, Mike. 2006. "Industrial production printers-DuPont Artistri 2020 textile printing system." In Digital printing of textiles, by Hitoshi Ujiie, 69-83.

Cambridge: Woodhead Publishing Limited.

34- $\quad$ R .W . Mucieff : "Man Made Fiber "6th . Edition 1975.

35- $\quad$ Sabri Abbas El Sayed Singer: study of applied method for mechanical Carpet and benefit from it to produce designs of Islamic Geometrical units, Unpublished Master treatise - Faculty of Applied Arts, Helwan University, 1999.

36- $\quad$ Tanaka, O.; Ryu, T.; Hayashida, A.; Moshnyaga, V.G.; Hashimoto, K. A Smart Carpet Design for Monitoring People with Dementia. In Progress in System Engineering, Advances in Intelligent Systems and Computing.

37- Yang, Donglian. 2003. "The trend of digital inkjet textile printing." Dyeing and finishing 25-30.

38- Zimmer Austria: CARPET AND PILE PRODUCT PRINTING, 24 July 2017

39- Zimmer Austria: CARPET PRINTING, J. Zimmer Maschinenbau , Copyright

(C) 2003 - GmbH Kufstein Eibergstrasse 2-8 A-6330 Kufstein/Austria

40- Zimmer Austria \& Tony Naschberger: Process Colour Printing on Carpet, , Digital jet printing system 